\title{
Funding the Retirement of the Baby Boomers
}

\section{Simon Kelly and Ann Harding}

\begin{abstract}
A fter World War II the number of births per woman rose above 3.0 and remained there until 1965. The peak of 3.6 was reached in 1961. Since 1961 , falling birth rates and longer life spans have combined to produce a steadily ageing population. Women today are bearing around 1.75 children on average, a substantial fall from the three children produced by women in the 1950s. An Australian man born in 1920 could expect to live until the age of 59 years, while a woman could expect to live until age 63 years. Today, the average man can expect to live until 77 years and the average woman until 82 years (ABS, 2002). Australians retiring in their 50s and 60s can now expect to spend two to three decades in retirement.

These trends mean that the proportion of the population who are aged 65 years and over will roughly double over the next 40 years, to almost one in every four Australians by 2042. At the same time, there will be almost zero growth in the number of Australians of workforce age. As a result, the elderly dependency ratio - people aged 65 years or more to the of working age (15-64 years) population - is projected to increase from 18 per cent in 2000 to over 37 per cent in 2050 (Table 1). In other words, in the future there will be fewer workers to support each retired person. The increasing elderly dependency ratio for Australia is not as severe as in some other countries (notably Italy, Germany and Japan) but it is still significant and the economic aspects are a major issue.
\end{abstract}

Table 1: Elderly Dependency Ratios, Selected Countries, 2000-2050

\begin{tabular}{|c|c|c|c|c|c|c|}
\hline & 2000 & 2010 & 2020 & 2030 & 2040 & 2050 \\
\hline & \multicolumn{6}{|c|}{ persons $65+$ years as Proportion of working age population - per cent } \\
\hline USA & 19.0 & 19.5 & 25.6 & 33.6 & 35.1 & 35.5 \\
\hline Japan & 25.0 & 33.8 & 43.8 & 46.0 & 54.3 & 58.4 \\
\hline Germany & 24.0 & 29.6 & 33.0 & 43.3 & 49.6 & 48.7 \\
\hline France & 24.4 & 25.3 & 32.2 & 38.7 & 43.4 & 44.2 \\
\hline Italy & 26.9 & 31.4 & 37.4 & 49.1 & 64.4 & 65.7 \\
\hline UK & 24.6 & 25.9 & 31.2 & 38.3 & 42.3 & 42.2 \\
\hline Canada & 18.7 & 20.7 & 28.0 & 37.3 & 39.8 & 40.1 \\
\hline Australia & 18.0 & 19.8 & 25.9 & 32.2 & 36.1 & 37.5 \\
\hline
\end{tabular}

Source: calculations based on OECD (2000:Tables and Figures on Ageing).

Simon Kelly is a Principal Research Fellow at National Centre for Social and Economic Modelling (NATSEM) and Ann Harding is the inaugural director of NATSEM and Professor of Applied Economics and Social Policy at the University of Canberra. 
The OECD has highlighted that the growing elderly dependency ratio means that future governments in most countries will be 'hard put to finance [retirement pensions] out of pay-as-you-go contributions from people still in employment' (2000). In addition, Disney and Johnson claim that most OECD pension systems are in a state of flux, as governments struggle to meet the costs of their current retirement income systems and grapple with the issue of future costs (2001).

In addition to the increasing fiscal strain on governments through the funding of retirement pensions there is also increasing pressure from health care. Sheehan noted that per capita health care costs increase with age (especially above 50 years), and that an ageing population will add to health care costs (2002). In Australia, the combination of rising health care costs and higher demands on retirement pensions are projected to cause living standards to fall by 27 per cent below where they would otherwise be (ASFA, 2004). The same ASFA report forecasts that as the baby boomers move to retirement, higher federal taxes, lower federal spending and higher state taxes will transfer an additional \$38 billion per year to Australian households. In addition, a further cost of $\$ 22$ billion will be required from households through higher privately incurred health costs and disincentive effects from higher taxes.

\section{Government Response}

The Australian government has become increasingly concerned about the challenges of population ageing. An early policy response was the introduction of compulsory superannuation in 1992 - the Superannuation Guarantee (SG). Under the SG, employers contribute a percentage (currently nine per cent) of earnings into the superannuation accounts of their employees. Treasury officials at that time estimated that these contributions would be sufficient to provide a gross superannuation income stream of around 40 per cent of final salary on retirement at age 65 after around 40 years' contributory service (Gallagher and Preston, 1993). In other words, provided a person is employed for 40 years mostly on a full-time basis, the SG will ensure they have an adequate retirement income.

Despite this early response and accolades from the observers such as Khan (1999), Australia's solution still has problems. The assumed 40 years of contributions will not apply to all Australians and some will not have sufficient retirement savings even under the SG. The oldest baby boomers will be 60 years old in just two years time and the majority have only been contributing to superannuation for 12-15 years. This short accumulation time and the opportunity to withdraw the funds from age 55 will see most baby boomers arriving at age 65 with only meagre superannuation balances. For many of the boomers the SG is too little and too late in their working lives to make a significant difference.

For subsequent generations, the SG will assist many to have adequate retirement incomes but others face a different issue. While those coming after the baby boomers may well have 40 years of SG contributions during their working life and the minimum age at which they can withdraw funds (the 'preservation' age) has been increased to 60, changing labour force patterns may impact on their 
superannuation. Recent labour force trends show growth in part-time, contract and casual employment and little growth in full-time employment. These trends could see future generations of workers spending less time as employees and more time in positions where superannuation contributions are not compulsory. The shorter periods of SG contributions may reduce their superannuation savings.

Projections of accumulated superannuation in coming decades suggest the problem of low retirement savings is particularly acute for women (Kelly, Harding and Percival, 2002; Kelly, Percival and Harding, 2002). While the poor financial situation in retirement for women has long existed, the increasing prevalence of marriage breakdowns and the changing gender roles are making individual financial independence more important. Many women in the baby boomer group have interrupted labour force careers as a result of child-bearing and child-rearing and, when in the labour force, are more likely to be employed in casual, part-time and low-paying positions. The results of these differing gender labour paths are that the average baby boomer woman has less than half the accumulated superannuation of her male counterpart. While labour force participation for women has increased in the last decade, according to projections undertaken at the National Centre for Social and Economic Modelling (NATSEM) the future still looks bleak and women's financial situation in retirement only improves marginally (Kelly, 2002).

In recent years the Australian government has recognised that the SG alone will not address the costs associated with population ageing and has begun raising public awareness of the issue. In the 2002-03 Budget the government issued the Intergenerational Report (IGR), and this was followed in February 2004 by the government issuing a new report aimed at stimulating further debate on policy change, Australia's Demographic Challenges. In the IGR, Treasury projected future taxation revenues and future outlays on social programs, assuming that the current structure of these programs remained broadly unchanged. The IGR found that spending on health and aged care would account for much of the projected rise in Commonwealth spending over the next four decades. The projected growth in health and aged care spending was particularly strong, rising from 4.7 per cent in 2001-02 to 9.9 per cent of gross domestic product in 2041-42.

The IGR projected that Commonwealth spending would exceed the amount raised in taxes by around 5 per cent of gross domestic product by 2041-42, with the Commonwealth budget starting to slip into the red from around 2017 onwards.

To put this into perspective, if we had a budget deficit of around 5 per cent of GDP today, then we would have a deficit of around $\$ 40$ billion instead of the forecast surplus of 4.6 billion. ... The sorts of expenditure cuts required to achieve a 5 per cent reduction of GDP could include the entire amount allocated to health (Treasury, 2004:25-26).

The ASFA-Access Economics 2004 Intergenerational Report (ASFA, 2004) paints a gloomier picture. It modelled the impact on State governments in 
addition to the Commonwealth government and found that the shortfall increased from 5 to 7 per cent of GDP when the State-level impacts were included.

The SG was introduced in 1992 to help people contribute to the cost of their retirement and reduce the strain of the public purse. However, it has since become apparent that the costs of the baby boomers in retirement will require more than just employer contributions of up to 9 per cent being put into superannuation.

\section{Baby Boomer Savings}

There are currently 2.7 million people in Australia aged 50-64 years. This important group consists of pre-retirees and others already in voluntary or involuntary retirement. Recent research (Kelly and Harding, 2002) found that typically they own their home and are married, but have no dependent children at home. Many have been forced out of the labour force or have retired voluntarily, while others are shifting to part-time work. Only one-quarter of men stay in fulltime employment until the traditional retirement age of 65 . The rate for women is even lower. Details of labour force status by age are provided in Table 2.

Table 2: Labour Force Status of 50-69 year olds, 2002-03

\begin{tabular}{lrrrr}
\hline \multirow{2}{*}{ Labour Force Status } & \multicolumn{3}{c}{ Age of the person } \\
\cline { 2 - 5 } & $50-54$ & $55-59$ & $60-64$ & $65-69$ \\
\hline \multirow{2}{*}{ Males } & \multicolumn{4}{c}{ Per cent } \\
Employed Full-time & 74.8 & 55.4 & 27.1 & 11.1 \\
Employed Part-time & 7.2 & 10.8 & 15.5 & 7.7 \\
Unemployed & 2.3 & 4.1 & 1.8 & \\
Not in the labour force & 15.6 & 29.7 & 55.6 & 81.2 \\
Females & & & & \\
Employed Full-time & 36.4 & 23.5 & 9.2 & 2.4 \\
Employed Part-time & 28.7 & 21.5 & 14.4 & 7.2 \\
Unemployed & 2.8 & 1.5 & 0.5 & 0.5 \\
Not in the labour force & 32.1 & 53.5 & 75.9 & 89.8 \\
\hline
\end{tabular}

Source: Kelly, Farbotko and Harding (2004:Table 2).

\section{Wealth}

Superficially, it appears that baby boomers have saved substantial wealth that is likely to help them through retirement. It seems that a generational shift in wealth has occurred over the past 15 years. The estimated share of total household wealth held by 40-54 year olds increased from 33 to 38 per cent between 1986 and 2003. The share of total wealth held by older Australians has also increased while that held by 25-39 year olds declined from 27 to 19 per cent in the same period 
(Harding, Kelly and Bill, 2003:12). Indeed, these trends recently caused the Governor of the Reserve Bank (Macfarlane, 2003) to warn that:

If we are not careful, there is potential for conflict between the generations. The young may resent the tax burden imposed on them to pay for pension and health expenditure on the old. This will particularly be the case if they see the old owning most of the community's assets.

Table 3: Distribution of Assets, Persons 50-64 years, January 2002

\begin{tabular}{lcccccc}
\hline & $\begin{array}{c}\text { Cash } \\
\text { deposits }\end{array}$ & Shares & $\begin{array}{c}\text { Home } \\
\text { (net) }\end{array}$ & $\begin{array}{c}\text { Rental } \\
\text { Properties } \\
\text { (net) }\end{array}$ & Super'n & $\begin{array}{c}\text { Total } \\
\text { Wealth }\end{array}$ \\
\hline Q1 (poorest 25\%) & 3 & 0 & 23 & 0 & 21 & 47 \\
Q2 & 7 & 1 & 83 & 2 & 37 & 131 \\
Q3 & 14 & 4 & 137 & 12 & 57 & 223 \\
Q4 (richest 25\%) & 55 & 77 & 265 & 52 & 111 & 559 \\
Average & & & & & & \\
$\quad$ all 50-64 year olds & 20 & 21 & 127 & 17 & 56 & 240 \\
$\quad$ all adults & 14 & 14 & 77 & 10 & 35 & 149 \\
\hline
\end{tabular}

Source: Kelly and Harding, 2002:9.

Note: The estimates are for each person. The average home equity of couples has, for example, been divided equally between them.

The family home is the most significant asset held by the average family. The equity in the home is a major contributor to the differences in wealth between the young and the old. As shown in Table 3, NATSEM estimated that the average 50-64 year old had accumulated $\$ 240,000$ of assets in January 2002; this is about two-thirds higher than the national average. Equity in a person's home stands out as a major difference between 50-64 year olds and the adult population as a whole - with an average home equity of $\$ 127,000$ for $50-64$ year olds versus an average of $\$ 77,000$ for all Australian adults. This difference reflects the older age group having a combination of higher overall ownership rates, a higher proportion owning the home outright and smaller mortgages where they still exist. Not surprisingly, the superannuation held by 50-64 year olds is considerably above the average. For many in this group, the years of contributions make this a sizable asset with an estimated average of \$56,000 for all 50-64 year olds.

But this analysis also immediately reveals two major problems facing 50-64 year olds. The first is that more than half of their total wealth is tied up in the family home. It is clearly going to be difficult to tap into this source of wealth to finance day-to-day living expenses in retirement. Although we can expect the 
rapid development of reverse mortgages in the future to help older Australians to do this, many will remain reluctant to run down their housing equity.

A second major problem is that while $\$ 56,000$ of superannuation is a significant asset, it will not sufficient to provide a comfortable living in retirement. Most financial planners suggest that a retirement income of 60-65 per cent of final full-time salary is required for a comfortable standard of living in retirement. ${ }^{1}$ This equates to around $\$ 30-35,000$ per year or around $\$ 600$ per week. Assuming that average retirees do not use their superannuation payout for other purposes, a $\$ 56,000$ lump sum paid by a 65 year old male into an allocated annuity will provide an income of only $\$ 100$ a week up to age 80 (just short of an average 65 year old male's life expectancy). In other words, it will provide a supplement of $\$ 100$ to the pension, giving a total income of around $\$ 300$ per week - still well short of the suggested $\$ 600$ to be comfortable. If the retirees choose to retire early and spend the lump sum, then they can look forward to many years on the very modest standard of living provided by the Age Pension with no supplementation.

The situation for women is worse than for men (Kelly, Harding and Percival, 2002; Kelly, Percival and Harding, 2002). Although not shown in the table, the average superannuation of males (around $\$ 80,000$ ) is more than two and a half times that of females (around \$30,000). This reflects the lower earnings, the greater likelihood of part-time employment, the disrupted work patterns and the higher incidence of non-participation in the labour force of baby boomer females.

Gender difference provides some insight into an even more serious issue than low average superannuation balances: the estimates of average wealth disguise the fact that the wealth distribution is highly skewed. From Table 3, the least wealthy quartile of 50-64 year olds has accumulated only an estimated $\$ 47,000$ in total wealth ( $\$ 21,000$ superannuation and $\$ 23,000$ home equity). That is, the poorest one-quarter collectively holds only five per cent of the total wealth of 5064 year olds. The wealth of the richest quartile averages more than $\$ 500,000$ and collectively owns almost 60 per cent of the total wealth of this age group.

These figures suggest that perhaps three-quarters of Australians in this age group have not yet saved sufficient resources to finance a comfortable retirement. Despite having insufficient funds, this age group are retiring early (see Table 2). This early retirement (or forced redundancy) has reduced the current average retirement age for men to 58 years and 41 years for women. In the period before becoming eligible for the Age Pension (65 years for men and 62.5 years for women) some are spending their modest lump sums on paying off their mortgage and other debts, subsequently facing the prospect of a couple of decades of retirement on the age pension without any top up from their own resources. About half of all early retirees had zero or negligible superannuation by the time they qualified for the Age Pension (Kelly, Farbotko and. Harding, 2004).

1 This of most financial planners was also accepted by the Senate Select Committee on Superannuation. The committee noted the high degree of consensus amongst industry experts that the desirable target for a person on average earnings should be a replacement rate of 70-80 per cent of pre-retirement expenditure. This equates to about 60-65 per cent of gross pre-retirement income (Dunsford and Rice, 2004). 
The purpose of superannuation is to increase self provision in retirement and therefore reduce the fiscal burden on younger generations. Superannuation was not designed to allow people to access early retirement. Financing voluntary early retirement through the drawdown of superannuation and then asking taxpayers to fund the remainder of their retirement years is not fair on future taxpayers. The generations coming after the baby boomers will be required to save for their own retirement through the SG and they will not be able to access it until at least age 60. At the same time these post baby boomers will be asked to pay increased taxes to support baby boomers during retirement. The Treasurer (2004) agrees that this is unfair on future generations; he recently asked:

As our retirement income system matures, is it fair to allow those with superannuation assets to retire early, run down their assets and then rely on taxpayers to fund the major part of their retirement? This is an important issue that we will need to consider very carefully.

\section{Income}

Currently over 70 per cent of people aged 65 and over live on incomes of less than $\$ 300$ per week. The high proportions in the \$160-199 and \$200-299 ranges suggest that the principal source of income for these people is government cash benefits (Figure 1). In January 2004, the Age Pension provides $\$ 226.40$ per week for a single person and $\$ 189.00$ for each member of a couple - that is, about $\$ 12,000$ for a single person and $\$ 20,000$ for a couple each year.

Figure 1: Weekly Income, Persons 65 or more years, Australia, 2001

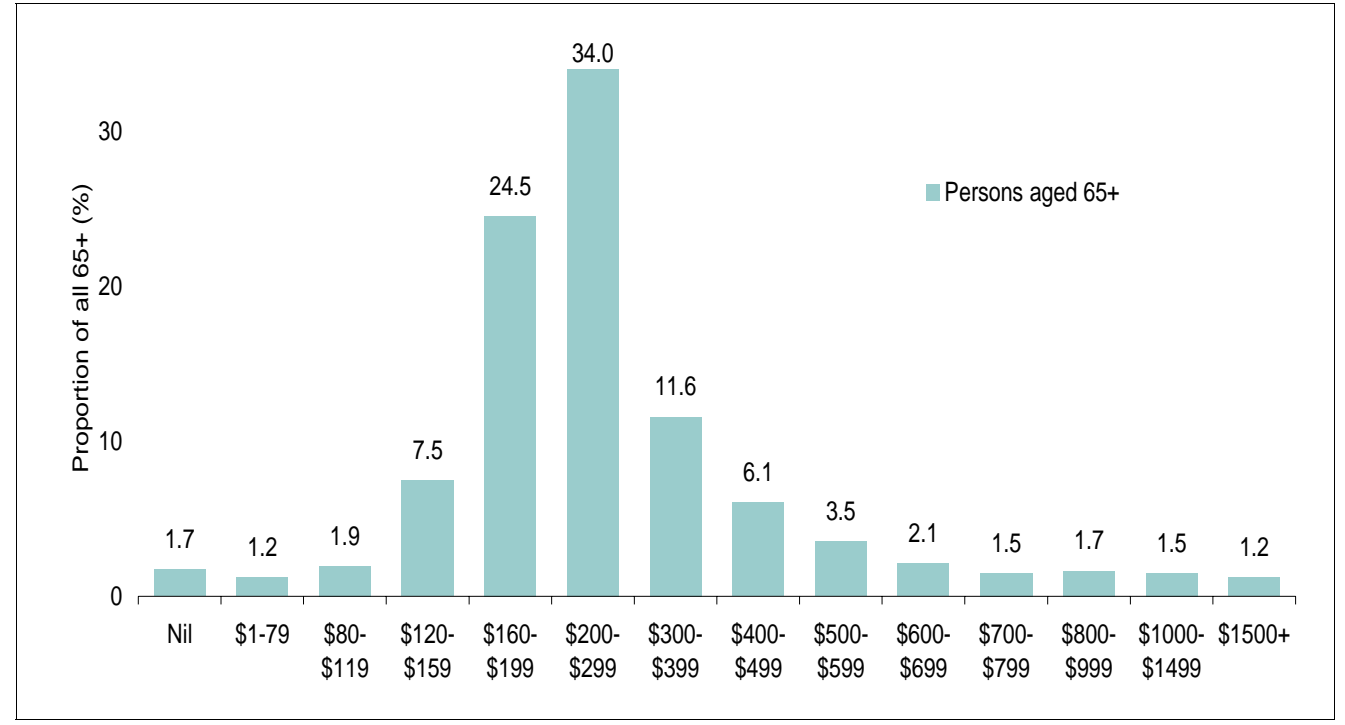

Data source: Special tabulation for NATSEM from ABS Census 2001 data. 
In contrast, a recent study found that a single person would spend around $\$ 16,930$ per annum on a 'modest but adequate' lifestyle in retirement - a more comfortable lifestyle would cost \$32,800 (Saunders, Patulny and Lee, 2004). These figures assume the retiree owns their own home. For a couple the figures are $\$ 23,550$ and $\$ 43,350$ respectively. Similarly, as stated earlier, most financial planners suggest $\$ 30-35,000$ is required for a comfortable lifestyle in retirement for the average person. The results in Figure 1 imply that about 90 per cent of current retirees are surviving on an income of less than 'modest but adequate'. For the next generation of retirees (those aged 50-64 with only slightly increased levels of superannuation savings by retirement and who have enjoyed a very high standard of living in their working years) this standard of living in retirement may not be acceptable. An improvement to a modest or comfortable standard will require a contribution from the retiree's private savings. Unfortunately, as we saw above, one thing that the baby boomers have not done well is to voluntarily save for their retirement. The superannuation that they have saved will provide a small supplement to the pension, but only if it is not exhausted before the official retirement age is reached. The self-funding of early retirement could easily result in little superannuation remaining at age 65, let alone at age 80 or 90 .

\section{Possible Solutions}

It seems clear that baby boomers should not rely on government to finance large increases in the age pension and to meet all of their health and aged care demands, given the fiscal pressures that government will be facing.

It could be that the baby boomers are not worried about how they will survive in their retirement - they're banking on inheriting a small fortune from their aged parents. Unfortunately, research by Harding, Kelly and Bill (2003) has shown that inheriting a fortune is unlikely. They found that generation-skipping, an uneven wealth distribution, a reduced bequest ethic and parents spending it on themselves or on their own health and aged care costs, are all working against a big inheritance.

With little in the way of current savings and inheritance unlikely to provide retirement incomes for many, the government will be looking hard at how private contributions can be increased, taxes can be increased or outlays can be reduced. Discussion of some of the possible options follows.

\section{Increasing Retirement Savings}

The 1992 introduction of compulsory superannuation was the first major initiative from the government to increase the private retirement savings of Australians, but almost continual 'tweaking of the system' has occurred since that time. The release of the government's Australia's Demographic Challenges paper acknowledges the need for further changes and reflects the government's preference for increasing private contributions to superannuation. 


\section{Greater labour force participation}

As only about half of all 50-64 year olds are working (Table 2), there is scope to lift the labour force participation rate. The Treasurer's speech at the release of Australia's Demographic Challenges showed the government's intention to introduce policy initiatives to encourage people to remain in the work force until age 65. This longer participation in the workforce would help superannuation balances to continue to grow from age 55 to age 65 . More importantly, it would stop superannuation being drawn down in the period before official retirement.

For many, therefore, there will be pressure to work longer. For some this will not be possible, because of ill health. By age 55 to 64, about two-fifths of lowincome Australians suffer from at least one major health problem (Walker et al., 2003). Even for middle to higher income Australians, about two-thirds suffer at least one major health problem at ages 55 to 64. The Treasurer (2004:3) has explicitly identified the critical importance of health in trying to increase the labour force participation rates of those in their 50s and 60s, and flagged a shift towards 'preventative health' and a renewed focus on living a healthy lifestyle.

Apart from ill health, many other Australians in their 50s and 60s have been forced out of work through unemployment caused by the rapid economic restructuring of the past decade. While many of these have found it very difficult to find new work, this should become easier in the future, as labour force shortages intensify. This will be one result of the lower number of new workforce entrants in the future, due to the decline in fertility rates. While business will face strong economic imperatives to employ mature age workers, this will also be facilitated by a campaign to shift business thinking. The Prime Minister has begun to exhort business to 'change its attitude' towards the employment of mature age workers, arguing that if workers wish to remain beyond what are now regarded as customary retirement ages then business and government should do everything possible to support them (Howard, 2003).

Many baby boomers will not want to retire and will want to continue in the labour force, albeit in a less demanding role perhaps working part-time or in a lower level position. Not surprisingly, the government has started campaigning for flexible job opportunities and the employment of mature-age workers. As the Treasurer (2004:5) argues, 'We need to move away from concepts of early retirement and compulsory retirement at a set age'. To this end, the government is proposing changes to superannuation to allow anyone under the age of 65 to make contributions to a superannuation fund and simplify the superannuation contribution and cashing rules for people between the ages of 65 and 74 years.

\section{Increasing the SG contribution rate}

Many commentators believe one way to ensure an adequate retirement income for the baby boomers is to further increase the compulsory employer contribution to 15 per cent from the current 9 per cent. However, calculations by NATSEM cast some doubt on the likely effectiveness of this proposal (Kelly, Harding and Percival., 2002). Most observers have based their projections on continuing full- 
time employment until age 65 and, under this assumption; the increase in the contribution rate does provide significantly increased retirement income. However, NATSEM has modelled the likely future behaviour of the baby boomers based on recent labour force participation trends and found that increasing the SG would only provide a small increase in the superannuation balances. The current trends towards early retirement and reduced hours prior to retirement would effectively negate the increased contribution rate. Thus, increases in the SG rate will only make a substantial difference to the retirement incomes of the baby boomers if they can be persuaded to remain in the workforce for longer.

\section{Reducing superannuation taxes}

It is well known that superannuation is taxed at three points under current arrangements - contributions are taxed on entry, earnings are taxed and superannuation withdrawals are taxed. The removal or reduction of any of these taxes would increase the funds available to be used in retirement. Dunsford and Rice note that the contribution tax on superannuation contributions effectively reduces the SG contribution rate, already argued as being too low, from 9.00 per cent to 7.65 per cent (2004). The detrimental long term effect the tax is having retirement savings should result in the government removing or at least reducing the contribution tax of 15 per cent. Further reduction in the superannuation surcharge tax is another area that is a likely candidate for change.

The dilemma for the government is to balance short-term budgetary requirements with the longer-term goal of self-provision in retirement. Concessional taxation of superannuation is already viewed as an expenditure (that is, as a cost to government). However, the Association of Superannuation Funds of Australia (ASFA) view it differently and estimate that the government collected taxation revenue of $\$ 50.5$ billion between 1989-90 and 2002-03 through a combination of taxation on fund earnings, taxation of contributions and taxes on the superannuation business of life companies (ASFA, 2003). ASFA argue that if these taxes had been left to grow in their member accounts, an extra $\$ 78$ billion would be available for private contributions to the cost of retirement.

\section{Reducing superannuation fees and charges}

In recent years, fees and charges associated with management of superannuation funds have attracted close scrutiny. In the 1990s, when returns of superannuation funds were above 10 per cent, management fees were not questioned but the recent poor performance of most funds has led many people to question whether the management fees are justified. The government opposition spokesman on superannuation has on numerous occasions expressed his concern at the level of fees and charges (particularly entry and exit fees of retail superannuation funds) and the impact they are having on the accumulation of retirement savings (Crean and Sherry, 2003). The entry and exit fees associated with retail superannuation funds can be expected to come under the microscope in the near future. 
The basis of most fund management fees is currently the value of the accumulated superannuation (that is, the annual fee is a percentage of the funds being managed). The recent poor performance of most funds will increase pressure on fund managers to change to performance-based fees rather than the amount being managed. Such a change would shift the focus of managers from increasing the size of the assets to ensuring maximum returns for the client.

\section{Increasing government revenue}

In the IGR, the Treasury noted that to prevent the budget moving into deficit 'future generations of taxpayers would face higher taxes ... or governments would need to reduce the projected growth in spending'. Despite frequent claims to the contrary, Australians are not particularly highly taxed. OECD Revenue Statistics show that taxation revenue as a percentage of GDP is lower in Australia than in most of the other developed OECD countries.

While no government likes talking about tax increases, organisations such as the Australian Council of Social Service (ACOSS) regularly issue blueprints for taxation reform. Its latest prescriptions for the Federal Budget include quarantining negative gearing, tightening the tax treatment of discretionary trusts and removing the FBT concession for company cars (ACOSS, 2004).

Australia is unusual among OECD countries in taxing neither wealth nor wealth transfers, by gifts or inheritances, via a broad-based wealth tax. ACOSS (2004:19) has suggested the imposition of a five per cent 'windfall' tax on large transfers of wealth, whether by gifts or inheritances, with provisions to protect family farms. Similarly, while the family home has always been considered a sacred cow in Australia, it would be possible to include it in the capital gains tax base, possibly with a generous exemption level that ensured that only large gains on luxury homes were snared within the net. The indirect tax base can also be expanded. The 10 per cent GST rate is relatively low by international standards. Other options might include special earmarked taxes or levies, like the Medicare levy, to fund particular needs such as aged care or pharmaceuticals.

A final option would be to remove or reduce the subsidisation of pharmaceuticals, aged care and health care. While such an option would be very unpopular with voters, it could save the government a considerable amount and needs to at least be considered in the near future.

\section{Reducing Government Outlays}

\section{Better targeting of the age pension}

Earlier discussion in this paper suggested that the majority of baby boomers reach retirement with little in the way of savings, except for their family home. As the home is exempt under the pension means test, it is difficult to see the proportion of people qualifying for the pension dropping significantly from current high levels for some decades. The lack of an upper limit on the value of the home is well 
known and exploited by some retirees to qualify for the pension - a person can own a million dollar mansion with no impact on pension entitlements.

Some commentators have suggested capping the value of the means-test exempt portion of the family home and treating the value above this limit as an assessable asset (Kelly, 2003; Dunsford and Rice, 2004). This would avoid penalising persons for living in a modest home and holding the rest of their assets in a form that generated retirement income. The introduction of such a significant change to the means-test of the pension might require such provisions as current older Australians being exempted; a significant lead time (say 5-10 years) being given to allow people to assess their situation; and that the value of the home only be assessed upon initial pension application and if a pensioner changes address.

Reverse equity loans would also make better use of the significant equity that older Australians have in their home. A reason for their unpopularity in the past has been the impact that conversion of home equity into cash would have on a retiree's pension entitlements. Changes to the pension means test to exempt funds raised through reverse equity loans would significantly change this situation.

\section{Income streams versus lump sums}

At present most superannuation is received as a lump sum. People are encouraged to convert this to an income stream through a range of preferential taxation treatments and preferential pension means testing. Despite these incentives, most take the lump sum and consume it in the first few years of retirement.

It is hard to argue for conversion of small superannuation balances into income streams. However, with future increases in balances and mounting fiscal pressure on the government purse, greater incentives to use superannuation for its intended purpose need to be considered. Superannuation is given special taxation treatment because it will be used to supplement or replace a taxpayer-funded public pension; not to allow people to buy a new car on their $55^{\text {th }}$ birthday.

Further changes to superannuation and taxation legislation to encourage more retirees to take their superannuation as an income stream seem inevitable.

\section{Conclusion}

Most baby boomers have not yet saved sufficiently to ensure a comfortable retirement. While the SG has led to increased retirement savings by many baby boomers, it is too little and too late, especially for early retirees. Increasing the SG contribution rate is not the solution unless the baby boomers can be persuaded to stay in the labour force for much longer, otherwise the low participation rates by those in their 50s and 60s mean that there are not sufficient years of working left at the higher SG rate to make much difference to the average baby boomer.

Clearly, no matter what the contribution rate, there will be strong pressure on baby boomers to work longer than many of them currently anticipate doing. This will not only provide them with a more comfortable retirement but will also ease the fiscal strains upon a worried government. 
As a society we may need to redefine the whole notion of retiring at 65 years or earlier. In the past many Australians retired at age 65 and then died not long afterwards. Early retirement seemed a sensible alternative in a society with high unemployment, as it opened up job opportunities for younger workers. But in a world of labour force shortages, when many Australians can expect to live in reasonable health into their late 70 s, it may not be desirable or even possible to sustain retirement at age 65 or earlier for such large groups of the population.

\section{References}

Australian Bureau of Statistics (2002), 'Table 47: Life expectancy at birth (years) by sex, States and Territories, 1881 onwards', Australian Historical Population Statistics, ABS Catalogue No. 3105.0.65.001 (available at: www.abs.gov.au).

Australian Council of Social Service (2004), Blueprint for a Fairer Australia: Federal Budget Priorities Statement 2004-05, Paper No 133, February.

Association of Superannuation Funds of Australia (2003), The Facts on the Concessional Tax Treatment of Superannuation, ASFA Research Centre, Sydney, February.

Association of Superannuation Funds of Australia (2004), Intergenerational Modelling for Australian Families, ASFA-Access Economics 2004 Intergenerational Report, ASFA Research Centre, Sydney, April.

Australian Government, 2004, Australia's Demographic Challenges, (available at: www.dcita.gov.au/cca).

Crean, S. and N. Sherry (2003), Superannuation: A Safer System, Policy Paper 016, 20 November, www.alp.org.au/dload/federal/media/safer_super.pdf

Disney, R. and P. Johnson (2001), Pension Systems and Retirement Incomes Across OECD Countries, Edward Elgar Publishing Limited, Cheltenham, UK.

Dunsford, G. and M. Rice (2004), Retirement Incomes Integration - Superannuation, Social Security \& Taxation, Institute of Actuaries of Australia, Sydney.

Gallagher, P. and A. Preston (1993), 'Retirement Income Modelling and Policy Development In Australia', RIM Paper 3/93, Paper prepared for the Economic Modelling Bureau of Australia Conference on the Asia-Pacific Economy, Cairns, August.

Harding, A., S. Kelly, and A. Bill (2003), You Can't Rely on the Old Folks' Money Wealth and Inheritance, AMP-NATSEM Income and Wealth Report, Issue 6, AMP Ltd, Sydney, June.

Howard, J. (2003), 'Address to Symposium on Mature Age Employment Luncheon, 27 August (available at: www.pm.gov.au/news/speeches).

Kelly, S. (2002), 'Simulating Future Trends in Wealth Inequality', Paper presented to the 2002 Annual Conference of Economists, Adelaide, South Australia, October.

Kelly, S. (2003), 'The Intergenerational Perspective - Older People's Income, Wealth and Housing', Paper presented at the 'Housing Futures in an Ageing Australia' Conference, Melbourne, 10 November. 
Kelly, S. and A. Harding (2002), Live Long and Prosper? The income and Wealth of Those About to Retire, AMP-NATSEM Income and Wealth Report, Issue 2, AMP Ltd, Sydney, May.

Kelly, S. and A. King (2001), 'Australians Over the Coming 50 years: Providing Useful Projections’, Brazilian Electronic Journal of Economics 4(2):1-31.

Kelly, S., C. Farbotko and A. Harding (2004), The Lump Sum: Here Today, Gone Tomorrow. Income, Superannuation and Debt pre and post Retirement, AMP-NATSEM Income and Wealth Report, Issue 7, AMP Ltd, Sydney, March.

Kelly, S., A. Harding, and R. Percival (2002), 'Live Long and Prosper? Projecting the Likely Superannuation of the Baby Boomers in 2020', Paper presented to the 2002 Annual Conference of Economists Business Symposium, Adelaide, South Australia, October.

Kelly, S., R. Percival and A. Harding (2002), 'Women and Superannuation in the 21st Century: Poverty or Plenty?', pp. 223-249 in Competing Visions: Proceedings of the National Social Policy Conference, SPRC Report 1/02 University of New South Wales.

Khan, Q. (1999), ‘Australia's Retirement Income System: An example of sustainable costeffective coverage', pp. 141-153 in Productivity Commission and Melbourne Institute of Applied Economic and Social Research, Policy Implications of the Ageing of Australia's Population, AusInfo, Canberra.

Macfarlane, I. (2003), 'Economic Opportunities and Risks over the Coming Decade', Talk to 2003 Melbourne Institute Economic and Social Outlook Conference Dinner, Melbourne, 13 November, (available at: www.rba.gov.au/Speeches/2003/sp_gov_131103.html).

OECD 2000, 'The Costs of an Ageing Society', OECD in Washington 22, OECD Washington Center, Washington DC, November/December .

Saunders, P., P. Patulny, and A. Lee (2004), Updating and Extending Indicative Budget Standards for Older Australians, Final Report for the Association of Superannuation Funds of Australia, University of NSW, Sydney, January.

Sheehan, P. (2002), 'Health Costs, Innovation and Ageing', Working Paper No. 9, Pharmaceutical Industry Project Equity, Sustainability and Industry Development Working Paper Series, Victoria University of Technology, Melbourne, August.

Treasurer (2004), ‘Australia’s Demographic Challenges’, Speech delivered on 25 February (available at: www.treasurer.gov.au/tsr/content/speeches/2004/003).

Treasury (2002), Intergenerational Report 2002-03, Budget Paper No. 5, May.

Treasury (2004), Australia's Demographic Challenges', Report, available at: http://demographics.treasury.gov.au/content/discussion.asp?NavID=6.

Walker, A., S. Kelly, A. Harding and A. Abello (2003), Does Your Wealth depend on Good Health? Health and Income in Australia, AMP-NATSEM Income and Wealth Report, Issue 4, AMP Ltd, Sydney, March.

The authors gratefully acknowledge the very helpful suggestions on an earlier version of this paper by two anonymous referees. 


\section{Portability of Superannuation Balances}

\section{Michael Drew and Jon Stanford}

$\mathrm{O}$ ver the last two decades the Australian financial system has experienced substantial deregulation, but the superannuation sector has run counter to this overall trend. While the superannuation sector has become a major segment of the financial system, this growth has been the result of compulsion, not choice by economic agents.

There are two forms of compulsory contributions to superannuation. The first is award superannuation, under which employers are required to contribute three per cent of wages to a superannuation fund specified in the award. The second is the Superannuation Guarantee, under which employers are required to pay a specified proportion of salary, currently nine per cent, to a superannuation fund of their choice. Despite being compelled to invest in superannuation, employees have no effective choice about which fund is to receive their contributions, and no choice about whether to retain accumulated balances in the original fund.

Some time ago the Commonwealth government announced a new policy of allowing members of superannuation funds to have unrestricted choice on portability of accumulated balances in superannuation funds, and published the necessary regulations under the Superannuation Industry Supervision Act (SIS Act). The proposed date under which these were to become effective was July 2004, but these regulations were disallowed by the Senate in September 2003.

In this paper we argue that the resulting ongoing lack of choice violates the fundamental principle of consumer sovereignty, under which it is held that consumers are the best judges of their own welfare and ought to be able to consume anything they can afford to buy; and similarly, in the investment area, that individuals are the best judges of their own welfare, and so should be able to place their retirement savings in any product they choose. Quite apart from our value judgment that consumer sovereignty is preferable to paternalism, we argue that the lack of choice of both initial and subsequent superannuation fund leads to a lack of competition in this sector. Trustees of superannuation funds are assured of both a flow of captive contributions and stability of accumulated balances, which removes incentives to operate the funds at lowest cost, much less in line with member preferences.

Michael Drew is Senior Lecturer in the School of Economics and Finance Queensland University of Technology and Jon Stanford is Senior Lecturer in the School of Economics, University of Queensland. 


\section{Defined Contribution and Defined Benefit Superannuation Funds}

Before proceeding, it is necessary to distinguish two quite different types of superannuation fund: defined benefit funds (DBF) and defined contribution (or accumulation) funds (DCF).

DBFs promise a retirement benefit defined by a formula that is usually based on final salary and years of service: the typical retirement benefit is either a pension amounting to a certain percentage of final salary, a lump sum equivalent to a certain multiple of final salary, or some combination of these. The liability to meet the promise is assumed by the fund's sponsor, usually the employer. On the other hand, in a DCF the retirement benefit is simply the accumulation of contributions, plus earnings less expenses. Under a DCF, members bear the entire investment risk, whereas in a DBF fund this risk is predominantly carried by the employer.

In DCFs it is appropriate that members should be able to choose the fund in which to hold their balances, since they bear the risk that trustee decisions will produce poor returns or high costs. By contrast, if DBFs are poorly managed this is a problem predominantly for the sponsor, not the member. For this reason, we argue that portability only makes sense in the case of defined contribution funds, where the value of the retirement benefit to members depends on performance of the trustee.

Figure 1 shows the membership of superannuation funds by public and private sector. The major features to note are that the overwhelming majority (over 90 per cent) of accounts are in private sector accumulation funds, and that membership of DBFs is largely confined to the public sector. Comparison with similar data for previous years also shows that membership of DBFs has been declining for some time, with a number now closed to new members. For these reasons the rest of this paper relates only to DCFs.

\section{Portability of Accumulated Balances}

We take it that the goal of members of accumulation funds is to obtain the maximum terminal balance at the age when they can exit the superannuation system (after allowing for risk). The important variables determining the terminal balance are the gross investment returns earned by the fund and the expense rate of operating it (Drew and Stanford, 2002). The gross investment returns will depend on the asset allocation strategy - that is, the proportion of the fund's portfolio in each asset class - and the market return to each asset. Expenses incurred by the fund are of two major types: administrative expenses, which are usually charged as a flat dollar amount per annum, and the expenses of investing the portfolio (for instance, the expense charges by the university superannuation scheme, Unisuper, are an administrative fee of \$127 per member per year, and an average investment expense of 0.37 per cent of funds under management.) 


\section{Figure 1: Membership of Superannuation Funds by Type of Fund and Sector, Australia, December 2003}

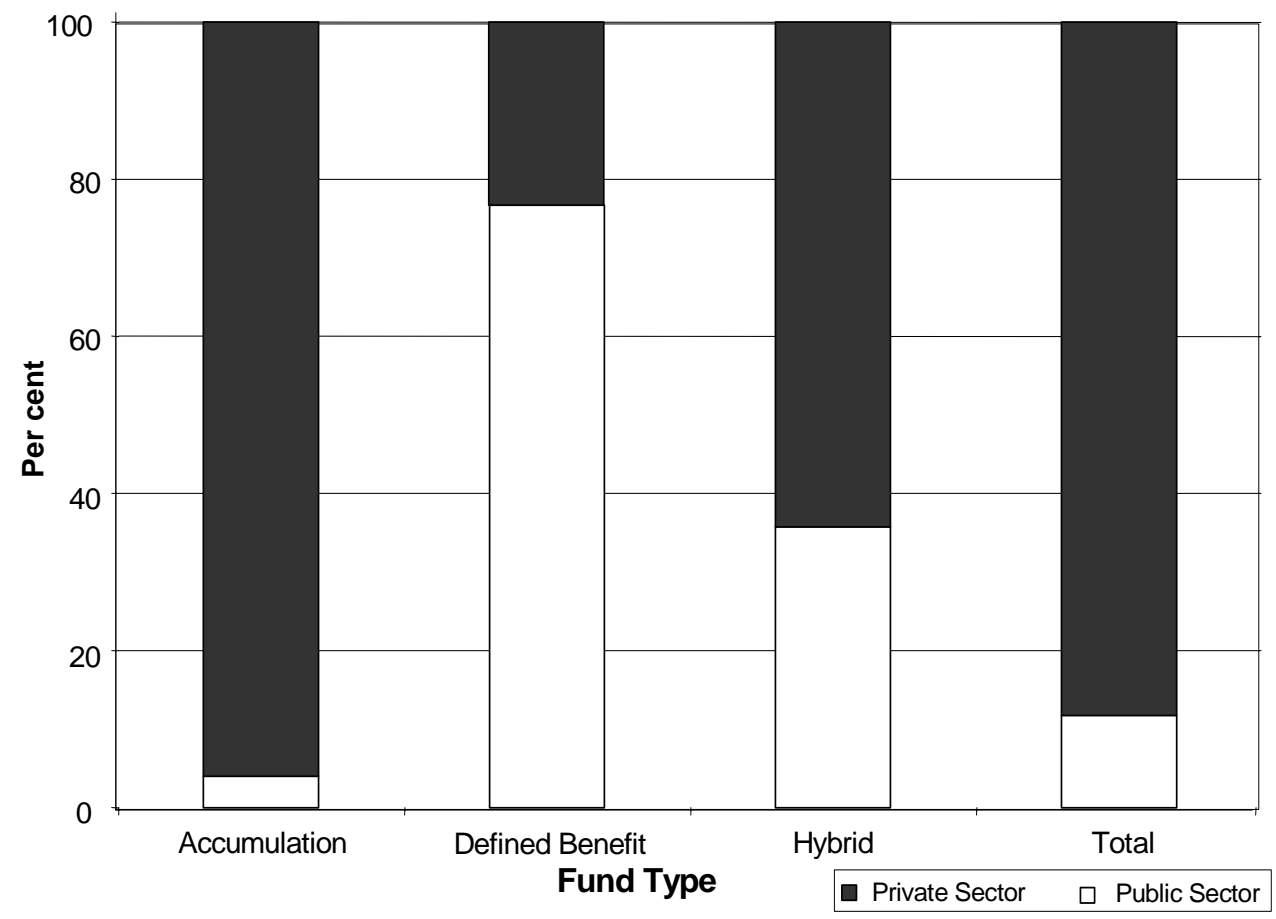

Note: Small Funds (those with less than 5 members), are assumed to be accumulation funds.

Source: APRA: http://www.apra.gov.au/Statistics/Superannuation-Institutions-Statistics.cfmdata.

Given freedom to do so, is it likely that members would be able to select funds that provide returns higher than a market benchmark? Our research shows that any superior performance by active funds managers does not persist (Drew, Stanford and Taranenko, 2001; Drew, Stanford and Veeraraghavan, 2002b); this supports the conventional wisdom that past performance of superannuation funds does not provide a reliable indication of future performance. From this we conclude that there is no information that would enable members of superannuation funds to predict future performance, and that it is therefore pointless for them to attempt to do so.

What, then, is the optimal strategy if there is freedom to choose the fund? We have shown that retail superannuation funds, specializing in the management of domestic equities, under-perform industry benchmarks, after taking into account the risk exposure of these funds (Drew and Stanford, 2003b); this research confirms findings from the US and the UK. We also have found that higher investment expenses (presumably reflecting active rather than passive portfolio management) are associated with lower returns to the portfolio (Drew and 
Stanford, 2003c). Finally, we have found some evidence that even the lowest cost cohort of wholesale funds have produced slight excess returns (Drew, Stanford and Veeraraghavan, 2002a), that is, managers are able to just recover the costs of active management. With these observations in mind, we argue that the optimal strategy for members seeking to maximise their terminal benefit is simply to concentrate on minimising expenses. The general rules for achieving this end are to consolidate balances in a single fund (to avoid paying the administrative expenses fee more than once); to choose a fund that charges wholesale rather than retail fees; and to choose a predominantly passively managed fund rather than an actively managed one. Note that following these rules requires no detailed knowledge of funds or of their past performance.

Table 1: Costs of Superannuation Fund by Type of Fund

\begin{tabular}{l|cccc}
\hline Type & $\begin{array}{c}\text { Investment } \\
\text { Cost }\end{array}$ & $\begin{array}{c}\text { Administration } \\
\text { Cost }\end{array}$ & $\begin{array}{c}\text { Distribution } \\
\text { Cost }\end{array}$ & $\begin{array}{c}\text { Total } \\
\text { Expense Rate }\end{array}$ \\
\hline Large & \multicolumn{3}{|c}{ per cent of Funds Under Management } & \\
\hline $\begin{array}{l}\text { Corporate } \\
\text { Wholesale }\end{array}$ & 0.34 & 0.38 & 0.33 & 1.05 \\
$\begin{array}{l}\text { Corporate Employer } \\
\text { Master Trust }\end{array}$ & 0.40 & 0.35 & 0.10 & 0.85 \\
$\begin{array}{l}\text { Industry } \\
\text { Government }\end{array}$ & 0.45 & 0.60 & 0.10 & 1.15 \\
\hline Retail & 0.20 & 0.23 & 0.00 & 0.43 \\
\hline $\begin{array}{l}\text { Small Retail } \\
\text { Employer Master }\end{array}$ & 0.60 & 0.90 & & 2.00 \\
Trust & & & 0.50 & \\
Personal Super & 1.24 & 0.60 & 0.50 & 2.34 \\
\hline
\end{tabular}

Note: Costs exclude entry and exit fees. The key cost determinants are access to wholesale investment rates and distribution methods. On both counts, retail funds have comparatively high costs. Government funds have low costs because the administration of superannuation has been integrated into the payroll function, and because many government funds are unfunded.

Source: Rice and McEwan (2002).

The potential gains from following these rules are significant. Avoiding an administrative fee of $\$ 127$ a year would increase the terminal balance by nearly $\$ 8,500$ over 30 years (assuming an average earning rate of 5 per cent a year). The advantage of paying wholesale rather than retail fees can be seen in Table 1, in which all types of corporate superannuation funds have lower costs than retail 
funds. Members could effect a saving of as much as 0.8 per cent annually by this means, and on reasonable assumptions, this would increase the terminal benefits by at least 15 per cent.

The gains from consolidating balances into passively managed funds rather than actively managed funds are also potentially high (at the extreme 0.94 per cent per year for members of retail personal superannuation funds), and are material for all members except those of government funds (for more detailed analysis of the data see Rice and McEwan, 2002).

The main point of this paper, however, is precisely that under current arrangements, superannuation fund members are not free to follow these rules. Their accumulated balances are an illiquid, unmarketable long-term asset that must be preserved in the superannuation environment until at least age 55 (the current policy is to extend this progressively to age 60 by 2025 . Members have no choice of fund and no right to transfer accumulated balances from one fund to another.

Superannuation funds operate as trusts; the trustee is the legal owner of the assets in the superannuation fund and invests them for the beneficial owners, the members. But members are not allowed to appoint or direct trustees: in general, they have no influence over trustee decisions. Trustees have explicit duties under common law and the SIS Act to act prudently and in the interests of beneficiaries but, as we have argued elsewhere, they are generally inexperienced in financial matters, and tend to accept the conventions of the funds management industry as espoused by investment or 'asset' consultants and funds managers. In other words, they are effectively 'managed' by these groups - for their benefit rather than that of the fund members (Drew and Stanford, 2003a). The problem is made worse by the absence of effective consumer protection measures. The Australian Prudential Regulation Authority (APRA) has a practice of referring member complaints to the superannuation fund for reply (Stanford, 2003). Moreover, the Australian Securities and Investment Commission (ASIC), is reluctant to act on consumer complaints about superannuation fund performance (Valentine, 2003).

The restrictions on choice of fund and portability generate a welfare loss to members, as the lack of competition between funds results in higher costs and lower investment returns. The implication is that the introduction of portability of superannuation balances would increase welfare, but the interests of fund managers are threatened by proposals for portability of superannuation balances. It should come as no surprise, therefore, that the broader funds management industry opposes portability.

\section{Wallis Committee Recommendations}

Several years ago the Wallis Committee (as part of the Wallis enquiry into Australia's financial system) considered investment management fees in Australia and concluded that they appeared to be higher than those in comparable countries (Wallis Committee, 1997). One of the major likely reasons for higher costs was the fragmentation of the managed funds industry, and so the committee argued 
that rationalisation would be assisted by stronger competition and the removal of regulatory constraints on the amalgamation of funds. In particular, the Wallis Committee (1997) noted that the existing arrangements restricted competitive pressure in the sector by providing member choice of fund only to self-employed individuals and members of public offer superannuation schemes.

However, the Wallis Committee argued that member choice raised several concerns:

- Administrative costs for employers and funds were likely to be greater if freedom of choice was unfettered and could be exercised at will. If members exercised choice frequently, additional exit/entry fees might offset any increase in investment returns.

- Investment strategies might need to be adjusted so that funds would hold more liquid assets, and might result in a greater focus on short-term investment performance. (However, the committee pointed to US experience, which suggests that investor choice has not led to higher volatility in fund liquidity.)

- These problems might be partly addressed by imposing limitations on exit, such as a suitable notice period or a limit on the frequency of change. Subject to these constraints, however, the additional competition engendered by choice was likely to put downward pressure on costs and to encourage rationalisation of the industry.

- Member choice would be successful in promoting competition only if consumers had appropriate information. It was the joint responsibility of the industry and regulators to ensure that consumers were educated and well informed. Education should cover issues such as the rights of members, different life cycle needs and their implications for risk and return, and the benefits and costs of exercising choice.

- Consumer protection would need to encompass requirements for adequate disclosure, proper regulation of the sales and advice process (including licensing of investment advisers), and speedy dispute resolution where problems occurred.

The committee recommended that superannuation fund members should have a greater choice of fund subject to any constraints necessary to address concerns about administrative costs and fund liquidity. Finally, the Wallis Committee recommended specifically that members should have the right to transfer vested amounts to any complying fund. On exercise of that right, payments should be transferred to the chosen fund as soon as practicable, subject to controls necessary to maintain orderly management for the benefit of all fund members. Transfer costs, including those incurred as a result of regulatory requirements should be transparent and reasonable.

In our view the Wallis Committee overestimated the difficulties associated with portability. For instance, liquidity problems in fact are likely to be minimal. The effect of portability would be to re-allocate balances between funds, but there 
is no possibility of a 'run' on the superannuation industry as a whole, since balances must be preserved until at least age 55. If, as we would expect, members took the opportunity to consolidate balances into a smaller number of accounts, those funds losing members would need to dispose of assets, while those gaining members would need to acquire them; sales would balance purchases in the aggregate, so there should not be significant disruption to the capital market.

If there were major transfer of balances from one class of funds to another, this would amount to strong evidence of member dissatisfaction with their initial trustees and their policies. In these circumstances it is to be hoped that trustees would review their procedures and policies so as to reduce the outflow. If they did not respond satisfactorily their funds would continue to shrink, and eventually they would find themselves out of a job. It is precisely this form of market discipline that will encourage the emergence of a superannuation industry that is more efficient and more in tune with the preferences of fund members.

We also argue that once a portability regime has been established a high level of transfers is unlikely. Transferring accumulated balances will undoubtedly be subject to exit fees and will be a somewhat time-consuming process, so the optimal strategy for maximising retirement benefits is analogous to that which should be adopted by fund managers: a passive buy and hold strategy that avoids the high transactions costs inherent in active portfolio management.

\section{Current Government Proposals}

As already noted, change to superannuation policy is now back on the agenda. The current proposals of the government are as follows:

- Allow portability through changes in the regulations of the SIS Act.

- Portability is to be implemented by way of regulations (under sections 31 and 32 of the SIS Act) that will require the trustees of all regulated superannuation funds to transfer an amount in respect of a member's superannuation benefits to another regulated superannuation fund (for instance, an approved deposit fund) at the request of that member.

- The transfer will be subject to agreement of the receiving fund.

- $\quad$ Portability would apply to the withdrawal benefits of a fund member.

- Funds would be required to transfer benefits as soon as practicable following receipt of a request from a member, but within 90 days of the request.

The government wishes that these portability proposals be extended to members of defined benefit schemes other than public sector (Commonwealth and State) schemes but, as pointed out above, this is not necessary. Members of DBFs have an entitlement to clearly specified retirement benefits; if they are unhappy with these benefits or any other of the terms of their employment, this is a matter for them to negotiate with their employer. Freedom to choose a different employer is the DBF analogue to portability of accumulated balances in a DCF. 
The following sub-sections highlight further matters of detail related to these proposals.

\section{Exit fees}

The government does not intend to impose new limits on exit fees, considering that previous action in terms of imposing a stronger disclosure regime for superannuation funds will mean that members must be informed about exit fees prior to, or shortly after, joining a fund. The government reserves the right to regulate exit fees, however, if there is evidence that exit fee arrangements are being structured for the purpose of preventing portability from operating as intended.

\section{Freezing portability}

APRA would be able to freeze the transfer of all, or a proportion of, benefits out of a fund to another fund where there are prudential concerns. Such concerns would arise if APRA had reason to believe that the transfer of funds would prejudice the financial position of the fund, or the interests of its members. In such circumstances APRA would be able to suspend or vary the fund's obligation to pay the benefit for such period as APRA determined. APRA would also have the discretion to freeze portability of benefits where the trustee of the fund had made an application to APRA to do so. Once APRA had discontinued a freeze, the maximum notification period for the transfer of benefits would recommence for any outstanding requests for transfer.

\section{Consumer protection and disclosure issues}

Many of the disclosure requirements that are necessary for portability are already provided by the Corporations Act 2001, the general disclosure requirements of which harmonise disclosure requirements for financial products, including superannuation. In addition, this Act now provides enhanced service provider licensing and conduct regimes. Disclosure requirements for superannuation funds are stipulated in the Act, as amended by the Financial Services Reform Act 2001 (FSR amendments), which came into force on 11 March 2002. These disclosure requirements ensure that all prospective members of public offer funds are made aware of the level of exit fees and other conditions prior to joining and transferring their benefits into a superannuation fund. At that time a superannuation-styled 'disclosure of interest' form is recommended or a Product Disclosure Statement (PDS) must be issued to the prospective member. The PDS must include information about any amounts that will or may be payable in respect of the product after its acquisition (including exit fees), either by the holder or out of a common fund. 


\section{Information about current fund}

Members require information about their current fund and the status of their benefits. The Corporations Act disclosure obligations include a requirement for fund trustees to provide certain member and fund information after each reporting period (usually 12 months). This includes:

- The amount of the member's withdrawal benefit at the start and end of the reporting period.

- The method by which that amount was worked out.

- The proportion of that benefit that must be preserved.

- The amount payable on the member's death, and details of any disability benefits.

- A description of the fund's investment strategy and investment objectives of the fund.

- A statement of fund assets and information on the fund's rate of net earnings.

- Information relating to the fees, charges, expenses and administrative or other operational costs of the fund and the amount of fees and charges deducted by the fund from any account held in respect of the member.

The government considers that fund trustees should also be required to provide information to members on request that would allow them to make an informed decision about the transfer of their superannuation benefits. This information should include the member's withdrawal benefit and amount of exit fees that would be payable at that time.

\section{Market conduct}

The FSR amendments to the Corporations Act have drawn together regulations on financial advice in relation to different types of financial products into a single licensing regime for persons seeking to carry on a financial services business. Accordingly, persons who advise on superannuation products (both life and nonlife products) will be subject to licensing or authorisation requirements administered by the Australian Securities and Investments Commission (ASIC). Licensed financial service providers are subject to a range of measures regulating their conduct and disclosure under the Corporations Act, designed to provide for a high level of consumer protection.

\section{Education campaign}

The government would conduct an education campaign prior to the commencement of portability. The campaign would be designed to meet the information needs of both fund trustees and fund members. 


\section{The Senate Select Committee on Superannuation}

The Senate Select Committee on Superannuation (SSCS), which reported on the portability proposals in September 2003, purported to support the principle of portability and the freedom of individuals to consolidate their superannuation accounts (p. xiii), but believed that portability out of an active account is an issue that is better dealt with through choice of funds legislation, on the grounds of efficiency and consumer protection (p. xiv). Recall, however, that the SSCS had earlier opposed the government's choice of funds proposals, and that the Senate later rejected the choice of funds bill.

The opposition to transfers from an active fund - that is, a fund into which superannuation guarantee contributions are paid - was on the grounds that such transfers constitute choice of funds. One submission cited by the SSCS (p. 10) expressed the view that:

... portability without choice could become a backdoor version of choice: the employer pays contributions into a fund and the employee systematically channels them into a different fund.

The attitude embodied in this statement is that employer sovereignty, not consumer sovereignty, should prevail at all times. We argue that the appropriate response to the hypothetical situation above is to say that if employees do not like the fund their employer has chosen for them, then the employer's choice should be overridden. It is not the role of the employer to tell employees that their preferences will not be met.

The SSCS (p. xiv) also expressed concerns that:

... portability out of active superannuation accounts could lead to an increase in superannuation account numbers in Australia, rather than the desired decrease.

The SSCS did not provide any analysis to support this assertion. On any reasonable analysis it is extremely improbable. To be true it would require portability to lead to the opening of more accounts than would be closed. In any case, even if this assertion were true this should not be considered a problem, since the increase in accounts would be the result of members' choices.

Although the SSCS has since been wound up, it should be noted that there were substantial problems with its mode of operation and its conclusions. It acted only on submissions to it, implicitly assuming that all submissions were of equal value. It did not investigate issues raised in the submissions, much less take expert advice. A good example of this is that it did not even consider the Wallis Committee findings and recommendations, and did not seek advice from any members of that committee. Thus, submissions were dominated by self-interested parties who were allowed to make uncontested assertions, and to have them regarded as factual and valid. 
The assertions of self-interested parties making submissions to the committee and were often self contradictory. One example concerning portability relates to timing of transfers between funds. The Corporate Super Fund Association suggested that members could time their departure from a fund so as to follow the allocation of reserves to members' accumulated balances, and to re-enter when reserves have been built up again (SSCS, 2003:55). The argument that members would engage in such a complex strategy contrasts strongly with the view that members do not understand superannuation and need further education to be able to make informed choices. In any case, we would argue that members should be free to maximise their returns to superannuation, and that seeking to join a fund with higher reserves is a rational strategy.

The appropriate response of a fund in these circumstances is not to deny portability, but to not hold reserves. The association asserted that holding reserves enables the smoothing of crediting rates (that is, investment returns net of expense charges) with the objective of promoting fairness between members and the perception that returns are stable over time. In fact, promoting fairness between members in an accumulation fund requires that returns are credited to members' accounts at the time they are earned. Moreover, the notion that 'returns are stable over time' is out of line with reality. Members understand only too well, given the performance of superannuation funds in recent years, that returns are highly volatile over time, and that funds are unable to reduce this volatility.

\section{Counter Arguments to Concerns About Portability}

Reflecting the discussion above, some of the common objections to portability are based on the belief that either members are unable to understand superannuation, or they do not have enough information to be able to make sensible decisions about it.

We argue that with superannuation being compulsory, members have little incentive to understand it in detail. No actions are required of them under the current arrangements, under which contributions are paid to a fund irrespective of their wishes, and contributions are invested by trustees without reference to them. It would be irrational for members to seek a better understanding of superannuation since this would be costly, yet there would be no benefit to themselves. Nevertheless, surveys show clearly that there is a quite a high level of understanding of the problems of superannuation, as well as a level of dissatisfaction with the current superannuation arrangements (members are well aware of the problem of multiple accounts, and that attempts to combine accounts are frustrated by the refusal of trustees to allow transfer of balances). For instance, the results of a survey about attitudes to retirement income ('Retirement Savings: Drivers and Desires'), conducted by the Investment and Financial Services Association, indicated that respondents showed a strong preference for a lump sum on retirement, were highly averse to risk, and were also averse to retirement income products with little or no residual value, no possibility of withdrawal of capital, and no age pension benefits (Drew, Stanford and Stanhope, 
2003). Thus the major problem is not a lack of information or an inability to process it, but the regulatory restriction that precludes superannuation fund members from acting on it.

\section{Concluding Comments}

The vast majority of Australians belong to defined contribution funds, and their objective is to maximize their retirement benefit - that is, the terminal benefit paid. Given that members of such funds bear both the investment risk and the risk that their funds may not be managed efficiently, we argue that the best strategy to achieve this end is to minimise the fees paid under superannuation arrangements, and for fund managers to use a predominantly passive asset selection strategy. We base our case for portability of superannuation on the principle of consumer sovereignty. Like a number of important ideas in economics, the sovereignty of the consumer has one important qualification - that is, the agent is fully informed and is able to act to maximise their utility. It is our conjecture that welfare and efficiency would be increased by the adoption of portability, since this would generate much greater competition between fund managers.

Portability is opposed by trustees and fund managers, who fear that their own economic interests will be harmed by it. These fears are well based: portability would be predicted to reduce the number of superannuation accounts, and result in a transfer of balances from high-fee, actively managed funds to less costly managed funds.

Although it may be preferable, in principle, to provide more information to members of funds, we argue that there is already enough information available to allow members to make valid choices. Current consumer protection measures in superannuation may well be inadequate, but the market-oriented measure of removing the prohibition of portability, so as to put competitive pressure on trustees and funds managers, is far more likely to be the most effective means of improving consumer protection in this field.

\section{References}

Drew, M., and J. Stanford (2002), 'The Economics of Choice of Superannuation Fund', Accounting, Accountability and Performance 8(2):1-19.

Drew, M. and J. Stanford (2003a), 'Principal and Agent Problems in Superannuation Funds', Australian Economic Review 36(1):108-117.

Drew, M. and J. Stanford (2003b), 'Returns from Investing in Australian Equity Superannuation Funds, 1991 to 1999’, Services Industries Journal 23(4):12-24.

Drew, M. and J. Stanford (2003c), 'Is There a Positive Relationship Between Superannuation Fund Costs and Returns?', Economic Papers 22(3):74-84. 
Drew, M., J. Stanford and B. Stanhope (2003), 'A Look at Consumer Preferences Toward Retirement Income Risks: Evidence from Australia', Paper given at the 11th Colloquium of Superannuation Researchers, University of New South Wales, Sydney.

Drew, M., J. Stanford and P. Taranenko (2001), 'Hot Hands and Superannuation Fund Performance: A Second Note for Trustees’, Economic Papers 20(4):18-25.

Drew, M., J. Stanford and M. Veeraraghavan (2002a), 'Efficiency with Costly Information: A Study of Australian Equity Wholesale Superannuation Fund Performance', Economic Analysis and Policy 32(1):35-47.

Drew, M., J. Stanford and M. Veeraraghavan (2002b), 'Selecting Australian Equity Superannuation Funds: A Retail Investor's Perspective', Journal of Financial Services Marketing 7(2):115-128.

Rice, M., and I. McEwan (2002), 'Superannuation Costs and Competition', Investment and Financial Services Association Limited Ltd, Sydney, www.ifs.com.au.

Senate Select Committee on Superannuation (2003), Report on Portability of Superannuation Balances, Canberra, September.

Stanford, J. (2003), 'Is Superannuation Safe? The Background and the Issues', Australian Economic Review 36(1):79-88.

Wallis Committee (1997), Final Report of the Financial System Inquiry, AGPS, Canberra.

Valentine, T. (2003), 'Is Superannuation Safe?’, Australian Economic Review 36(1):108117.

An earlier version of this paper was given at the 32nd Conference of Economists, Canberra, 2003. We express our thanks to those participants at the session for comments on the paper. We also acknowledge the contributions of Ross McLeod, Franco Papandrea, the editorial committee, and the valuable suggestions of two anonymous referees. All remaining errors are the responsibility of the authors. 



\section{Community Understanding of Superannuation}

\section{Diana Beal and Sarath Delpachitra}

$\mathrm{S}$ uperannuation has had a chequered history in Australia. From its beginning early in the mercantile history of Australia, when banks used their employee provident funds as 'golden handcuffs' to keep employees loyal and honest, until the 1980s, superannuation remained essentially the preserve of senior whitecollar male employees (McKeown, 2003). Along the way, some interesting abuses were perpetrated by employers for personal gain. Such abuses included 'cherry-picker' funds where employers of short-term employees set up selfmanaged funds, contributed funds for employees including themselves and claimed tax deductions to reduce taxable incomes and tax liabilities. However, under the terms of the trust deeds, only long-term employees could benefit and thus only the employers qualified. The employers then paid the majority, if not all, of the invested funds to themselves (McKeown, 2003).

Things began to change for the better in the second half of the 1980s and early 1990s. Two forces of change stand out. First, the union movement and the Federal Government agreed to a series of Prices and Incomes Accords which were designed to increase rewards to employees but to restrain inflationary pressures. In Accord Mark II, wage rises were traded for superannuation contributions. Employers then objected to subsequent Industrial Commission rulings and, on appeal, the High Court of Australia in 1986 (160 CLR 341) decided that superannuation would be regarded henceforth as a condition of employment. Second, in order to try to overcome a looming budgetary problem caused by the ageing of the population, the Federal Minister for Social Security in 1989 released a retirement incomes policy which had three pillars - compulsory superannuation contributions, voluntary superannuation contributions, and the age pension as income support or top-up for those with insufficient other income in retirement (Howe, 1989). By that time, the age pension had been in place for nearly a century, but compulsory superannuation contributions made by employers in addition to employees' salaries and wages for nearly all employees were new. The legislation, the Superannuation Guarantee Charge Act 1992, made the compulsory contribution 3 per cent in the first instance, rising to 9 per cent by July 2002.

In the twelve years since the introduction of compulsory superannuation the government has, on several occasions, proposed legislation to require employers to offer their employees a choice of funds to which their contributions would be made. Even though this legislation has not been passed, the industry has reacted to the proposals by introducing several investment choices for most fund members. The upshot of these proposals, even though they were made with the

Diana Beal is Director, and Sarath Delpachitra is a Research Fellow, in the Centre for Australian Financial Institutions at the University of Southern Queensland. 
best of intentions to allow fund members to align their superannuation investments with their personal risk tolerances, has been to put pressure on members to learn more about superannuation and to take some responsibility for decisions which will impact significantly on their eventual retirement incomes. As Assistant Treasurer, Helen Coonan, (2002:19) noted: 'measures such as choice ... give greater responsibility to the individual'.

The Assistant Treasurer's allusion to choice highlights the philosophical environment within which this issue resides. On one hand, economists argue that individuals are the best judges of their own welfare and thus make the best decisions regarding their own actions. In this context, individuals must choose between current consumption with its instant gratification and deferred consumption with its delayed gratification which eventually is enjoyed during their retirement years. Many individuals find it difficult to defer gratification, even though they are aware that, unless they do so, they are sentencing themselves to lifestyles significantly less comfortable than they enjoy during their years of employment. On the other side of the argument, the government is aware that individuals are generally not deferring sufficient consumption to allow adequate saving for their retirements. To try to improve retirement savings and to relieve future pressure on public-sector budgets, policy makers have imposed this compulsory savings strategy on the community in the form of the superannuation system.

The issue of choice, and especially informed choice, has been widely acknowledged as vitally important to the success of the superannuation policy. Indeed, the Senate convened a Select Committee to investigate and report on the choice of superannuation funds in 1997-98 (Senate, 1998). The Committee noted two requirements of informed choice: the education of consumers [investors]; and employers, and adequate disclosure of funds information (Senate 1998:Part 5.1). According to the Committee (Senate,1998:Parts 5.9-5.10), informed choice will promote competition and efficiencies among funds and a culture of active interest among consumers. The importance of informed consumers is highlighted by the Australian Bankers' Association's evidence to the Committee that 'with compulsion, people do not feel in control. There is still a negative attitude to super as an investment. ... There are low levels of literacy' (Senate, 1998:Part 5.11).

Some may argue that individuals do not need to be familiar with the details of the superannuation framework, as they may employ advisers. Certainly, people may purchase advice, but confident knowledgeable people then make their own decisions after considering the advice received, their own knowledge and their understanding of their own wants and goals, both stated and tacit. People without such knowledge of the system are condemned to second-best solutions as they are unable to evaluate the advice received.

The research reported in this paper investigates the level of knowledge of individual fund members about the superannuation system. In addition, the investigation was designed to throw some light on members' perceptions of their own knowledge as well as their knowledge as revealed by their answers to the 
technical questions posed. To this end, the next section provides a brief review of the literature, followed by an outline of the data collection and analytical methodology. The penultimate section presents the findings and while the final sections provides discussion and conclusions.

\section{Literature Review}

To the best of the authors' knowledge, there have been no academic published papers examining Australians' understanding of their superannuation system, even though detailed knowledge is vital to most employees' achievement of their individual informed choice and retirement objectives, to the achievement of efficiencies in the superannuation industry and to the achievement of effective policy on the part of the government.

There has, however, been limited relevant research conducted overseas, most notably in the USA and Canada. An early study in the USA by Mitchell (1988) used data from the 1983 Survey of Consumer Finances together with surveys of individuals to examine the quality of workers' knowledge of their pension plans. She found unionised, higher-income, better-educated and senior staff were better informed than others. In addition, she found demographic differences in that Americans of European racial origin were better informed, as were women, about several facets of their pension plans.

Gustman and Steinmeier (1999) compared descriptions of their pension plans given by respondents to the 1992 US Health and Retirement Study (HRS) with data given by their respective employers. They found that only half of the respondents could correctly identify the type of pension plan they participated in (that is, defined benefit or defined contribution). Fewer than half could identify correctly (within one year) their eligibility dates for early or normal retirement. The authors noted that their findings raised considerable doubt about how well respondents understood the more complex areas of pension and social security rules.

Gustman and Steinmeier (2001) built on their earlier work using data from the HRS to report that imprecision, wrong information and lack of information about retirement benefits is the norm. They found women, contrary to Mitchell's (1988) findings, and racial minorities were less well informed. In addition, they found people that planned were 'modestly' better informed than non-planners.

Further relevant retirement-policy research was reported by Chan and Stevens (2003). Chan and Stevens were perplexed that retirement policy incentives appeared to be effective, yet both anecdotal evidence and academic research pointed to the population not knowing much about their pension schemes. They found uninformed people showed no response to actual retirement incentives, while informed people reacted much more strongly than previously thought. As virtually all recent empirical research had been based on administrative data which effectively averages responses, their findings have important implications for retirement policy formation and policy assessment. In addition, they noted the generalised finding that lack of knowledge of policy incentives by individuals, 
and the paucity of education programs contribute to reduced responsiveness to economic policies and made the policies less effective.

Luchak and Gunderson (2000) reported a 1988 survey of 529 employees of a large unionised public utility in Ontario, Canada. They found the level of pensionplan knowledge was low among all employees on average, but 'quite high' among those for whom the information mattered most for decision-making. These included older workers, higher-skilled and higher-paid workers, workers likely to retire early due to ill-health and workers who facing higher losses of pension entitlements if they quit or were sacked.

Focusing more closely on the Australian superannuation scene, the relevant literature is sparse. Stimulated by the failure of the proposed 'choice of fund for members' legislation, which was mentioned in the introduction to this paper, Brown, Gallery and Gallery (2002) developed a framework to examine the endogenous and exogenous constraints affecting the achievement of informed choice by superannuation fund members. They argued that a genuine choice paradigm should provide options for members to achieve either active or passive (default) choice. Further, they argued, in agreement with Senate (1998), that education programs and standardised disclosure by funds managers are critical for successful active management by members of their personal superannuation savings. Moreover, to cater for individuals wishing to select a passive management style, the authors argued that a government-managed default fund could protect the savings of vulnerable members much more effectively than the current arrangements.

The Senate (1998) Committee heard evidence from Coopers and Lybrand on the efficacy of focussed education programs. Although Telstra offered investment choice to its superannuation fund members in 1997, fewer than two per cent of more than 70,000 members elected to exercise a different choice from the trustees' default selections. In contrast, the Optus fund offered an 'intensive education campaign' and 75-80 percent of its superannuation fund members subsequently exercised investment choice (Senate,1998:Part 5.22). The Committee concluded that 'well designed and implemented communication and education campaigns are effective change agents' (Senate,1998:Part 5.23).

Drew and Stanford (2002) examined the current institutional arrangements for contributions which stem from the superannuation guarantee charge and award-mandated superannuation. Employees cannot currently choose where to place these contributions as the choice of fund is a decision made elsewhere. The authors found that the failed government legislation (referred to in the introduction to this paper) was too prescriptive, and argued that unlimited choice is the preferred policy for members. Gallery and Gallery (2003) argued that a better disclosure and reporting regime is required in the current context of narrow regulatory focus to enable informed members to make better choices.

Recent research conducted by ANOP Research Services for the Association of Superannuation Funds of Australia (ASFA) investigated perceptions and attitudes to superannuation, using a national survey of 706 people in the workforce aged 25-64 years. In a section reporting respondents' perceived knowledge of 
superannuation, seven per cent of respondents thought they were very well informed and 37 per cent thought they were quite well informed, thus making 44 per cent who were at least quite well informed. Another 48 per cent thought they were not very well informed and a further eight per cent were not at all informed or could not answer the question. Those more likely not to feel informed were the less skilled, lower income, women and part-time workers (ASFA, 2002:17-18). The question posed by these findings is: what does 'very well' or 'quite well informed' mean in practical terms?

In summary, while the relatively small Australian superannuation literature has been chiefly concerned with the adequacy of savings and superannuation contributions, funds returns, asset selection and funds safety, one policy issue which continues to be controversial is the matter of choice. Stemming from that issue is the concomitant concern with members' levels of superannuation knowledge. Many papers either directly or indirectly have pointed to the need for further education of the community. This research was designed to inform the debate about the deficits in community knowledge and where educational activity would assist.

\section{Research Method}

This section explains the way in which the data were collected, describes the characteristics of the sample, and discusses our approach to analysing the data.

\section{Data Collection}

The data for this analysis were collected by survey. A survey instrument was designed to include 18 technical questions about superannuation and retirement incomes, six standard demographic questions and one question which asked respondents to rate their own perceptions of their personal levels of superannuation knowledge.

Any test of the apparent knowledge of the Australian community about superannuation could be easily biased by the difficulty of the questions asked. In order to try to overcome this problem in the design of the survey 'test', a threestage process was followed to develop the final questionnaire. First, the member of the research team who teaches financial planning courses considered the question of just what constitutes basic knowledge of the superannuation system. A number of possible multiple-choice questions were devised. Second, the Commonwealth Government publication, A Brief Guide to Superannuation, was examined and it was ascertained that the answers to most questions were included in the guide. Only two questions of the 18 technical questions asked called for knowledge outside that contained in this brochure. These two questions called for a basic knowledge of the effect of the compounding of periodic returns and for current knowledge of the payment rate for the Commonwealth age pension. Finally, the draft questionnaire was pilot-tested among university colleagues and others to fine-tune wording and increase readability. 
That the information needed to achieve a high score and to be classified as 'very well informed' is included in the Commonwealth's Brief Guide indicates that the technical questions were not difficult and constituted what could be reasonably considered to be basic knowledge. The 'knowledge of compounding' question could be answered by any financially-literate person. Only the 'agepension payment-rate' question, which was not multiple-choice, called for knowledge that may not be generally known, but is nevertheless likely to be known by people nearing the pension threshold age or who have parents at or near age-pension age.

The survey was administered by post. In order to limit the cost of administration and to avoid the privacy problems arising when researchers attempt to use databases of names collected for other purposes, the 'unaddressed mail' householder delivery service provided by Australia Post was used. Under the conditions of this service, Australia Post will deliver an unaddressed letter to all or a specific number of street addresses or Post Office boxes as required for about 20 per cent of the cost of a normal letter delivery.

Two suburbs in Brisbane were chosen as the target population. In view of the evidence that the general level of knowledge of superannuation is very low, no attempt was made to select a random sample of the Australian population - the ING survey found, only a well-off minority were interested in the subject. Hence it was postulated that the highest levels of knowledge were to be found among the higher-educated and higher-income segments of the population. Thus, if testing found knowledge to be low among this group, it could be safely concluded that knowledge among the whole population is parlous. The two suburbs were Bardon and Chapel Hill, both (upper) middle-class western suburbs with high populations of tertiary-educated people. According to 2001 census data, almost 61 per cent of both Bardon's and Chapel Hill's population over 15 years of age held postsecondary qualifications of which 36.2 per cent and 34.7 per cent respectively were undergraduate degrees or above, compared with 46 per cent (with 17 per cent undergraduate or above) for the national population (Australian Bureau of Statistics, 2003).

The survey instrument together with an introductory letter and a reply-paid envelope was posted in mid-September 2003 and replies were received until early October. A total of 393 useable replies were received, an apparent response rate of eight per cent. The actual response rate is impossible to compute with unaddressed surveys because researchers cannot be sure all of the despatched survey packets were indeed delivered to householders. However, an eight per cent response rate in these circumstances is gratifying. Respondents reported the demographic characteristics as given in Table 1.

\section{Analytical approach}

The data were entered into a spreadsheet and the number of correct responses ascertained for each respondent. A comprehensive suite of descriptive statistics was computed. Then, OLS regression models were developed and estimated for 
the whole sample and separately for the two sexes and two subsets based on wealth. Other statistical models such as probit regression together with data transformations were estimated, but were rejected in favour of the simplicity and parsimony of OLS. OLS regression modelling is able to provide estimates of the signs and statistical significance of the independent variables that were, arguably, considered to be more important than the estimated values of the coefficients.

Table 1: Demographic Characteristics of Respondents

\begin{tabular}{llc}
\hline Characteristic & Male & $\begin{array}{c}\text { Respondents } \\
\text { (per cent of 393) }\end{array}$ \\
\hline Gender & Female & 58.8 \\
& $<39$ years & 41.2 \\
\hline Age & $40-54$ & 20.8 \\
& $55-69$ & 45.0 \\
& 70 and above & 31.8 \\
\hline Education & Secondary & 2.3 \\
& Trade/diploma & 16.3 \\
& Graduate & 13.0 \\
& Postgraduate & 35.1 \\
Income & $<\$ 30,000$ pa & 35.6 \\
& $\$ 30,000-\$ 50,000$ & 14.0 \\
& $\$ 50,000-\$ 70,000$ & 26.4 \\
& $\$ 70,000-\$ 100,000$ & 23.7 \\
& $>\$ 100,000$ & 16.0 \\
& $<\$ 500,000$ & 17.8 \\
\hline Wealth & $>\$ 500,000$ & 51.6 \\
& & 48.4 \\
\hline
\end{tabular}

\section{Results}

Descriptive Statistics

Table 2 explains the subject of each technical question and gives the percentage of respondents with the correct answer. It is apparent from the table that the bestknown information about superannuation is that superannuation funds are invested in the same assets as other financial investments but that the funds are quarantined in a separate taxation and investment structure ( 77.9 per cent correct) and, 
secondly, that the size of regular contributions is the most important determinant of the final lump-sum value (73.8 per cent correct), rather than earning rates, taxation or fees charged. Next well-known was the preservation age of 55 years for people born before 1 July 1960 (64.1 per cent correct).

Table 2: Percentage Correct for Each Technical Question

\begin{tabular}{lc}
\hline Question & $\begin{array}{c}\text { Correct Responses } \\
\text { (per cent of 393) }\end{array}$ \\
\hline How super differs from other investments & 77.9 \\
Most important determinant of size of lump sum & 73.8 \\
Preservation age & 64.1 \\
Current rate for super guarantee scheme & 59.0 \\
Contributions tax rate & 57.5 \\
Compassionate access to super & 57.0 \\
Earnings tax rate & 56.0 \\
Lump-sum benefits tax rate & 45.0 \\
Nature of undeducted contributions & 33.3 \\
Nature of allocated pension & 25.2 \\
Taxation of undeducted contributions & 22.9 \\
Number of sets of RBLs & 22.6 \\
Size of lump sum at retirement & 20.1 \\
Why allocated pensions counted against lump- & 18.1 \\
sum RBLs & \\
Size lump-sum vs pension RBLs & 17.0 \\
Age limit for super guarantee contributions & 15.5 \\
Time limit after working for super contributions & 12.0 \\
Size of age pension & 9.7 \\
\hline
\end{tabular}

There were four questions for which 56-59 per cent of the respondents knew the correct answers. These were:

- the current mandated percentage of 9 per cent of employees' pay which must be paid by employers into superannuation for their employees;

- the contributions taxation rate of these mandated contributions of 15 per cent;

- $\quad$ grounds for APRA to approve compassionate early access to superannuation;

- taxation rate of 15 per cent on superannuation funds' current earnings. 
In addition, 45 per cent of respondents knew lump-sum benefits from contributions made in the last 20 years are taxed at 15 per cent above a tax-free threshold.

Finally, two-thirds or more of the respondents did not know the answers to 10 of the 18 technical questions. Only one-third (33.3 per cent) knew the nature of undeducted contributions as contributions made by superannuation fund members from their after-tax funds. Thereafter, there were two groups totalling nine of the 18 questions for which only 20-25 per cent and 10-20 per cent of respondents gave correct answers.

The questions for which correct answers were known by 20-25 per cent of respondents were:

- the nature of an allocated pension in that benefit payments are flexible and may be re-set annually;

- undeducted contributions are tax-free on entry and exit with taxed earnings;

- retirees have one set of RBLs even though they might have funds with several providers;

- the nature of compounding of returns so that about $\$ 400,000$ may be needed at retirement to provide $\$ 30,000$ annual income for 25 years.

- In addition, the questions for which fewer than 20 per cent of respondents gave the correct answers were:

- the reason allocated pensions are counted against lump-sum RBLs (18.1 per cent correct);

- the relative sizes of the pension and lump-sum RBLs (17.0 per cent correct);

- the age to which compulsory superannuation contributions are mandated (15.5 per cent correct);

- the period of two years after working in which a person aged less than 65 years may make superannuation contributions (12.0 per cent correct);

- the current amounts of either the single or couple Commonwealth age pension (9.7 per cent correct).

Table 3: Scores Gained by Respondents

\begin{tabular}{lcc}
\hline Score class & Score range & $\begin{array}{c}\text { Respondents in } \\
\text { each score class } \\
\text { (per cent) }\end{array}$ \\
\hline Very well informed & $15-18$ & 3.6 \\
Quite well informed & $10-14$ & 18.1 \\
Not very well informed & $6-9$ & 38.9 \\
Not at all informed & $0-5$ & 39.4 \\
\hline
\end{tabular}


Table 3 provides the percentages of respondents who scored in each of four classes ranging from very well informed to not at all informed. From this table, it is apparent that only 21.7 per cent of respondents scored a 'pass' if the hurdle is set at the traditional 50 per cent mark. The mean score was 6.8 , the median 7 and the modal score 5. Table 4 gives respondents' reported perceptions of their own knowledge by the same classification and contrasts these with their achieved ranges of test scores.

\section{Table 4: Perceived Knowledge and Achieved Scores}

\begin{tabular}{lcc}
\hline Score class & $\begin{array}{c}\text { Respondents' own } \\
\text { perceptions of } \\
\text { knowledge } \\
\text { (per cent) }\end{array}$ & $\begin{array}{c}\text { Achieved scores } \\
\text { by respondents in } \\
\text { each class }\end{array}$ \\
\hline Very well informed & 4.3 & $5-17$ \\
Quite well informed & 31.8 & $2-18$ \\
Not very well informed & 53.9 & $0-14$ \\
Not at all informed & 10.0 & $0-8$ \\
\hline
\end{tabular}

In all, 29 respondents under-estimated their own knowledge of superannuation - eight 'quite well informed' people achieved 'very well informed' scores, 17 'not very well informed' achieved 'quite well informed' scores and four 'not at all informed' people achieved higher scores than this category. On the other hand, 187 respondents over-estimated their knowledge as measured by this test. Twelve respondents who rated themselves 'very well informed' scored one, two or three classes below this category, 70 'quite well informed' respondents scored either one or two classes below and 105 'not very well informed' respondents scored in the 'not at all informed' class. Testing of the demographic characteristics of this subset of overconfident respondents showed that there was no characteristic which differentiated this group from the rest of the sample. In other words, people overconfident of their superannuation knowledge came from all the groups represented - both male and female, from all age groups, all education levels, all incomes and all wealth classes.

\section{Regression modelling}

OLS regression modelling was used to test the proposition that the score gained by each respondent as the dependent variable was influenced by that person's knowledge-perception (SPK) variable, gender, age, education, occupation, income and wealth. Table 5 gives the values each variable could take and the researchers' a priori estimates of signs. Most variables were postulated to be positive on the basis that the older the respondent was and the higher the education, skill level, income and wealth, the better would be the knowledge of the superannuation 
system. In contrast, the SPK variable was likely to be negative as it was defined so that the high values indicated less SPK. The gender variable was thought to be either positive or negative, but was more likely to be positive as anecdotal evidence and previous research (ASFA, 2002; Beal and Delpachitra, 2003) have suggested that males are more likely to be interested in retirement-income issues.

Table 5: Definition of Variables and Expected Signs

\begin{tabular}{|c|c|c|}
\hline Variable & Values & $\begin{array}{c}\text { A priori } \\
\text { signs }\end{array}$ \\
\hline SPK & $\begin{array}{l}1=\text { very well informed to } \\
4=\text { not at all informed }\end{array}$ & - \\
\hline Gender & $1=$ male $; 0=$ female & + or - \\
\hline Age & $\begin{array}{l}1=\text { age } 22-30 \text { years to } \\
5=70 \text { years and above }\end{array}$ & + \\
\hline Education & $\begin{array}{l}1=\text { mid-secondary or less to } \\
5=\text { postgraduate }\end{array}$ & + \\
\hline Occupation & $\begin{array}{l}1=\text { semi-skilled to } \\
3=\text { professional } / \text { managerial }\end{array}$ & + \\
\hline Income & $\begin{array}{l}1=\text { less than } \$ 20,000 \text { to } \\
8=\text { more than } \$ 150,000\end{array}$ & + \\
\hline Wealth & $\begin{array}{l}1=\text { less than } \$ 50,000 \text { to } \\
5=\text { more than } \$ 500,000\end{array}$ & + \\
\hline
\end{tabular}

Table 6: Results of Regression Analysis

\begin{tabular}{lll}
\hline Variable & $\begin{array}{l}\text { Estimated } \\
\text { Coefficient }\end{array}$ & t-ratio \\
\hline SPK & -2.37 & $-11.3^{*}$ \\
Gender & 1.09 & $3.43^{*}$ \\
Age & 0.60 & $3.41^{*}$ \\
Education & 0.27 & $2.08^{*}$ \\
Occupation & -0.17 & -0.69 \\
Income & -0.06 & -0.74 \\
Wealth & 0.45 & $3.37^{*}$ \\
\hline
\end{tabular}

* statistically significant at the 0.05 level 
Table 6 gives the results of the regression model, using the whole sample, with the test score as the dependent variable. As can be seen from the table, the SPK variable, gender, age, education and wealth were found to be statistically significant determinants (at the 0.05 level) of the attained knowledge scores. The adjusted $\mathrm{R}^{2}$ for the estimation was 0.41 . The residuals were checked for normality with the Jarque-Bera test (4.189 with two degrees of freedom.)

Further models were estimated. The data were divided into two subsets on the basis of, firstly, gender and, secondly, wealth with the hurdle set at $\$ 500,000$. Table 7 gives the estimated coefficients, the t-scores and the adjusted $\mathrm{R}^{2}$ values for each model. The adjusted $\mathrm{R}^{2}$ values for the five estimated models show that 30-46 per cent of the variation in the dependent variable is explained by variation in the independent variables in the respective models. The Jarque-Bera normality tests indicated the residuals were normally distributed in all four cases.

Table 7: Results of Regression Analysis

\begin{tabular}{lllll}
\hline Variable & $\begin{array}{l}\text { Estimated } \\
\text { Coefficient }\end{array}$ & t-ratio & $\begin{array}{l}\text { Estimated } \\
\text { Coefficient }\end{array}$ & t-ratio \\
\hline Males & & & Females \\
SPK & -2.08 & $-7.34^{*}$ & -2.94 & $-10.18^{*}$ \\
Age & 0.57 & $2.34^{*}$ & 0.46 & $1.98^{*}$ \\
Education & 0.54 & $2.65^{*}$ & 0.01 & 0.07 \\
Occupation & -0.24 & -0.64 & -0.12 & -0.41 \\
Income & -0.22 & -1.67 & 0.16 & 1.32 \\
Wealth & 0.71 & $3.65^{*}$ & 0.09 & 0.54 \\
$\mathrm{R}^{2}=0.30$ & & & $\mathrm{R}^{2}=0.46$ & \\
Wealth $<\mathbf{\$ 0 0 , 0 0 0}$ & & $\mathbf{W e a l t h}>\mathbf{\$ 5 0 0 , 0 0 0}$ \\
SPK & -2.38 & $-8.62^{*}$ & -2.43 & $-7.45^{*}$ \\
Gender & 0.89 & $2.13^{*}$ & 1.12 & $2.24^{*}$ \\
Age & 0.67 & $3.36^{*}$ & 0.65 & $2.12^{*}$ \\
Education & 0.17 & 0.92 & 0.39 & $1.98^{*}$ \\
Occupation & -0.14 & -0.42 & -0.02 & -0.05 \\
Income & 0.04 & 0.29 & -0.06 & -0.48 \\
$\mathrm{R}^{2}=0.35$ & & & $\mathrm{R}^{2}=0.31$ & \\
\hline
\end{tabular}

* statistically significant at the 0.05 level. 
When comparing the results of the subset models with the full-dataset model, it can be seen that the significant variables remain much the same among all models, the only exceptions being that education and wealth are shown not to be statistically significant determinants of score for the women in the sample and education level is not significant for the less wealthy cohort of the group.

\section{Discussion and Conclusion}

These research findings highlight the parlous state of knowledge of the Australian community about their government-mandated superannuation system which has been designed to deliver to them their retirement incomes. The findings complement the results of research conducted in the USA and Canada and highlight the relatively superior knowledge among older, higher-educated and more wealthy people.

The research was not conducted among the general population, but was purposely directed towards a higher-educated, higher-wealth, mainly professional and managerial cohort, on the basis that these people have the highest probability of having an active interest in and knowledge of superannuation (as shown by the ING survey). They may also be familiar with the political debate regarding choice and be aware of the personal implications should unlimited choice be granted.

The results, therefore, were deliberately biased towards apparent greater knowledge of superannuation. In addition, while nearly 400 responses is a useful number of responses, the response rate was low and it is to be expected the scores of the non-respondents would have been worse than those of the respondents. Indeed, the researchers noted the late respondents almost uniformly scored poorly. Thus, the results are undoubtedly biased on at least two fronts - the higheducation, high-wealth basis and the low response rate. With 70.7 per cent of respondents reporting having gained either undergraduate degrees or postgraduate qualifications as their highest level of education, it would be reasonably difficult to find a group of the general public with higher education levels. Yet, even with this background, no more than 21.7 per cent of the sampled respondents could score a traditional more than 50 per cent pass mark.

That a majority knew that superannuation funds are invested in the 'ordinaryinvestment' asset classes and not in special areas, that the size of regular contributions is more important for lump-sum aggregation than earning rates, fees and taxes (even though these too are important), and that the 'standard' (born before 1 July 1960) preservation age is 55 years is comforting, but these gems of knowledge must be supported by much more understanding before an individual could be considered to be superannuation-literate. A smaller majority of 56-59 per cent of respondents knew the current mandated employer-contribution rate of nine per cent, the grounds for APRA to grant compassionate access to superannuation and a number of the pertinent tax rates. That 41 per cent did not select 'nine per cent' as the employer contribution seems, by itself, to indicate a blithe indifference to this important social issue. In light of this result, if nothing else, the result of 57 per cent selecting the correct answer to the compassionate grounds question was 
somewhat surprising, but perhaps this issue is talked about more often among groups of friends and workers. Similarly, perhaps the ubiquitous 15 per cent tax rates for various cash flows to and from the superannuation framework are discussed among friends, or perhaps, for some, the correct answers were just lucky guesses.

Most important are the issues about which the respondents knew little. Only 33.3 per cent knew the nature of undeducted contributions, and 22.9 per cent knew undeducted contributions are tax-free on entry to and exit from the superannuation system with taxed earnings. This knowledge is vital to the formulation of appropriate savings and investment strategies. This suggests there is little active discretionary saving being practised through the superannuation system, except perhaps through salary-sacrifice. For many people in the middle-aged cohorts, who are without lifetime compulsory superannuation support, this suggests their superannuation savings will not be sufficient to support comfortable retirements. An alternative explanation is that people are not conversant with the correct terminology. For example, some funds refer in documentation to 'member contributions' without defining exactly the tax-status of these contributions which could be before-tax (that is, 'salary sacrifice' or tax-deductible non-employer supported contributions) or after-tax (that is, 'undeducted contributions'). Keeping track of the tax status of members' own contributions underlies the effective management of RBLs.

With regard to allocated pensions, 25.2 per cent knew that the benefit payments are flexible and may be re-set annually but only 18.1 per cent knew the reason these pensions are counted against lump-sum RBLs. Both these characteristics are important knowledge for people involved in retirement planning, whether they be on the verge of retirement or many years away from that event. Similarly, only 22.6 per cent of respondents knew that they have only one set of RBLs regardless of the number of different superannuation-fund accounts, and 17 per cent knew that the pension RBL is about double the lumpsum RBL. Again, this is vital knowledge for active retirement planners.

Two general superannuation questions were also poorly known. Only 15.5 per cent knew that employers must make contributions for employees until age 70 years and 12.0 per cent knew that funds may accept personal contributions from members under age 65 years at any time within two years of their last full- or parttime gainful employment. Additionally, only 20.1 per cent were able to nominate $\$ 400,000$ as a lump-sum which may provide $\$ 30,000$ pa for 25 years in retirement. Some of the more financially-literate people wrote next to the question, 'What is the discount rate?' However, part of the point of the question was that people planning their retirement incomes must think about and select an appropriate discount rate which they believe their funds will be able to earn. Moreover, for the answer ' $\$ 700,000$ ', which was given by 53 per cent of respondents, to be correct, the retirement funds would have to earn only 0.5 per cent pa on average for the whole 25 years. This is unlikely!

Finally, respondents' knowledge of the age-pension payment rate, currently available when self-funding fails, was very poor. At the same time, there is a 
great deal of evidence that Australians of middle age and nearing retirement have not saved enough and will be relying on either full or part-pensions for their retirement incomes. Only 9.7 per cent of respondents were able to quote either the single person's or couple's maximum annual benefit rate to the nearest thousand dollars. The average of nominated amounts was about $\$ 16,000$ for single people and $\$ 23,000$ for couples. These amounts are both about $\$ 4,000$ pa too high at the current time. The ranges of amounts nominated also highlight the general lack of knowledge of this issue: $\$ 3,000$ to $\$ 70,000$ for single people and $\$ 8,000$ to $\$ 50,000$ for couples. Perhaps over-optimism about the age-pension maximum benefit is part of the explanation for individuals' insouciance about their superannuation planning.

Another issue of concern is over-confidence of knowledge of the superannuation system. Even though only 21.7 per cent of respondents could achieve a 'pass' mark, 36.1 per cent thought they were at least 'quite well informed'. Some of these people achieved scores as low as two, three and four. One self-styled 'very well informed' person achieved a score of five on this test, which included questions only on basic characteristics. None of the questions concerned the more difficult area of strategy, which financially-literate retirement planners must also master if they are to make best use of their savings.

The most important policy issue from these research results is that more money must be spent by the Commonwealth Government on education of the community. Without having the requisite knowledge, people are inclined to ignore superannuation as a savings vehicle. Additionally, they certainly are unable to make informed choices about contributing through salary-sacrifice or after-tax funds given the constraints of RBLs and taxation issues.

First, money must be spent on trying to raise awareness and improve the connection people have with their superannuation savings. At the moment, people apparently feel at the remove, and that these funds are not theirs to manage. Second, money must be spent on improving the community's knowledge of how the system works. Television advertising designed to reach to the whole community and to advance knowledge in small incremental steps would appear to be a better use of funds than the production and distribution of more comprehensive 'manuals'. The private sector has used these methods to advantage, and there would appear to be no reason that superannuation could not be 'sold' in the same manner. The findings of this research may serve as a starting point for the design of such a program.

\section{References}

Australian Bureau of Statistics (2003), Usual Resident's Profiles, Postcodes 4065 and 4069, Canberra Catalogue 2004.0.

Association of Superannuation Funds of Australia (2002), 'Report on Workforce Perceptions and Attitudes to Superannuation' [Online], Available: http://www.asfa.asn.au/policy/ANOP\%20Aug\%202002.pdf, [Accessed 23 February 2004] 
Beal, D. and S. Delpachitra (2003), 'Defying the Clock - A Profile of Australians who Ignore Retirement Planning', Journal of Economic and Social Policy 7(2):1-14.

Brown, K., G. Gallery and N. Gallery (2002), 'Informed Superannuation Choice: Constraints and Policy Resolutions', Economic Analysis and Policy 32(1):71-90.

Chan, S. and A. Stevens (2003), 'What You Don't Know Can't Help You: Pension Knowledge and Retirement Decision Making', NBER Working Paper 10185, NBER, Cambridge, MA.

Coonan, H. (2002), A Brief Guide to Superannuation, Commonwealth Treasury, Canberra.

Drew, M. and J. Stanford (2002), 'The Economics of Choice of Superannuation Fund', Accounting, Accountability and Performance 8(1):1-20.

Gallery, G. and N. Gallery (2003), 'Inadequacies and Inconsistencies in Superannuation Fund Financial Disclosure: The Need for a Principles-Based Approach', Australian Economic Review 36(1):89-97.

Gustman, A. and T. Steinmeier (2001), 'Imperfect Knowledge, Retirement and Saving', NBER Working Paper 8406, NBER, Cambridge, MA.

Gustman, A. and T. Steinmeier (1999), 'What People Don't Know about their Pensions and Social Security: An Analysis using Linked Data from the Health and Retirement Study', NBER Working Paper 7368, NBER, Cambridge, MA.

Howe, B. (Minister for Social Security) (1989), Better Incomes: Retirement Incomes Policy into the Next Century, AGPS, Canberra.

Luchak, A. and M. Gunderson (2000), 'What do Employees Know about their Pension Plan?', Industrial Relations 39(4):646-670.

Mitchell, O. (1988), 'Worker Knowledge of Pension Provisions', Journal of Labor Economics 6(1):21-39.

McKeown, W. (2003), 'Superannuation', Chapter 12 in D. Beal and W. McKeown, Personal Finance, Wiley, Brisbane.

Senate (1998), Choice of Fund, 28th Report of the Senate Select Committee on Superannuation, Senate, Parliament of Australia, Canberra.

The authors are indebted to two anonymous referees for their helpful comments 


\title{
The Housing Lifeline: A Housing Affordability Policy
}

\author{
Joshua Gans and Stephen King
}

$\mathrm{H}$ ousing affordability, particularly for low-income households, is a major public policy concern. This paper considers the basis of the affordability problem and potential solutions. In contrast to other work, we distinguish between long-term and short-term affordability and focus on short-term income fluctuations that may create affordability problems for low-income families. Our goal is not to review existing housing policies for low-income households. Gans and King (2003) includes such a review. Instead we highlight the nature of the short-term affordability problem and consider associated market failures. Our chief contribution is to suggest an innovative policy response - The Housing Lifeline - that uses an income contingent 'loan' to fund assistance for lowincome households in overcoming problems associated with short-term housing affordability. We consider both the theoretical basis for the housing lifeline and a variety of issues relating to its practical implementation. In particular, we note that a housing lifeline may have a variety of economic benefits relative to existing housing policies.

Recent concerns over housing affordability have reflected rising house prices. The Australian Bureau of Statistics (2002) reported that over the three years from July 1998 to June 2001 the weighted average price of existing dwellings in Australia's capital cities rose by almost 8 per cent per year. While these increases reflect general prosperity in Australia, this prosperity has not been evenly distributed over the population. Rising house prices can lower the affordability of housing to those families who are at the lower end of the income distribution.

What, however, is actually meant by housing affordability? How do we judge if low-income families are facing an affordability problem for housing? If there is an affordability problem, is this due to a rise in housing prices relative to other goods and services or a fall in the relative income of the poorest in society? It is well accepted in Australia that governments should take an active stance in alleviating poverty and the hardships faced by low-income families. But an antipoverty program is different from a housing policy and the linkage between the two may be very weak if an apparent fall in housing affordability for the poor actually reflects a reduction in real income for the poor rather than a rise in the relative price of housing.

In the next section of this paper, we discuss the nature of low-income housing affordability, before focusing explicitly on short term affordability issues. We then present and discuss the housing lifeline in detail.

Joshua Gans and Stephen King are Professors at the Melbourne Business School and Department of Economics, The University of Melbourne. 


\section{The Affordability Problem}

Affordable housing is usually defined with reference to the (post tax) income that is sufficient to meet household basic needs (food, clothing, medical care, etc.). Under this definition, if a household is spending more than 25 percent (for rent) to 30 percent (for mortgage repayments) of its income on housing, then that household is experiencing an affordability problem.

This definition could apply to high-income households who spend a lot on housing. Thus, this benchmark on affordability is usually only applied to households that fall into the bottom 40 percent of the overall distribution of income. In Australia in 2001 the affordability threshold based on 30 per cent of the second quintile of average weekly household income was only \$141 compared with the median weekly rent in Australia of $\$ 183$ and a median weekly mortgage repayment of $\$ 230$ (see Gans and King, 2003). Berry and Hall (2001) determined that around 70 per cent of private tenants in the bottom 40 per cent of the overall distribution of income paid more than 30 per cent of household income on rent. This proportion was higher in Melbourne and Sydney.

This approach to housing affordability, however, does not allow us to easily distinguish between a housing problem and a low-income problem (Glaeser and Gyourko, 2002). Moreover, it does not take into account the period of time over which there is an affordability problem. Relevant policies to deal with housing affordability will generally depend on whether it is a long-term structural problem or a temporary situation.

\section{Long-Term Versus Short-Term Affordability}

Affordability problems fall into two classes: long and short-term. The long-term affordability problem involves households who, for the foreseeable future, will be unlikely to have an income that would allow them to purchase appropriate housing services. The short-term affordability problem concerns households who over time have an average income that would be sufficient to purchase appropriate housing in the private market, but who face short-term fluctuations in income that precipitate housing stress or crises. That is, a household may face the short-term loss of employment, illness of a primary income provider or a rise in interest rates or rents precipitated by macroeconomic conditions. Such households may find themselves unable to afford their current accommodation in the short-term and face hardship from being forced to move; losing personal capital incorporated into their homes. These short-term fluctuations harm both the households and the parties providing them with housing. As a result, households with a higher risk of short-term income fluctuations may find it difficult to gain appropriate housing in the private market.

The long-term and short-term affordability problems have different causes and, hence, require different policy approaches. The long-term problem is a problem of low income as opposed to an issue of housing policy per se. Government interventions that are designed to improve conditions in the housing 
market are no solution to this type of problem: there is no sense in improving the operation of a market that these households cannot effectively access. The longterm affordability problem requires anti-poverty programs with housing as a key element. For this reason, while it is an important aspect of overall social welfare programs, the long-term affordability problem is not the focus of this paper.

The short-term problem is caused by income fluctuations rather than a permanent lack of income and it requires a mechanism to deal with short-term income loss. This is a concern for government if private markets are unable to provide adequate solutions to housing stress caused by income uncertainty. While, in principle, capital markets should be able to provide short-term finance to get households through rough patches, in practice, this does not occur. The main economic reason for this is that, for quite understandable reasons, banks and other lenders are reluctant to extend loans to households that have just suffered a dramatic loss of income or a rise in housing prices.

\section{Market Imperfections and Short-Run Affordability}

The market failures associated with long-run affordability problems are wellknown: focussing on the indivisibility of housing assets, externalities between housing submarkets, government regulation and taxes and the slow response of supply to changes in demand. For short-run affordability, the potential market imperfections that generate a need for government intervention have not featured in housing policy. For this reason, we briefly review those market failures below.

\section{Financial and rental market imperfections}

Housing market and financial markets are closely connected. In theory, financial markets should provide finance to potential homeowners and investors who are likely to be able to make the relevant repayments. However, financial markets suffer from problems of asymmetric information that may lead to market failures and credit rationing (for example, Stiglitz and Weiss, 1981).

Information problems arise in financial markets because potential lenders may have difficulty distinguishing between individuals who can make repayments and those who cannot. As a result, potential lenders may be reluctant to provide funds to customers who appear more risky; for example individuals with a lack of credit history or who are proposing more risky investments.

The underlying problem here is asymmetric information, not risk. After all, risk accompanies all lending and, in the absence of information asymmetries, would simply be reflected in higher interest rates to more risky borrowers. Rather, the problem is that the potential lender cannot adequately distinguish between high and low risk borrowers and so may be reluctant to lend any funds. Further, this problem cannot be solved by simply raising the interest rate on borrowed funds. Raising interest rates may simply act to dissuade the low risk borrowers leaving only the high risk borrowers. After all, the high risk borrowers, who know that there is a higher chance they might default on the loan, will be less influenced by 
interest rates. In this way, a simple interest rate charged equally to all potential borrowers, adversely selects for borrowers with a higher risk profile. To attempt to solve this problem a lender might try to ration credit; attempting to infer borrower risk through indirect means.

In financial markets that provide housing funds, information asymmetries mean that low-income households, particularly those with a chequered history of employment, will tend to be excluded from access to housing finance. Financial institutions may minimize adverse selection risk by shifting risk back on to the borrower, for example by requiring a large deposit on a house before funds are provided. This reduces the risk that the financier will be stuck with a house that is valued at less than outstanding debt if default occurs. Low-income households will find such a deposit hurdle difficult to meet as they are least able to save for a significant housing deposit while at the same time paying for rental housing. Overall, this means that credit rationing is likely to have the greatest adverse effect on low-income households.

Similar adverse selection problems arise in rental markets. Investors are keen to rent properties to households or individuals who will be able to pay the relevant rent and who will not impact too heavily on the depreciation of the dwelling. But landlords cannot determine the exact risk associated with particular tenants and will try to infer this risk from other factors. Again, an obvious method used by investors to distinguish between tenants is their employment history and their current job and income. This discriminates against low-income households who are viewed as having a higher risk by landlords and makes the rental prospects for low-income households less certain than those for higher income households.

Economic discrimination in both financial and rental markets biases those markets against low-income earners. This discrimination need not reflect any bias on the part of lenders or landlords. Rather it is simply a rational attempt by lenders and landlords to at least partially overcome information asymmetries. However, the end result may be to ration many low-income families out of the private markets for housing. Put simply, the market imperfections can make housing unobtainable for low-income households.

\section{Income risk and affordability}

While market imperfections reduce access to private housing markets for lowincome households, even if a low-income household is able to gain appropriate housing, either as tenants or owner-occupiers, these households remain particularly vulnerable to future income risk.

Income risk is something that faces all households. It can arise through a number of sources. For example, unemployment is usually associated with a significant but temporary drop in income for individuals and households. Injury or significant illness can also lead to a sudden reduction in income.

An unforeseen drop in income can lead to a large but temporary reduction in housing affordability for the relevant household. For example, if the household is renting, then it may be impossible for the household to make its regular rental 
payments when it suffers a sudden reduction in income. In such circumstances, the tenants face eviction. Similarly, recurring mortgage payments may not be met due to a sudden income shock, leading to potential foreclosure.

Income risk, like any other form of risk, can be reduced by insurance. For example, income protection insurance is available to households. Similarly, both landlords and lenders may be willing to renegotiate agreements to overcome shortterm income shocks. After all, finding new tenants or foreclosing on a mortgage and selling a property are both expensive activities. Both landlords and lenders have incentives to take actions to avoid incurring these expenses. Finally, households may self-insure against income risk, for example by keeping ahead of mortgage payments or by keeping a readily accessible pool of savings.

These solutions to reduce the cost of income risk, however, are less likely to be available to low-income households. For a household with a history of unemployment, income protection insurance is likely to be either unavailable or prohibitively expensive. The moral hazard problem facing the insurer makes such insurance not viable. Self-insurance through discretionary saving is difficult, if not impossible, for low-income earners. And renegotiation to avoid foreclosure or eviction is less likely to occur for higher risk, marginal households. Consequently, low-income families are likely to face significant residual income risk that creates short-term housing crises for these families.

\section{The Housing Lifeline}

The income risk faced by low-income households feeds into the two housing market failures discussed above. Income risk directly leads to short term dislocation and cannot be fully addressed by private insurance due to moral hazard. A history of low, variable income can be rationally used as an economic discriminator by landlords and housing financiers seeking to overcome issues of adverse selection.

How should the government address this problem of income risk? Unable to meet rental or mortgage payments, low-income households faced with short-term income distress can face the loss of appropriate housing. Current assistance programs, however, are not well equipped to deal with short-term distress. For example, Federal government rental assistance in Australia only becomes relevant once a household becomes eligible for other forms of benefits. In the US, Section 8 voucher programs often involve waiting lists, meaning that they are unable to meet the needs of low-income families facing short term distress.

Existing policies for low-income housing are often designed for households that not only have low income today, but are destined to remain on low incomes forever. Further, the eligibility criteria for these programs often create poverty traps that exacerbate the plight of low-income families over the longer term. In other words, the programs are means tested so that a low-income family who has a rise in income can face punitive effective taxation rates as their benefits rapidly diminish with the rising income. 
Rental and interest guarantees provide one way to help overcome market failures for low-income households. These types of programs help to remove the risk from lenders and landlords. However, these programs often lack flexibility and cannot address income shocks when they arise.

An alternative approach would involve governments addressing the income risk associated with low-income households directly. In particular, the government could provide a form of income insurance to low-income families, to ensure that short term income fluctuations do not create long term housing problems. For example, the government might allow a household that has suffered a short-term drop in income, due to say unemployment or temporary lay off, to draw down a payment (say up to an eventual maximum of $\$ 5,000-\$ 10,000$ ) towards rental or mortgage costs.

How would such insurance work? After all, if an individual is unemployed, they can (after the relevant waiting period) receive unemployment benefits and rental assistance. Isn't this already a form of government income insurance? Yes: these benefits are not explicitly designed as insurance but conflate the goals of short-term and long-term assistance. In addition, housing stress can arise for income shocks not necessarily the result of unemployment (for example, sickness or profit reductions for small business owners). From the perspective of providing income insurance for low-income households, existing rent assistance does not address short-term income fluctuations, requires low-income households to draw down (possibly non-existent) savings while waiting for eligibility, fails to offer security to lenders and landlords, and creates undesirable incentives for the lowincome household as it tries to overcome the temporary setback.

In this section, we consider an alternative approach that we call a 'housing lifeline.' This is essentially a government provided insurance product. It has a number of similarities to the Higher Education Contribution Scheme (HECS) in that it is based on lifetime income rather than current income, it limits the impost on government funds while providing short-term relief for relevant households and it is a product where benefits are determined by the needs and requirements of the low-income household themselves.

\section{The basic concept of a housing lifeline}

Suppose that a household suddenly finds itself facing a crisis where it is unable to meet short-term commitments for housing payments. With a housing lifeline the household would be able to draw down a payment from the federal government to tide it over the short-term crisis. This payment would be a loan to the household and the household would incur a future tax liability associated with the loan. The payment of this liability would be tied to future income, like the HECS. Further, the liability may or may not have a reduced interest rate associated with it, depending on government policy. For example, the lifeline might have an interest rate equal to the long-term government bond rate. This is likely to be substantially below equivalent interest rates available to low-income families. 
Payments to a household would be capped. The housing lifeline is designed to provide short-term relief, not to provide a permanent source of support for those families who will not have the means to adequately fund housing in the medium to long-term. Thus, the lifeline does not replace other long-term poverty programs but supplements these programs providing more appropriate assistance to lowincome households facing temporary crisis. The payments may be capped on both a weekly and a total basis. For example, it might be possible to 'borrow' up to $\$ 200$ per week under the cap up to a total of $\$ 10,000$. Thus, the scheme would provide up to 50 weeks (or more if less than $\$ 200$ was drawn upon) support for a relevant household. The cap would also apply over successive periods of crisis, so that a household would not be able to build up more than say $\$ 10,000$ of debt at any time.

We envisage that the payments under a housing lifeline would be tied to housing. Thus, funds would be paid directly to a (registered) landlord or lender specified by the relevant household. This would require a contractual agreement that ensures that the funds do reduce the household's liability to landlords and lenders directly. At present, Medicare payments operate in this manner.

Drawing down the lifeline would be a choice made by the relevant household. But because this access to an instant 'line of credit' removes a substantial amount of the risk that would otherwise face lenders and landlords who provide housing solutions to low-income families, the lifeline directly addresses the problems embedded in the rental and mortgage markets.

The risk, of course, does not disappear, but it is both reduced and it is passed onto the government. The risk is reduced because the government takes on a portfolio of 'loans' to low-income households. Unlike an investor with only one or two properties, the government can pool the risk of income loss for low-income households, reducing the idiosyncratic variability of that risk.

It is recognised that there are significant differences from the government's perspective in the positions of people who are in housing stress because they cannot meet their mortgage payments and those who cannot pay their rent. The housing lifeline proffered to a struggling mortgagor can readily be constituted as a second (or third) mortgage ensuring that the government has some real security for its advance over and above the promise of the borrower to repay. Advances to a struggling tenant are supported only by the obligation of the borrower to repay and that of course being contingent on earning sufficient income in the future to enable him or her to do so. It is for that reason that government may consider this housing lifeline is best first tested with those in the process of buying homes. The government might, for example, introduce the housing lifeline for home buyers at the same time as it reduces or removes the current first home buyer grant. As a policy to help low-income households, the housing lifeline is clearly better targeted than the general first home-buyer grant.

While the government takes on board the risk associated with low-income households, through the housing lifeline insurance, the government is also in a good position to deal with that risk. The government has the substantial advantage of ensuring appropriate repayment of any lifeline loan through the taxation 
system. A low-income household can use the lifeline in periods of crisis and then repay the loan when its circumstances improve. This may be in the short-term or in the longer term, depending on the relevant household's circumstances. For example, modest repayments to the government may begin when household income approaches a set level above poverty-line income.

This illustrates the basic concept of the housing lifeline. However, a myriad of practical issues present themselves. In what follows we provide some answers to natural questions that arise.

\section{Government responsibility}

A housing lifeline would most sensibly be a federal government initiative. A key reason for this is that the federal government controls the income taxation system that would be used for lifeline repayments.

In addition, the federal government is the obvious instigator as the lifeline would need to be incorporated into the existing federal social security system to avoid households 'double dipping' and to ensure consistency between systems of assistance. The lifeline would apply across Australia and would be integrated with other welfare payments. Indeed, the housing lifeline would make some parts of the existing federal social security safety net redundant in the short-term. For example, if the lifeline applied to renters as well as home owners then it would at least partly replace existing rental assistance provided by the federal government.

\section{Funding of the lifeline}

In principle, the housing lifeline could be self-funding. So long as the interest rate charged by the government is above the long-term bond rate on government funds and accumulated debt is eventually repaid, the government will be operating on the same funding principles as any lender.

In practice, however, full repayment from every household will not be possible. Some households will move from temporary to long-term crisis and will be unlikely to ever gain a lifetime income that would allow repayment. In such a situation, the household can be transferred onto appropriate long-term benefits after the lifeline expires or when the long-term nature of the crisis becomes evident. Further, to the extent that the government subsidises the lifeline interest rate (especially in situations where the crisis is protracted), the repayments will be less than the financial cost of the associated funds.

At the same time, because the lifeline aids households in temporary crisis and provides appropriate short-term assistance to these households, it can help these households avoid becoming reliant on more long-term government assistance. The timely and temporary intervention allowed by the lifeline can help households avoid long-term problems, with the associated long-term government payment of benefits. 


\section{Eligibility for the lifeline}

We envisage that the housing lifeline be available to households with insufficient financial assets (as defined by a means test) to utilise to overcome short-term housing crises. The financial assets would include equity in properties (other than the family home), shares and other financial assets but not superannuation (which is currently illiquid).

The idea of basing eligibility on an asset rather than income test goes to the heart of the lifeline concept. An income test is inappropriate because (1) it is income that is fluctuating and generating the need for a lifeline (so it is unclear what the appropriate measure of income would be); and (2) income-based eligibility tests have the potential to create poverty traps. On the other hand, assets are a proxy measure of lifetime income and wealth accumulation. Thus, for the same reason that these are used for eligibility to old-age pensions, they are an appropriate sorting mechanism for who should be entitled to a housing lifeline.

\section{Maximum debt allowed}

The basic idea of the housing lifeline is to insure households against loss of housing during short-term fluctuations in income. The level of debt allowed will be related to the period of time the household is in crisis as well as the level of liabilities in terms of rent and loan repayments it faces. Evaluating this would require more information regarding the length of time and level of payments that could see an average low-income household through a crisis.

Suppose it was determined that typical housing stress can take 12 to 18 months to overcome and required payments of $\$ 100$ to $\$ 200$ per week. This suggests that a maximum debt of between $\$ 10,000$ and $\$ 15,000$ would be sufficient to cover this period. Nonetheless, the exact amount would really require a careful examination of the reality of housing stress.

Adjustments would also have to be made for the number of people in the household (in particular, the number of dependents). This, however, is something that is currently dealt with through the social security and taxation system and could carry over to the housing lifeline.

\section{Rate of interest to be charged}

We envisage that debt accruing under a housing lifeline would be subject to interest that would compound over the life of the debt. To break-even, the scheme would have to charge an interest rate exceeding the rate on long-term government bonds to take into account the debt that is never repaid. However, it is likely that the interest rate in this situation will still be less than market rates on home and other lending available to low-income households.

In principle, the lifeline need only provide a 'no questions asked' access to normal market lending rates that might not otherwise be available to households in crisis. This would avoid any credit rationing that might otherwise occur. In this 
situation, the government may actually generate long-term revenue from the scheme.

It is also possible that the interest rate could be lower than market rates or even below a break even rate. In this case, the scheme would provide a subsidy to low-income households.

The level of interest rate ultimately depends upon whether the government wishes to use the lifeline as just pure insurance or something more. This is not a policy judgment that can be made here.

\section{Exhaustion of household lifeline resources}

A household that remains in crisis for a longer period of time will exhaust its lifeline resources. In this situation, closer intervention will be required. This could be in the form of a review that extends the loan or it could involve moving the household to other social security and housing plans designed to deal with long-term low income. It needs to be emphasised that the housing lifeline is designed to provide assistance to short-term loss of income and housing stress. Long-term issues need to be addressed through other means.

\section{Effect of lifeline on household incentives}

Ordinary government housing assistance can create a poverty trap. That is, if the assistance is income based, when incomes rise, households may face very high marginal tax rates. This, in turn, reduces household incentives to find employment or otherwise restore income to its previous level.

Because the lifeline repayment is based on a notion of lifetime income rather than current income, it is less likely to create a poverty trap. While repayments through the taxation system will create income zones where the household faces slightly higher taxation rates than otherwise (for example, a 10 per cent increase), these changes are small compared to the effective marginal taxation rates under, for example, rent assistance schemes. Thus, a housing lifeline can retain incentives for households to take appropriate actions and risks to improve their standard of living.

The lifeline is based on a loan, not a gifted payment, so there are reduced incentives for higher income households to try and abuse the system. For example, in the simplest scheme a household only needs to provide a tax file number and appropriate identification to access the lifeline. But repayment begins as soon as the household income exceeds a certain level. A household earning income above that level has little incentive to 'borrow' funds then immediately repay them through the taxation system. If such a problem arose it could be addressed through a penalty charge on households if taxable income exceeded a specific level in the year that the lifeline was drawn down. 


\section{Responsibility for the debt}

Under the HECS scheme, debt is incurred by individuals. The taxation system is based on individual income. In the case of the housing lifeline, however, an individual based debt would raise some problems.

The most salient problem has to do with the possibility that only one member of a household earns income. If the housing lifeline were available to individuals, then households would face an incentive for one or more members not to earn income but to utilise the housing lifeline (without the need to ever repay the debt). For this reason, some household-based unit would seem appropriate.

This, in turn, raises other difficulties. For example, issues of liability in case of the break-up of the household need to be considered although lifeline debt could be treated as any other joint household liability in such circumstances.

In addition, a household based scheme would create an incentive for individual members to represent themselves as members of different households. We have no clear solution to this practical problem at this stage. Nonetheless, it should be noted that such problems arise for many social security payments and for the private health insurance rebate. Penalties may have to be imposed and enforced, a registration system may be needed and some means of identifying household-based income would be desired.

\section{Political risks}

Introducing a housing lifeline creates some political risks. In particular, as the total level of debt under a lifeline grows, there might be political pressure to 'write off' the debt.

Such a risk can easily be overstated. First, the risk exists under the current HECS scheme but has not been a significant factor in the Australian education debate. Second, because the lifeline tends to save the federal government money relative to existing welfare programs such as rental assistance, the cost of any write-off or write-down of outstanding debt under the housing lifeline will be less problematic than, say, under the HECS scheme.

\section{Conclusion}

The housing lifeline directly addresses an important problem facing low-income families in a way that is cost effective for government and that avoids creating welfare dependency and poverty traps. The housing lifeline is not about providing new housing solutions for low-income families but rather opens up housing opportunities through the private market for low-income households and helps them to retain appropriate existing housing in the face of temporary setbacks. The policy is about housing insurance. It helps low-income households gain adequate housing with almost no micro-management. It increases choice for low-income households rather than decreasing choice, so it respects the preferences and wishes of individual households. 
The housing lifeline addresses the problems of low-income households facing income fluctuations. It is not aimed at addressing broader housing affordability. While the lifeline will make it more desirable for private investors to develop housing for low-income families, supply constraints on housing may still arise. For this reason, the housing lifeline should be considered in tandem with other policies that help improve general housing affordability, such as the re-evaluation and reform of transaction taxes and planning laws discussed in Caplin et.al. (2003).

The housing lifeline helps to bring private funds to play in low-income housing solutions. In particular, it brings the private funds of the low-income households themselves into the market to provide appropriate housing. Unlike other policies, it does not view low-income households as 'victims' to be 'helped' through benefits funded by others. Rather, it empowers the low-income household and helps them to access their future income rather than just depending on their current low income.

While the government takes on board the risk associated with low-income households, through the housing lifeline insurance, the government is also in a good position to deal with that risk. The government has the substantial advantage of ensuring appropriate repayment of any lifeline loan through the taxation system. A low-income household can use the lifeline in periods of crisis and then would repay the loan when its circumstances improve. This may be in the shortterm or in the longer term, depending on the relevant household's circumstances. For example, modest repayments to the government may begin when household income approaches a set level above poverty-line income.

The housing lifeline avoids artificial constraints on mobility for low-income households, unlike schemes that are tied to particular dwellings. It is highly flexible and the choice of how much or how little of the scheme to use at any point in time is largely up to the relevant household. Thus, while the scheme does not explicitly allow for geographic differences, the household itself can adjust for those differences within the payment bounds set by the government. Further, because it is based on individual household needs, as seen by that household itself, it responds instantly to the changing circumstances of that household.

Finally, the housing lifeline avoids creating poverty traps that harm lowincome households. Indeed, a primary benefit of this scheme is that it would potentially enable to the government to save on social security costs by preventing short-term income problems from transitioning into longer-term poverty.

In summary, the housing lifeline is essentially a government provided insurance product. It has a number of similarities to HECS in that it is based on lifetime income rather than current income, it limits the impost of government funds while providing short-term relief for relevant households and it is a product where benefits are determined by the needs and requirements of the low income household themselves. For these reasons, we believe that it is a policy worthy of close examination by the Federal Government. 


\section{References}

Australian Bureau of Statistics (2002) Yearbook of Australia 2002: Housing prices, Canberra.

Berry, M. and J. Hall (2001), Policy Options for Stimulating Private Sector Investment in Affordable Housing Across Australia, Stage 1 Report: Establishing the Need for Action, Report to Affordable Housing National Research Consortium, Sydney, February.

Caplin, A., C. Joye, P. Butt, E. Glaeser and M. Kuczynski (2003), 'Innovative Approaches to Reducing the Cost of Home Ownership,' Report to the Prime Minister's Home Ownership Taskforce, Menzies Research Centre, Canberra.

Gans, J. and S. King (2003), 'Policy Options for Housing for Low Income Households,' Report to the Prime Minister's Home Ownership Taskforce, Menzies Research Centre, Canberra.

Glaeser, E. and J. Gyourko (2002), 'The Impact of Zoning on Housing Affordability,' Working Paper, No. 8835, NBER.

Stiglitz, J. and A. Weiss (1981), 'Credit Rationing in Markets with Imperfect Information,' American Economic Review, 71 (3):393-410.

Parts of this paper are drawn from our report for the Prime Minister's Taskforce on Home Ownership, 'Policy Options for Housing for Low Income Households' (Gans and King, 2003). This paper benefited greatly from discussions and comments by two anonymous referees, Ed Glaeser, Ian Harper, Elvis Jarnecic, Warwick McKibbin, Adrian Pagan, Malcolm Turnbull and, especially, Chris Joye. Richard Hayes provided outstanding research assistance. We also thank the Menzies Research Centre for financial support. All views expressed here are our own and do not necessarily reflect those of the above individuals and organisations. 



\section{HECS System Changes: Impact on Students}

\section{Gillian Beer and Bruce Chapman}

$\mathrm{I}$ n early 2002 the new Minister for Education, Science and Training, Brendan Nelson, announced a wide-ranging reform agenda with respect to the funding (and other areas) of Australian higher education. Over the ensuing months the Government released a number of discussion papers, in a process referred to as Crossroads, and initiated and promoted a series of consultations with stakeholders and others covering the essential issues.

The process led to potentially far-reaching policy changes with respect to the financial operation of Australian universities, announced in the 2003-2004 Commonwealth Budget, and passed by the Parliament in modified form at the end of 2003 (to take effect from 2005). An important part of the reforms concerns the nature and extension of the operation of the Higher Education Contribution Scheme (HECS), the income related arrangement for the payment of student charges introduced in 1989.

This paper addresses several questions. One, what is likely to be the true financial cost for different types of students and graduates subject to increases of 25 per cent in HECS charges (the new HECS-HELP arrangements), given that the first income threshold of repayment is to be increased substantially? Two, what is likely to be the true financial cost to different types of students and graduates of so-called 'full-fees', covered by an income related loan known as FEE-HELP? And three, what are the potential consequences for effective student charges of capping loans at $\$ 50,000$, meaning that some students will have to face the unpalatable requirement of paying a proportion of the charges up-front?

It is important to note that it is not possible to predict from this type of analysis the absolute numbers of students who will face higher, lower or unchanged effective HECS debts from the 2005 reforms. The reason is that there are no available data on the likely distributions of the future incomes of students and the number of graduates in the income categories modelled. We seek instead to illustrate the consequences for students and graduates with typical hypothetical debts and future incomes.

A brief analysis of the benefits of income related loan arrangements, and a description of the changes to HECS to be implemented in 2005 follows. Subsequent sections, in turn, explain the methodology used to analyse the impact of changes on students, present the results under various scenarios for HECSHELP students, and describe the results for those paying full fees under different

Gillian Beer is a Principal Research Fellow at the National Centre for Economic and Social Modelling, University of Canberra, and Bruce Chapman is the Director of the Centre for Economic Policy Research at The Australian National University. 
scenarios of FEE-HELP. These sections are followed by a commentary on the HECS-HELP and FEE-HELP systems and some conclusions.

\section{HECS-HELP and FEE-HELP}

The background to income related charges for higher education

Australia introduced the world's first nationally operated income related charge for higher education in 1989 (the background to the introduction of HECS is examined in Edwards, 2001; and Chapman and Ryan, 2002). At the time the Labor government was intent on students paying for a proportion of the costs of their higher education, for several reasons. One was that there was evidence of emerging and considerable unmet demand for university places, but the government was not prepared to expand the system through the provision of additional taxpayer resources. A second reason was the view, held strongly by some in Federal Cabinet at the time, that a so-called 'free' higher education was very regressive economic policy. The essential argument is that if higher education is financed from general tax revenue, it follows that the majority of these resources are provided by average taxpayers with much lower lifetime incomes than those received by graduates. This argument is documented and supported in Chapman (1997).

Given the policy commitment to a charge, the next important issue related to the form in which it should be paid. In an international context there are many possibilities such as: up-front fees with means-tested scholarships; and up-front fees with means-tested access to government guaranteed commercial bank loans. For a variety of reasons examined in Chapman and Ryan (2002) these approaches have significant weaknesses and are unlikely to maximise the chances of the participation of relatively disadvantaged students. Income related loans, on the other hand, seemed to provide the opportunity of minimising the problems associated with other approaches. It was these advantages that lead to the design, development and implementation of HECS.

Income related loans were not invented in Australia, and can be traced in the economics literature to at least as far back as Friedman (1955). However, a workable income related loan scheme was not in practice before HECS. At the time of the debate surrounding the introduction of HECS, public concerns were expressed suggesting that the scheme would discourage the enrolment of disadvantaged groups. However, there is now a considerable body of research suggesting that there have been no discernible effects on university enrolments of relatively poor students from either the introduction of, or changes to, HECS (see, for example, Andrews, 1999; and Chapman and Ryan, 2002).

At the same time as the government introduced HECS for undergraduates, it allowed universities to charge up-front fees for some postgraduate students, and the numbers involved grew consistently over the 1990s. The up-front form of Australian postgraduate charges sat uncomfortably alongside HECS, and some commentators argued strongly for the application of income related loans to both 
postgraduates and for TAFE students. Productive changes came in the form of the Postgraduate Education Loan Scheme (PELS), which provided postgraduate students paying up-front fees access to a HECS-type loan. An analysis of PELS is provided in Chapman and Salvage (2001). From 2005, PELS will become part of FEE-HELP, described below.

\section{HECS-HELP}

Under the new legislation, from 2005 universities will be able to set their own prices for all HECS students, up to a ceiling. With the exception of nursing and education (where no real changes will be allowed) the ceilings will be 25 per cent higher than the projected 'standard' HECS levels in that year. These changes to the basic HECS arrangements are known as 'HECS-HELP'.

The other important feature of HECS-HELP is that the repayment parameters for the repayment of the debt will be changed significantly in 2005. Most importantly, the first income threshold of repayment has been raised considerably, from its current level of about \$26,500 per annum to just over \$36,000 (and there are some additional steps, including higher repayment rates for incomes above $\$ 50,000$ ). Current and 2005 repayment rates are shown in Table 1, with these changes constituting a very critical factor concerning the likely impact of the policy reforms.

Changes to the HECS repayment rules illustrated in Table 1 suggest that there are two forces at work with respect to the present values of future HECS obligations. The first, and by far the most important, is that graduates with annual incomes between about $\$ 27,000$ and $\$ 36,000$ per annum in 2005 will repay none of their debt in that particular year, compared to between about $\$ 750$ and $\$ 1,400$ per year under the current parameters. This change affects significantly the results of our simulations reported below because it decreases the present value of 2005 higher education debts, and very significantly so for some students.

The second set of changes takes the form of higher HECS repayment rates above just over $\$ 50,000$ per annum. Currently, the highest rate is 6 per cent of taxable incomes but after 2005 this will be increased, reaching 8 per cent at $\$ 67,000$ per annum. Our calculations reveal that this increase will have a minor effect on the present value of new debt for graduates expecting to earn relatively high future incomes. 
Table 1: Current and New HECS Repayment Rates and Thresholds in 2005

\begin{tabular}{lclc}
\hline $\begin{array}{c}\text { 2003-04 HECS repayment schedule } \\
\text { inflated to 2005-06 levels }\end{array}$ & 2005-06 HECS repayment schedule \\
Taxable income & $\begin{array}{c}\text { Per cent } \\
\text { applied to } \\
\text { repayment }\end{array}$ & \multicolumn{1}{c}{ Taxable Income } & $\begin{array}{c}\text { Per cent } \\
\text { applied to } \\
\text { repayment }\end{array}$ \\
\hline Below $\$ 26,363$ & Nil & Below $\$ 36,184$ & Nil \\
$\$ 26,363-\$ 27,427$ & 3.0 & $\$ 36,184-\$ 40,306$ & 4.0 \\
$\$ 27,428-\$ 29,958$ & 3.5 & $\$ 40,307-\$ 44,427$ & 4.5 \\
$\$ 29,959-\$ 34,751$ & 4.0 & $\$ 44,427-\$ 46,762$ & 5.0 \\
$\$ 34,752-\$ 41,942$ & 4.5 & $\$ 46,763-\$ 50,266$ & 5.5 \\
$\$ 41,943-\$ 44,145$ & 5.0 & $\$ 50,267-\$ 54,439$ & 6.0 \\
$\$ 44,146-\$ 47,454$ & 5.5 & $\$ 54,440-\$ 57,304$ & 6.5 \\
$\$ 47,455$ and above & 6.0 & $\$ 57,305-\$ 63,062$ & 7.0 \\
& & $\$ 63,063-\$ 67,199$ & 7.5 \\
& & $\$ 67,200$ and above & 8.0 \\
\hline
\end{tabular}

Source: 2003-04 HECS repayment schedule from HECS Information 2004, Department of Education, Science and Training, 2003, http://www.hecs.gov.au/hecs.htm.

\section{FEE-HELP}

The second significant change to student funding is known as 'FEE-HELP', and represents an extension of Australia's income related loan scheme. Under FEEHELP, HECS-type loans will be made available to cover full-fee paying domestic and postgraduate courses, with repayments to be made according to the new repayment parameters. Universities will be able to fill up to 35 per cent of domestic places with full fee paying students.

Arguably FEE-HELP had its origins in the extensive reforms to funding arrangements introduced by the Coalition in 1997. As part of this policy package the government allowed universities, for the first time, to charge domestic students full fees. Only a very small number of students took up this opportunity, for reasons undoubtedly associated with the need for students to find the financial resources to pay up-front, which would have required access to as much as $\$ 16,000$ per full time year.

However, from 2005 there will be no need for a student accepted under full fee paying arrangements to have up-front financial resources because such an enrolment can be accessed with the (substantial) help of a HECS-type loan. As a 
result of this (and other changes) Phillips and Chapman (2003) suggest that the offer of an income related loan facility for full fee paying students will result eventually in a significant take-up of this option.

A critical issue for an analysis of the potential effects of FEE-HELP is that the total level of loans will be capped at $\$ 50,000$ per student. This introduces the real possibility that some students, denied access to further loans, will have to pay up-front fees to complete their higher education, a prospect modelled with the results being reported below. Some (major) concerns with the conceptual basis of FEE-HELP are discussed later.

\section{Methodology}

\section{Conceptual background on the effects of HECS-HELP and FEE-HELP}

There are two opposing forces at work with respect to the effects of changes to the system on the true charges faced by students. The obvious likely change, and the one that has had prominent media and political attention, is that the new arrangements have the very real potential to result in higher levels of HECS debts for a large number of students. There is little doubt that this will happen, in part because the government's indexation rule with respect to recurrent grants means that most institutions have experienced on-going effective real cuts in public sector support since 1995. Phillips and Chapman (2003) document the importance of this issue and explain why shortfalls in indexation will strongly encourage universities to increase charges in 2005 and beyond.

On the other hand, there is a critical aspect of the reforms with significant potential to diminish the financial impact for students of increases in the apparent levels of debt. It is that the repayment parameters for HECS will generally be much more generous after 2005. Most importantly, the first income threshold of HECS repayment has been increased to over $\$ 36,000$ per annum, or by nearly $\$ 10,000$.

The large increase in the first income threshold of repayment after 2005 is a fundamental issue with respect to an assessment of the possible impact of both HECS-HELP and FEE-HELP for students. It is also an issue not generally well understood by those not well versed in financial accounting. Because it is an essential aspect of our exercises, it is worth taking space here to explain its importance.

The critical policy point is that once incurred, HECS debts have a real interest rate of zero. The importance of this relates to what economists call "discounting". Discounting refers to the notion that a financial obligation of a given real amount that has to be met today is more of a burden than if the same sum has to be paid in, say, one year's time. To illustrate this, imagine that you have to repay a loan of $\$ 100$, but you have the choice to pay it today or in one year's time. The reason that most would choose to repay later is that if the debt is not paid now, the money has value over the ensuing year. 
The critical point is that the HECS interest rate subsidy means that a financial advantage accrues that increases with the length of time it takes a graduate to repay a given level of debt. That is, the longer is the expected period of nonrepayment of HECS, the lower is the true cost and significance of the debt at the point that the obligation is incurred. For this reason economists focus on what is known as the present value of a debt, since this calculation takes into account the value of discounting in assessments of the real consequences of debt.

The above explanation of discounting suggests strongly that it is the present value of a HECS debt which will affect higher education students' enrolment behaviour. The importance of this for our exercises is that the new arrangements combining higher HECS with more generous repayments can increase or decrease the present values of higher education debts, meaning that the overall effects cannot be predicted a priori. But, because the exercises reported below are comparisons of changes in the present value of student charges, we are able to model the true financial effects of nominal HECS increases juxtaposed with the more generous 2005 repayment rules.

\section{The modelling approach}

In order to analyse the effects of changes to HECS on the new prices faced by students it is necessary to define hypothetical student experiences. We begin with the assumption that in all cases the individual begins full time higher education at age 18 and studies full-time for a period of four years, regardless of the course taken. It is acknowledged that, in general, courses in the lower HECS bands are of shorter duration. However, we are confident that this simplification has no significant consequences for the overall results.

After graduation, individuals are assumed to start full time work (at age 22). For each hypothetical student considered, the approach imposes a 'typical' lifetime labour force profile (detailed below). On the basis of assumed labour force and earnings profiles, taxable incomes are calculated for each year from age 18. From these taxable incomes HECS repayments are calculated using the parameters from Table 1. Comparative HECS debts are calculated on the basis of assumed course type using the projected standard 2005-06 HECS charges. For a middle (that is, Band 2) HECS band course, the standard HECS charge in 2005-06 is $\$ 5,400$ per annum. For simplicity, the body of what follows considers only the effects on students assumed to be undertaking a course in the middle HECS band, since the essence of the results are similar for other HECS bands.

The model is run a number of times for each hypothetical individual, in two stages. First, present values of HECS repayments are estimated under the current system (that is, using the projected 2005-06 standard HECS charges and the current repayment thresholds inflated to 2005-06 dollars). These are then compared to present values calculated for a range of 2005 hypothetical scenarios: a 25 per cent increase in the charge; a FEE-HELP debt of \$50,000; and a FEEHELP debt of $\$ 50,000$ with an up-front fee. In all cases we use a discount rate of five per cent per annum to calculate the present value. This is a rate 
conventionally used in empirical applications of this kind, although others could have been employed. It is unlikely that the essential results would be changed importantly if different discount rates had been employed.

A total of nine hypothetical cases are modelled. Each case is assumed to have done a course in the middle HECS band. They are as follows:

1. Male, high-income graduate;

2. Male, middle-income graduate;

3. Male, low-income graduate;

4. Female with no children, high-income graduate;

5. Female with no children, middle-income graduate;

6. Female with no children, low-income graduate;

7. Female with two children, high-income graduate;

8. Female with two children, middle-income graduate;

9. Female with two children, low-income graduate.

\section{Assumed lifetime labour force and earnings profiles}

Typical lifetime labour force profiles are assumed for each hypothetical case, with the profiles being constructed on the basis of gender and education. The profiles are used to derive an individual's projected wage and salary income in each year over their lives.

In general, individuals without children are assumed to work full-time for most of their working lives. For women with children, it is quite different. After they complete university at the age of 22, they are assumed to work full time until they reach 30 years of age, when they leave the labour force to rear children. They re-enter the labour force part-time after four years and then resume full-time employment when they reach 40 years of age.

The lifetime earnings profiles have been derived from the Australian Bureau of Statistics (ABS) 1996-97 and 1997-98 Surveys of Income and Housing Costs (SIHC). The two different survey years were used to ensure that sample sizes are sufficiently large.

Graduates were allocated into high, medium and low earning categories as follows. The profiles for high-income males and females are calculated as the average wage and salary income for the highest 33 per cent of full-time male and full-time female undergraduate degree holders respectively. The profile for middle-income earners is calculated as the average wage and salary income for the middle 33 per cent of full-time male and full-time female undergraduate degree holders respectively. Accordingly, the profile for low-income earners is taken as the average wage and salary income for the lowest 33 per cent of full-time male and full-time female undergraduate degree holders respectively.

Overall, therefore, the construction of the lifetime profiles is undertaken separately by gender, with no differentiation in the estimation from the SIHC data by marital status. There is also no differentiation on the basis of the university at which the individual undertook their undergraduate degree. 
The profiles have been estimated for full-time workers only. In the calculations for the hypothetical cases, wage and salary income for any part-time work is assumed to be 30 per cent of full-time earnings for males and 45 per cent of full-time earnings for females. These ratios are set on the basis of a comparison of part-time and full-time earnings as revealed by the 1994-95 ABS SIHC.

The incomes derived from the two SIHCs have been inflated to 2005 levels on the basis of expected changes in average weekly earnings. We have assumed an increase of 7.5 per cent in nominal earnings between 2003 and 2005. The final earnings profiles used in this study are shown in Figures 1-3.

An important point from the profiles is that there are very large differences both within and between groups. The earnings of high-income male graduates working full time, for example, peak at around $\$ 120,000$ per annum, but the peak for low-income female graduates working full time is less than $\$ 40,000$ per annum. These differences suggest a strong potential for the calculations to reveal very large contrasts by group in the present value calculations related to HECS changes.

Figure 1: Derived Lifetime Earnings Profiles for Low, Middle and High-income Graduate Males

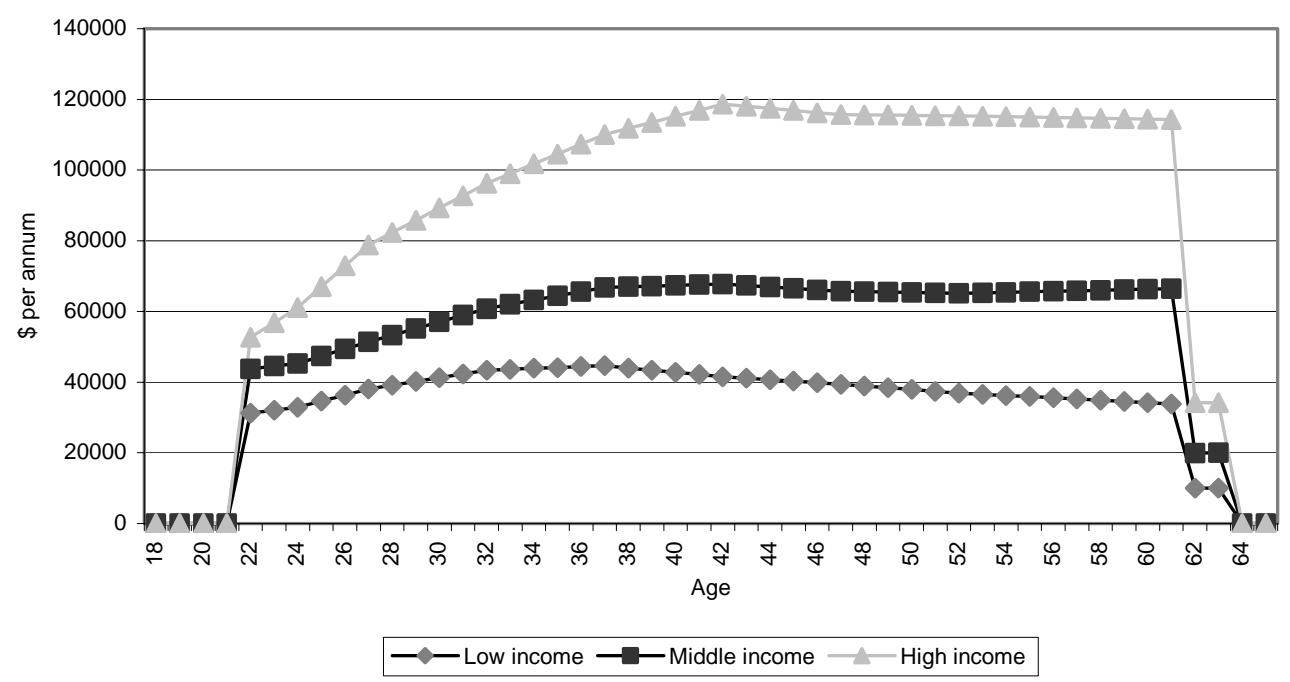

Data source: ABS, 1996-97 and 1997-98 Survey of Income and Housing Costs. 
Figure 2: Derived lifetime Earnings Profiles for Low, Middle and High-income Graduate Females without Children

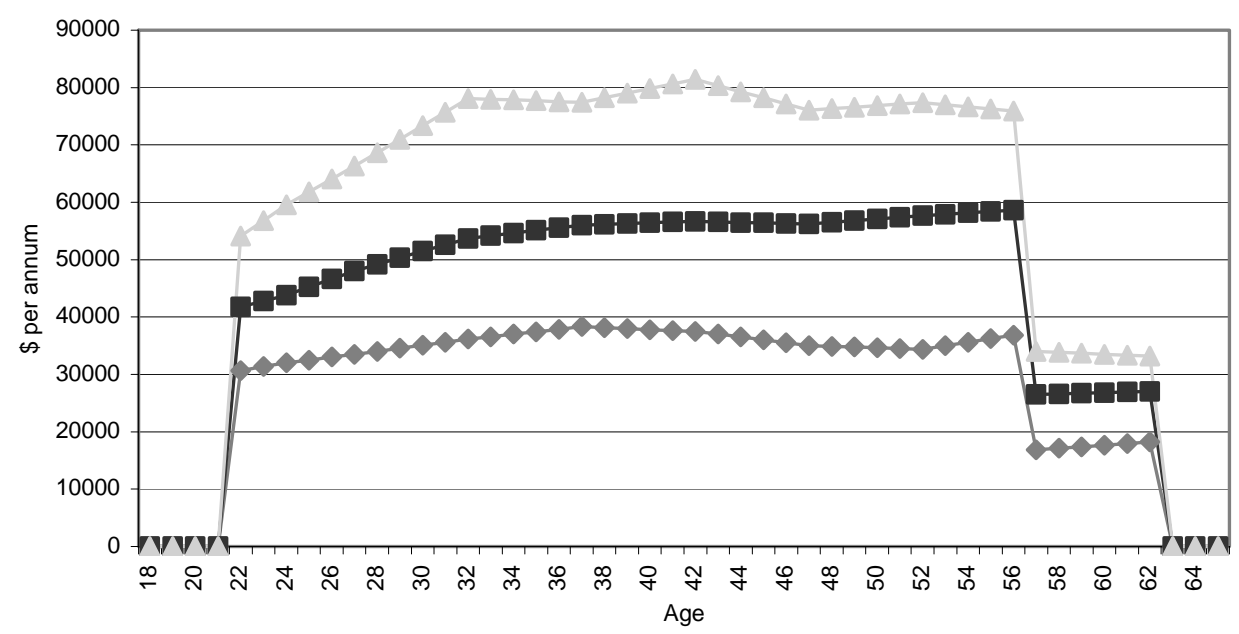

$\longrightarrow$ Low income $\longrightarrow$ Middle income $\longrightarrow$ High income

Data source: ABS, 1996-97 and 1997-98 Survey of Income and Housing Costs.

Figure 3: Derived Lifetime Earnings Profiles for Low, Middle and High-income Graduate Females with Two Children

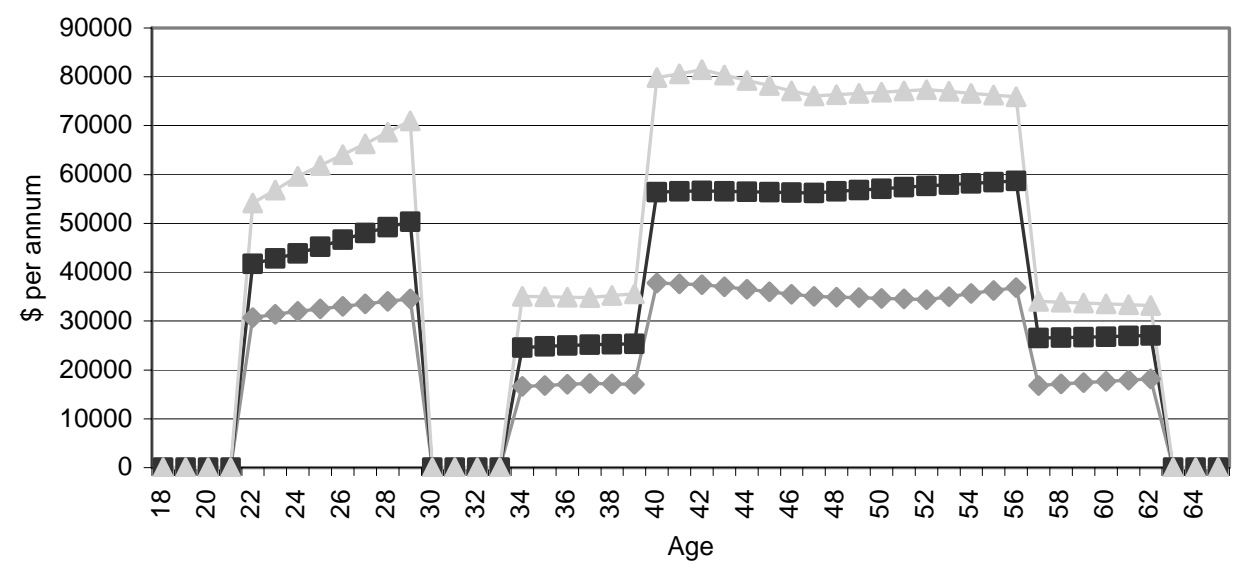

$\multimap-$ Low income $\neg-$ Middle income $\longrightarrow$ High income

Data source: ABS, 1996-97 and 1997-98 Survey of Income and Housing Costs. 


\section{Results for HECS-HELP Students}

In this section results are presented for hypothetical HECS-HELP students/graduates. The approach is to calculate the present value of HECS repayments for the current arrangements (the base case) and to compare these with 25 per cent increases in the debt under HECS-HELP. Table 2 shows the results.

Table 2: Present Value of HECS Repayments for Hypothetical HECS-HELP Individuals Paying Middle HECS under Alternative Scenarios

\begin{tabular}{lccc}
\hline & Males & $\begin{array}{c}\text { Females } \\
\text { no children }\end{array}$ & $\begin{array}{c}\text { Females } \\
\text { 2 children }\end{array}$ \\
\hline $\begin{array}{l}\text { Low-income } \\
\quad \text { Base system } \\
\text { 2005-06 system with 25\% } \\
\text { surcharge }\end{array}$ & 12,600 & 12,000 & 9,900 \\
$\begin{array}{l}\text { Middle-income } \\
\quad \text { Base system }\end{array}$ & 12,000 & 4,100 & 1,400 \\
$\quad \begin{array}{l}\text { 2005-06 system with 25\% } \\
\text { surcharge }\end{array}$ & 14,200 & 13,900 & 13,300 \\
$\begin{array}{l}\text { High-income } \\
\quad \text { Base system }\end{array}$ & 16,800 & 16,400 & 14,500 \\
$\quad \begin{array}{l}\text { 2005-06 system with 25\% } \\
\text { surcharge }\end{array}$ & 18,700 & 18,600 & 18,600 \\
\hline
\end{tabular}

The results from the table suggest very large differences in the present value calculations of HECS arrangements. For example, in the base case, low-income females with children face present values of their debt of $\$ 9,900$, while highincome males face $\$ 15,200$. Moving to the new system, these differences increase significantly, with members of the former group now facing only $\$ 1,400$ (since most of the debt will remain unpaid) compared to $\$ 18,700$ for the latter.

The very striking result is that for low-income graduates the new system, even with a 25 per cent increase in HECS, results in lower present values of students' debts. However, between groups the changes are very different. For example, for males there is close to no change, but for females without and with children the decreases are in the order of 66 and 86 per cent respectively. This illustrates the very considerable benefit of the increase in the first threshold of repayment for low-income females. 
The data suggest that the new system will increase the present value of the debt for all three middle-income groups but by less than the 25 per cent apparent increase in the charge. For males and females without children the increase is about 18 per cent, but for females with children the increase is around 9 per cent.

The results illustrate that the new system impacts much more adversely on the present values of high-income graduates. Males, for example, will pay 23 per cent more, and even females with children will face present values of the debt which are 23 per cent higher. The basic reason that the high-income graduates face significantly higher increases in the present values of their debts is that members of these groups receive none of the subsidy benefits associated with the large increase in the first income threshold of repayment of HECS.

Several other results are worth explaining. One is that the lower present value for women with children generally is a result of members of this group taking time out of the labour force at age 30 to rear children. In the case of those in the low and middle-income bands, they will not have fully repaid their HECS debt before this time. Once they start having children they have around 10 years in which they make no HECS repayments because they are either not working for pay or are working part-time and thus earning less than the threshold. This results in very large subsidies going to this group.

Second, the higher present values of debt for males stems from the fact that males have higher wage and salary incomes than females of the same age (as shown in Figures 1-3). This in turn means that their taxable income is higher and thus, they repay their HECS debts more quickly than females. The greater are repayments at earlier ages the lower is the effective subsidy for males and thus, the higher are the present values of their debts.

The essential messages remain the same under a 25 per cent increase in the HECS charge for graduates who undertake a course in the low or high HECS bands.

\section{Results for FEE-HELP Students}

In this section results are presented for FEE-HELP students. We have simulated a debt of $\$ 12,500$ per year for a four-year duration of study, under the assumption that students admitted under FEE-HELP are unable to access a HECS-HELP place at any stage of their undergraduate program of study. FEE-HELP takes the form of there being a surcharge of 25 per cent on top of the fee level, so the $\$ 12,500$ borrowed per year is equivalent to an annual charge of $\$ 10,000$. The figures have been chosen to reflect the maximum allowed total debt of $\$ 50,000$.

The student/graduate income hypothetical cases we have used are the same as those for HECS-HELP scenarios, but obviously without the distinction between the HECS bands. Thus, again there are a total of nine cases - males, females without children and females with two children, on low, middle and high-incomes.

There are two sets of simulations, with the first being explained above. The second allows insights into the possible importance of HECS debts being capped at a level of $\$ 50,000$ per student. An issue in this circumstance is that some 
students might reach the loan cap before they have completed their education, and will thus need to pay the remaining charge up-front (if, of course, they are able to access the required finances). To simplify the analysis we assume for this simulation that the student is in a course charging $\$ 13,333$ per year for three years, which puts the student at the loan cap after three years and means that they will need to pay for the final year up-front. The results of these simulations are shown in Table 3. For comparative purposes the table also shows the present value of debt repayments for HECS-HELP students in the middle HECS band.

Table 3: Present Value of HECS Repayments for Hypothetical FEEHELP Individuals under Different Scenarios

\begin{tabular}{|c|c|c|c|}
\hline & Males & $\begin{array}{l}\text { Females } \\
\text { no children }\end{array}$ & $\begin{array}{l}\text { Females } \\
2 \text { children }\end{array}$ \\
\hline \multicolumn{4}{|l|}{ Low-income } \\
\hline $\begin{array}{l}\text { HECS-HELP individual in the } \\
\text { middle HECS band (base system) }\end{array}$ & 12,600 & 12,000 & 9,900 \\
\hline $\begin{array}{l}\text { Full fee paying with a total debt of } \\
\$ 50,000\end{array}$ & 16,300 & 4,100 & 1,400 \\
\hline $\begin{array}{l}\text { Full fee paying with a total debt of } \\
\$ 50,000 \text { plus an up front payment } \\
\text { of } \$ 13,333 \text { in fourth year of study }\end{array}$ & 27,200 & 15,100 & 12,300 \\
\hline \multicolumn{4}{|l|}{ Middle-income } \\
\hline $\begin{array}{l}\text { HECS-HELP individual in the } \\
\text { middle HECS band (base system) }\end{array}$ & 14,200 & 13,900 & 13,300 \\
\hline $\begin{array}{l}\text { Full fee paying with a total debt of } \\
\$ 50,000\end{array}$ & 26,600 & 25,200 & 20,200 \\
\hline $\begin{array}{l}\text { Full fee paying with a total debt of } \\
\$ 50,000 \text { plus an up front payment } \\
\text { of } \$ 13,333 \text { in fourth year of study }\end{array}$ & 37,500 & 36,200 & 31,100 \\
\hline \multicolumn{4}{|l|}{ High-income } \\
\hline $\begin{array}{l}\text { HECS-HELP individual in the } \\
\text { middle HECS band (base system) }\end{array}$ & 15,200 & 15,100 & 15,100 \\
\hline $\begin{array}{l}\text { Full fee paying with a total debt of } \\
\$ 50,000\end{array}$ & 31,100 & 30,400 & 27,400 \\
\hline $\begin{array}{l}\text { Full fee paying with a total debt of } \\
\$ 50,000 \text { plus an up front payment } \\
\text { of } \$ 13,333 \text { in fourth year of study }\end{array}$ & 42,100 & 41,400 & 38,400 \\
\hline
\end{tabular}


The data from the table show some surprising results. One is that even if low-income females incur a debt of $\$ 50,000$ they will pay close to nothing (that is, $\$ 1,400$ ), and even females with no children will face a present value of a debt of only $\$ 4,100$. As incomes increase, so too does the present value of the debt, and for high-income males a $\$ 50,000$ debt on paper is associated with a present value of over $\$ 30,000$, which is around double the base case of HECS-HELP for a middle level charge. The most striking result however, relates to the requirement of paying an up-front fee on top of the debt, and this is stressed in what follows.

The data for low-income FEE-HELP students are of great interest. They show that low-income individuals face small (or zero) increases only from having a $\$ 50,000$ debt (compared to HECS-HELP) but that there are extremely high present value increases once an up-front payment is required. The results are particularly striking for females, with just one year's up-front payment meaning an increase in the present value of the debt of over 300 per cent (from about $\$ 4,000$ to over $\$ 15,000$ ) for females with no children and about a factor of 8 (from $\$ 1,400$ to $\$ 12,300$ ) for females with two children. These are extraordinary results illustrating the great financial importance of HECS-type loans for those expecting to earn low-incomes.

The results for middle-income students suggest that the present value of the $\$ 50,000$ debt is approximately doubled from the HECS-HELP arrangement for middle-income graduates. As with low-income graduates, the effects of the addition of the up-front payment are striking, although less so. The up-front charge adds at least 40 per cent to the present value of the charge, with the relative increase for females with children being the highest, from about $\$ 20,000$ to over $\$ 30,000$.

The results for high-income students suggest that FEE-HELP with a $\$ 50,000$ debt will have similar proportionate effects on the present value of the debts of high-income earners as is the case for middle-income graduates. However, while the up-front payment considerably increases the extent of the charge burden for high-income graduates, in proportionate terms the effects are far lower than for less advantaged graduates. Overall, the up-front payment scenario illustrates that the capping of the loan has the strong potential to burden the lowest earning graduates and can be seen to be regressive in a lifetime income sense.

\section{A Commentary on HECS-HELP and FEE-HELP}

\section{Price flexibility in theory}

There seem to be two important motivations for the proposed introduction of HECS-HELP. One is apparently the recognition that in the early 2000s there are significant financial pressures on Australian universities, and that some price flexibility would be likely to increase their revenue. Phillips and Chapman (2003) argue that overall there is little doubt that the new arrangements will mean higher average contributions from HECS students; in a sense the government will be 
transferring the problem associated with indexation shortfalls away from taxpayers to students.

The second likely reason for increased higher education pricing autonomy is the recognition that Australia is now in a situation whereby universities supply services for a large and diversified market. Higher education is no longer elite and small, and there might increasingly be opportunities for specialisation in terms of both subject matter and the targeting of particular consumers.

In this context, issues of resource allocation promote the case for allowing universities to offer services and prices reflecting (to a limited extent) their circumstances and goals. The argument promoted by Norton (2002) and others is that this would allow more choice for both providers and students, and thus has the potential to improve service delivery.

In summary it would seem that, apart from the implications for the prices faced by students, HECS-HELP is likely to have two institutional effects. One is that universities would have more revenue, which would be supplied through higher imposts on students. Whether or not this is desirable in terms of economic theory depends on the subjective valuation given to the value of externalities. However, it would seem to be the case that the potential for further large changes in this context is limited.

Second, so long as most of the additional revenue is delivered directly to the university departments (this is in fact how HECS-HELP is proposed to operate) there is some potential to promote economically propitious outcomes, such as relative changes in academic salaries to more accurately reflect outside opportunities.

But if universities are to have some discretion over prices, several questions arise. The most important of these concerns the extent to which there should be price regulation. That is, a critical issue concerns the extent to which universities should be free to set prices.

Clearly, given the price ceiling that has been set of 25 per cent above standard HECS, this policy change has been motivated by the view that there should not be unlimited price discretion for the majority of undergraduate students. There are very solid grounds to support such a position, now considered.

The reasons to be concerned about unfettered price competition between Australian universities are as follows. First, the extent to which institutions will be able to benefit from price discretion will be a result of their location and history. For example, the Universities of Sydney, Queensland, Western Australia, Adelaide and Melbourne are located in prime areas of their respective cities, and this gives them a significant commercial advantage. The fact that universities do not pay rent means that the playing field is not level.

Second, an important part of universities' relative standing is the result of many years of public sector subsidy. Reputations have been built from these subsidies, implying that there might be important rents accruing to some universities from unfettered price competition. In turn this suggests that the alleged benefits of competition could be undermined without close attention to these issues of both geography and history. 
These first two reasons suggest that allowing completely free market principles in the pricing of higher education services in Australia, such as with respect to FEE-HELP, is currently inappropriate, and will likely lead to significant economic rents accruing to well-placed and highly reputable institutions. These concerns could be resolved in part if universities were to compensate the public sector for these advantages, but there seems to be little contemporary discussion of this issue.

There is an additional reason for not allowing unfettered pricing flexibility, and it relates to the charge burdens on students. It is difficult to believe that the current HECS levels are markedly below what they should be. In some cases, Law for example, it is very likely that students are currently paying almost as much as the teaching costs involved. Full price discretion would suggest that such examples are likely to become commonplace. This rests uneasily with the economic rationale for public sector additional financial support, which suggests that activities associated with spill-over social benefits should be subsidised by taxpayers; in other words, that students should pay less than the full costs of the activity.

\section{Concerns with FEE-HELP}

FEE-HELP makes a HECS-type loan available to full-fee paying students and this constitutes an improvement over the current poor arrangements introduced in 1997 in which universities are able to charge full fees for 25 per cent of the course quota. But there are several significant problems with FEE-HELP. The first, outlined above, is that there is not a case to allow universities full price discretion. Particularly when seen in the context of restrictions in the supply of places, this will deliver unreasonable non-market rents to institutions and will not foster competition.

These arguments reinforce the case for the Government capping fees. Indeed, the force of this point seems to underlie the Government's decision to set the limit of 25 per cent on the extent to which universities are able to increase HECS-HELP charges. It is notable that the same understandings have not apparently influenced the policy approach to so-called 'full-fee paying' students.

There are several possible alternatives involving price capping. Perhaps the most persuasive has been argued by Phillips, in which the cap on fees could be set somewhat higher than the maximum HECS-HELP. Phillips' proposal thus suggests that there should be no HECS charge differences between domestic students. In his arrangement there is the major equity plus of the removal of the price distinction between full-fee and HECS-liable students, since all domestic students in the same course would pay the same charge. Not only would this simpler alternative eliminate the equity concerns about having two classes of domestic students, it would also remove the need for measures to constrain and penalise over-enrolment (Phillips and Chapman, 2003).

The second major issue concerning the design of FEE-HELP is that the loan is capped at a total level of $\$ 50,000$ per student. This is likely to result in the 
emergence of up-front fees for some students to allow them to complete their courses. If this happens our exercises show quite powerfully that such a scenario will add very significantly to the relative charge obligations of those graduates earning the least over their lifetimes.

One final comment on both FEE-HELP and HECS-HELP is the implications of the new arrangements for the access of students from different socio-economic backgrounds. This is a very important issue but one that this exercise is unable to offer insights into. Further research could shed some light on this matter.

\section{Conclusion}

In the current funding environment many universities are considering whether an increase in the HECS charge is a desirable policy option and if so, how great the increase should be. In this study we have examined the effects of increasing the HECS charge by 25 per cent for HECS-HELP students, introducing debts of $\$ 50,000$ for FEE-HELP students and having up-front fees on top of a $\$ 50,000$ FEE-HELP debt.

One important question is the likely impact upon students and graduates of such changes. The appropriate way to assess this is through examination of the present value of the repayments made by graduates differing in future incomes faced. These parameters are critical to an assessment of the possible impact of HECS-HELP, since once the debt is incurred there is a real interest rate of zero, implying the possibility of very large differences between individuals in the present value of changes to HECS.

The first part of this study has explored these issues for HECS-HELP graduates under a system of a 25 per cent HECS surcharge and applying the 2005-06 HECS repayment schedule. Analysis was undertaken of three types of hypothetical graduates - males, females without children and females with two children. Each of these graduates was assigned three different income levels (high, medium and low). Results were reported for the middle HECS band results for the other HECS bands are similar.

The analysis demonstrates that the lifetime profiles of graduates vary greatly and thus so too will the impact of changes to the HECS system. For example, even increasing the HECS charge by 25 per cent results in substantial falls in the financial burden of a HECS debt for low-income males and, especially, lowincome female graduates, compared with the current system. This is due to the very large increase in the first income threshold of repayment of HECS, which effectively delivers substantial HECS reductions for many individuals.

For 'average' males and females (those earning middle incomes), an increase of 25 per cent in the HECS charge will result in a slightly lower true financial cost than this (around 18 per cent for 'average' males and females without children). On the other hand, people with high incomes will in effect pay about 25 per cent more.

The second part of this study examined the impact of changes to the HECS system on FEE-HELP students. Two broad scenarios were explored: a debt of 
$\$ 12,500$ per year for the four years of tertiary education; and a debt of $\$ 50,000$ in combination with a likely typical up-front fee (chosen to reflect the impact of the capping of the loan).

The analysis shows that incurring a total debt of $\$ 50,000$ results in substantial increases in the present values of the debt for middle and high-income graduates. However, for low-income individuals, especially low-income women with children, the present value of HECS repayments is nowhere near as great as for their higher income counterparts, because none of the low-income individuals in this study will fully repay their debt. In the case of low-income women with children, repayments are even less (relative to their counterparts without children) because they spend a substantial amount of time out of the labour force and working part time.

However, if the capping of the loan leads to up-front fees, the effects are much more considerable and arguably much more regressive. It was found, for example, that the up-front component of this policy variant would result in a very considerable increase in the present value of charges for female graduates receiving low future incomes, of the order of 3 and 8 fold. Accordingly, and different to the likely effects of HECS-HELP, this aspect of FEE-HELP has the important potential to jeopardise the access of those who expect to receive relatively low future incomes. While this does not necessarily mean that relatively poor students at the point of entry will be adversely affected, this aspect of the 2005 reforms seems to be very regressive when viewed in a lifetime context.

\section{References}

Andrews, L. (1999), 'Does HECS Deter?’, Department of Education, Training and Youth Affairs, Occasional Paper Number 99F, Canberra.

Chapman, B. (1997), 'Conceptual Issues and the Australian Experience with Income Contingent Charges for Higher Education’, The Economic Journal 107(442):738-751.

Chapman, B. and T. Salvage (2001), 'Post-graduate Charge Policy’, Agenda 8(4):349-364.

Chapman, B. and C. Ryan (2002), 'Income Contingent Financing of Student Higher Education Charges: Assessing the Australian Innovation', The Welsh Journal of Education 11(1):64-81.

Edwards, M., C. Howard and R. Miller (2001), Social Policy, Public Policy: From Problem to Practice, Allen and Unwin, Sydney.

Friedman, M. (1955), 'The Role of Government in Education', pp 123-44 in A. Solo (ed.), Economics and the Public Interest, Rutgers University Press, New Brunswick, NJ.

Phillips, D. and B. Chapman (2003), ‘Our Universities: Backing Australia's Future. Issues and Analysis’, mimeo, Australian National University, Canberra, July. 
174 Gillian Beer and Bruce Chapman

The authors wish to acknowledge the valuable input from the editor and two anonymous referees. We also wish to acknowledge the support of the University of Sydney, the University of Western Australia, La Trobe University and RMIT University. All errors and omissions are those of the authors alone. 


\title{
REVIEW
}

\section{Evolution of Privacy Policies}

\author{
Colin J. Bennett and Charles D. Raab, The Governance of Privacy: Policy \\ Instruments in Global Perspective, Ashgate Publishing Limited, Aldershot \\ England, 2003
}

\section{Review by Solveig Singleton}

I n The Governance of Privacy, political science professors Bennett and Raab offer a survey of privacy policies in the industrialized world to explore the intersection between globalisation and privacy policy. Their ultimate concern is to explore whether privacy protection has seen a 'race to the bottom' or a 'race to the top,' or 'something less uni-directional and complex'. (Even without having read beyond the introduction, astute readers should feel confident in predicting that the author's answer will fall in the last-named category.) The book offers a valuable resource in exploring how different privacy policies have evolved since the 1970s. Although helpful in confining the work to one volume, some of the authors' assumptions about privacy and its recent legal incarnation, data protection, sadly limit their insights into the more persistent puzzles of privacy and globalisation. Asking somewhat deeper questions might have yielded some more interesting answers of greater durability.

\section{A Panorama of Privacy in the Late Twentieth Century}

In essence, the first two-thirds of the book offer an outline of privacy protection goals and institutions as seen by the larger community of privacy advocates, supplemented with other sections offering the authors' own perspective. For example, early on they set out four key assumptions of the privacy-conscious elite. First, privacy is an individual right linked to liberal democracies; second, privacy is being eroded; third, the source of the erosion is structural (that is, a set of impersonal and remote forces outside the control of individuals); and fourth, privacy-invading entities are subject to control by nation-states. In addition, they describe in greater detail the theory that privacy is linked to trust in institutions and, in particular, to the growth of electronic commerce. The authors then offer their own take: privacy is a social value; privacy related risks stem from many sources; and privacy problems may no longer be controlled and defined within state borders. The concluding chapters offer more comparative analysis and evaluation.

The authors' summary of the logic of the privacy elite is a good one. The central part of the book offers an excellent summary of the history of data protection institutions in Europe and of self-regulatory instruments, but the authors 
fail throughout to offer a more than cursory glimpse at the views of critics of data protection, and leave out some important strands of criticism altogether. For example, Jacob Palme in Sweden and Eugene Volokh ${ }^{1}$ in the US, among others (including myself) have pointed out the tension between privacy regulation of the private sector and another liberal democratic value, the free flow of information the right of human beings to talk about each other, to learn and communicate their knowledge of other people. Additionally, there are substantial data suggesting that the economic cost of data protection to consumers may be extreme. These omissions of the 'minority view' mean that while the book may be 'global' in its scope in one sense, it is far from complete. And while the authors seem to strive on the one hand to provide an objective critique of the privacy paradigm, they sometimes seem to slip into the role of advocates.

\section{Privacy as a Social Value}

If the omission of a longer account of views of critics were essential to save space, one would hope that it would be because the authors felt a burning need to convey other insights of importance. One candidate is the thesis that privacy is a social value, but their arguments for this position are not sufficiently concrete to be really strong. There are many types of privacy; while a journalist's loss of the privilege of confidentiality respecting his sources will have broader social effects on free speech, it is hard to see how a consumer who elects to qualify for a discount on groceries by letting the store track his purchases is doing much of broader social consequence.

If one thinks of privacy as having absolute value in and of itself, the mere fact that information about a consumer is accumulating in a database somewhere is troubling. But that is rather a simplistic position to take: human beings often need to know about the behaviour of others in order to make better decisions. The insistence that privacy is an absolute value seems more designed to insulate extremely restrictive privacy regulations from criticism than to serve any real human need. The authors seem to share this view, but present no argument for it: they vaguely note anthropological studies stressing the importance of some kind of undefined privacy to human well-being, but authors on the other side could equally well cite anthropological studies stressing the importance of information exchanges about other people (even gossip) to human beings.

Their discussion of privacy protection as broad social policy also stumbles inadvertently into the surreal. One thesis is that a lack of privacy can lead to social inequities; certainly this would come as no surprise to the average dictator (indeed, it seems to be the whole point of being a dictator). The authors then propose a more systematic study of who is and who is not actually being protected by data protection, criticizing it for being too categorical and institutional. By

\footnotetext{
${ }^{1}$ Eugene Volokh (2000), 'Freedom of Speech, Information Privacy, and the Troubling Implications of a Right to Stop People From Speaking About You', Stanford Law Review 52:1049.
} 
contrast with marketing, which is increasingly targeted with 'fine-grained precision', they say they 'know of no equivalent impetus on the part of regulatory agencies to know systematically more about those whose privacy they are protecting' (p. 38). Did they write this sentence, seeming to support yet more compilation of data, all in the name of privacy, with a straight face?

In asking who is being left out of the world of data protection, the authors do ask a tremendously important question. One interesting part of the answer, though, is staring us all in the face: taxpayers and criminals, since the taxation and criminal investigation arms of government cheerfully exempt themselves. Indeed, the more closely one looks at data protection the less real protection it seems to offer to anybody. France, for example, has 'strong' data protection, but that does not stop labour inspectors from scrutinizing workers as they leave their offices, looking for laptops or some other indication that the hapless employees are exceeding the bounds of the 35-hour work week at home. Swedish data protection authorities intervened to get an airline to delete from its databanks the identity of passengers who ordered kosher meals. But suppose an anti-Semitic regime actually came to power in Sweden. If it was looking for lists of Jewish citizens for some evil purpose, wouldn't it just seize the membership lists kept by synagogues or other Jewish organizations (exempt from data protection) on some pretext? Or look for family names at a Jewish cemetery? The most likely result of 'dekoshering' the airline's database seems to be to inconvenience those who order kosher meals.

The idea that tyranny can be contained in a powerful welfare state by a bureaucratic structure such as data protection is extraordinarily naïve; the entire premise of the welfare state is that there ought to be few limits on government intervention in citizens' daily lives. The authors sometimes teeter on the verge of realizing the extent to which data protection has failed, but are too much members of the privacy elite themselves to step outside of it and answer their own question.

\section{Privacy in the Market}

The book's high level of abstraction continues to handicap its analysis as the authors move into the realm of economics. They deplore market 'ideologies and technologies of individual choice and tailor-made preferences' (p. 41). Wreathed in egalitarian language, this signals compassion in academic circles. But what the authors seem to support in fact is top-down policies that make it illegal or technically difficult for people to reveal information - even when they choose to in exchange for a real benefit. Privacy is evidently not just a right, but an inalienable right. The first generation of privacy advocates thought that people should be able to choose whether to reveal information about themselves; the next generation is horrified that people in fact so choose, and would like to prevent them from doing so.

The level of intervention that this would entail with technology and with the economy is extraordinary. And it seems entirely unjustified, given that consumers are - even in that last refuge of supposed laissez faire, the US - doing nicely 
without it, thank you very much, cheerfully piling onto electronic commerce in ever greater numbers (whatever they may say in surveys, a poor guide to preferences). ${ }^{2}$ The authors' note that in the US business lobbyists held back data protection laws, which some readers might take to refer to a deplorable exercise of raw power and unseemly influence. But the business side succeeded in Washington DC because it made strong arguments. No one was able to point to real problems caused by a lack of broad privacy laws; narrower problems like identity theft are being better addressed with sector-specific laws and new enforcement tools; and consumers enjoy many benefits from a default rule that allows businesses to learn more about their preferences. Early security problems with electronic commerce and spam are gradually being straightened out, and consumers do not seem to attach concrete value to privacy much beyond that.

In suggesting that privacy is a 'public good', the authors might argue that this is a market failure. But the fact that consumers do not attach the value to privacy that advocates think they should is not evidence of market failure. Indeed, the free flow of information has more of the qualities of a public good than privacy. Everyone would prefer if his own unpaid bills were left off the credit report, but wants to know what the baby-sitter is up to.

\section{Conclusion: Another Stripe on the Paper Tiger}

The Governance of Privacy offers an excellent summary of worldwide trends in data protection in the late twentieth century. While valuable as a resource, it is weak as a guide to policy going forward. It fails to grapple with the central failings of data protection - a conflict with liberal values such as free flow of information, its economic cost to consumers, and its failure to offer a real check on the power of the welfare state.

Solveig Singleton (solveig.singleton@comcast.net) is a lawyer based in Washington, DC, and the author of many articles on privacy and data protection issues, including 'Privacy and Human Rights: Comparing the US to Europe', in The Future of Financial Privacy (Washington, DC: Competitive Enterprise Institute, 2000) and 'Privacy Versus the First Amendment: A Skeptical Approach', XI Fordham Intellectual Property, Media and Entertainment Law Journal 98 (2000).

2 To do them justice, the authors themselves note that 'Although many people say that the lack of privacy is a crucial barrier to participation in cyberspace, there is no clear indication that significant numbers of individuals actually do perform their transactions online as soon as better privacy statements and rules are offered' (p. 77). 


\section{NON-AGENDA}

With the view of causing an increase to take place in the mass of national wealth, or with a view to increase of the means either of subsistence or enjoyment, without some special reason, the general rule is, that nothing ought to be done or attempted by government. The motto, or watchword of government, on these occasions, ought to be - Be quiet...Whatever measures, therefore, cannot be justified as exceptions to that rule, may be considered as non-agenda on the part of government.

— Jeremy Bentham (c.1801)

\section{Indigenous Employment Forecasts: Implications for Reconciliation}

\section{Boyd Hunter and John Taylor}

$\longrightarrow$ urrent government policy seeks to achieve 'practical reconciliation' between Indigenous and other Australians by focusing on closing the gap in the key social policy areas of health, housing, education and employment. Reflecting on progress to date, Altman and Hunter (2003) have analysed a range of Indigenous socioeconomic outcomes over the reconciliation decade of 1991 to 2001 concluding that there is little statistical evidence so far from census information to indicate a narrowing of the gap in the manner sought.

This finding is of interest as it reflects the net impact of Indigenous social and economic policy settings enacted during the years of the Hawke and Keating governments in the first half of the 1990s, and then of the first two Howard administrations from 1996 to 2001. Very briefly, from a labour market perspective, such initiatives (chronologically) included the establishment of Indigenous training and job programs under the Aboriginal Employment Development Policy (AEDP), then their enhancement under the Working Nation initiative, followed by the dismantling of Working Nation and associated privatisation of employment services, and most recently the revitalisation of dedicated Indigenous labour market programs under the Indigenous Employment Policy (IEP).

Over this same decade the Australian labour market underwent significant structural and compositional change. In general, the income distribution in Australia has tended to become more unequal over the last 15-20 years, a trend also observed in many other OECD countries (Saunders, 2003). Other trends in labour markets - shift to the private sector, casual jobs and part-time work, as

Boyd Hunter and John Taylor are Fellow and Senior Fellow respectively in the Centre for Aboriginal Economic Policy Research at The Australian National University. 
well as ongoing secular increases in female labour force participation, dual-earner families, and long-term unemployment (Borland, 2003) - have also tended to exacerbate economic inequality. In the context of Indigenous Australia, the rise of 'mutual obligation' based welfare regimes, such as the work-for-the-dole scheme and the Community Development Employment Projects (CDEP) scheme, are also profoundly significant (Hunter, 2004). Under the CDEP scheme, Indigenous community organisations receive an allocation of similar magnitude to their collective unemployment benefit entitlement to undertake community defined 'work'.

Against the background of these policy and structural changes, the labour force status of Indigenous Australians has been routinely tracked with predictions made about likely outcomes in terms of employment and unemployment levels and rates (Taylor and Altman, 1997; Taylor and Hunter, 1998). In building a prognosis for Indigenous labour force status at the end of the present decade, this paper revisits these various predictions and considers their accuracy against observed outcomes. The essential finding is that aggregate labour market outcomes for Indigenous people during the 1990s were reasonably predictable, notwithstanding administrative shifts in government employment policies, major restructuring of the labour market, and a self-identified Indigenous population that expanded substantially mostly by the social ascription of individuals whose socioeconomic status is ultimately unknown. It is argued here that this assessment of predictability in Indigenous labour market outcomes provides a sound basis for developing further projections as a guide to likely future outcomes. First, though, the case needs to be established.

\section{Demographic Issues and Forecasting}

During the 1990s, or more precisely the ten years leading up to the 2001 Census, the census-based estimate of the Indigenous working-age population rose by 35 per cent from 208,000 to 280,000. This increase was substantially above the contribution from natural increase and it reflected, for whatever reason, growing inclusion in the census population of individuals who were not previously recorded as Indigenous. Obviously, with a population expanding by social ascription as much as by demographic factors, questions arise as to the potential for compositional change due to possible bias in the socioeconomic status of new entrants. While there is no means of assessing this directly, proxy measures have been developed for North American Indians (Eschbach, Supple and Snipp, 1998) and, in similar fashion, Hunter (1998) traced changes in the educational characteristics of single-year cohorts of Indigenous Australians between 1986 and 1996 on the understanding that if the composition of the cohort altered over time, then this would manifest itself as apparent change in the characteristics of the cohort. Fixed effect regression models of time-invariant 'age left school' variables were estimated on a 'synthetic' panel of Indigenous and non-Indigenous cohorts between 1986 and 1996. The null hypothesis of compositional change 
was rejected for all cohort groups. That is, the characteristics of the respective cohorts did not to change significantly over this period.

While this finding provides some basis for an assumption of stability in socioeconomic characteristics in spite of demographic change, a more tangible transformation of the Indigenous population in the second half of the twentieth century, and one that appears potentially more significant from the point of view of possible impacts on aggregate labour force status, has been a shift in overall Indigenous population distribution from an emphasis on remote and rural areas towards the towns and cities of the south and east (Taylor, 2003a).

The proportion of the Indigenous population resident in urban areas rose from just over two-thirds in 1991 (67 per cent) to almost three-quarters in 2001 (74 per cent). Almost one-third of Indigenous Australians are now resident in major urban areas. While this is still substantially less than that for the overall Australian population (66 per cent), it nonetheless represents a marked increase from the 15 per cent of the Indigenous population counted in 1971. As this process of greater population counts in urban areas has unfolded, ipso facto the rural share of the population has continued to decline: down from 56 per cent in 1971 to almost one-quarter in 2001. However, it is significant for the present exercise that the key factor driving this spatial redistribution of the population has not been migration, though undoubtedly this has occurred. Rather it has been the increasing tendency over time for individuals in the more settled parts of the nation to identify in the census as Indigenous. Indeed, the evidence to support an overall migration of Indigenous people towards areas with more favourable labour markets is slim with as much movement away from cities as towards them, a finding that has been consistently reported since the 1980s (Gray, 1989; Taylor and Bell, 1999). Thus, while the Indigenous population is increasingly recorded in areas with established labour markets this has not been due to migration, nor has it had any apparent distorting effect on overall labour force status or our ability to predict aggregate labour force status as will be demonstrated.

\section{Evaluating Recent Forecasts of Indigenous Labour Force Status}

In 1997, ATSIC commissioned a report, The Job Ahead, by the Centre for Aboriginal Economic Policy Research (CAEPR). That report estimated the fiscal costs to government of Indigenous employment disparity and provided a measure of the number of future additional jobs required to reduce the gap in labour force status (Taylor and Altman, 1997). The projections of working age in that report (ABS/CAEPR, 1996) were based on 1991 Census data, while employment trends covered the period from the 1986 Census to the 1994 National Aboriginal and Torres Strait Islander Survey (NATSIS). Following the release of 1996 Census data and the subsequent upward revision of population projections, these estimates of future employment numbers and job needs were revised, with the title of the resulting paper, The Job Still Ahead, indicative of the key findings (Taylor and Hunter, 1998). Hunter and Taylor (2001a) provided revised forecasts because the Spicer Review of the CDEP scheme induced policy changes that changed the 
likely projections of Indigenous labour force status. Results from the 2001 Census are now available and provide a basis for re-estimating future outcomes and evaluating previous forecasts for 2001.

Table 1: Validating Forecast Estimates of Labour Force Status of Indigenous Australians, 2001

\begin{tabular}{lcccc}
\hline & $\begin{array}{c}\text { Job Ahead: } \\
\text { Hunter and } \\
\text { Taylor (1997) }\end{array}$ & $\begin{array}{c}\text { Job Still Ahead: } \\
\text { Hunter and } \\
\text { Taylor (1998) }\end{array}$ & $\begin{array}{c}\text { Hunter and } \\
\text { Taylor (2001a) }\end{array}$ & 2001 Census \\
\hline Employment population ratio & 36.2 & 39.8 & 42.1 & 40.4 \\
$\begin{array}{l}\text { Mainstream Employment } \\
\text { (non-CDEP/Adult population) }\end{array}$ & 26.4 & 29.1 & 29.1 & 29.5 \\
CDEP/Adult population & 9.8 & 10.7 & 13 & 10.9 \\
Unemployment rate & 37.4 & 24.5 & 20.0 & 20.0 \\
Participation rate & 57.9 & 52.7 & 52.7 & 52.1 \\
\hline
\end{tabular}

Note: CDEP estimates for 2001 are based on administrative data because of the incomplete geographic coverage of the CDEP question in the 2001 Census. In any case, there was no data on the extent of CDEP scheme employment in the 1991 Census.

Table 1 presents these recent forecasts of Indigenous labour force status with a view to evaluating the performance of estimates based on population projections. The original Job Ahead was mostly based on 1991 Census data, while The Job Still Ahead and Hunter and Taylor (2001a) were based on 1996 Census data. However, the 1994 NATSIS was also used to estimate labour force participation in The Job Ahead, and administrative data from ATSIC was used to estimate the number employed in the CDEP scheme in all forecasts. The accuracy of projections depends on the reliability and source of data used in the forecasts.

For example, Hunter and Taylor (2001a) assumed higher CDEP employment than The Job Still Ahead because the Spicer Review marked a policy shift by which all CDEP participants were expected to be employed. However, the 2001 'Census' estimate of CDEP scheme employment was lower than in Hunter and Taylor (2001a) because ATSIC identified non-Indigenous participants in the scheme for the first time in that year. There were also some minor adjustments to the planned expansion in CDEP scheme places around this time. This overestimate of the number of CDEP jobs resulted in a rather high employmentpopulation ratio in Hunter and Taylor (2001a).

Notwithstanding, predictions about mainstream (non-CDEP employment have been reasonably accurate, especially for those forecasts based on 1996 Census data. The only substantial difference between the actual 2001 employment population ratio and the forecast was for the Job Ahead, which underestimated the eventual outcome by 3.1 percentage points. Given that the 
CDEP-population ratio in that publication underestimated the actual outcome by 1.1 percentage points, 2.0 percentage points of the differential were attributable to the shortfall in employment forecasts. In a sense, this shortfall is understandable in that the employment projection for The Job Ahead was based around the 1991 Census and hence failed to take into account either the historically large growth in Indigenous identification during the 1990s or the sustained period of macroeconomic growth. Neither of these conditions are likely to be repeated in the next ten years given that both variables are coming from a reasonably high base (for example, the economy is operating close to full capacity).

The assumption about labour force participation is particularly important when estimating unemployment rates. For example, Hunter and Taylor (2001b) demonstrate that NATSIS data systematically overestimate both unemployment and participation rates relative to census data. Consequently, The Job Ahead, which based its assumptions about participation on NATSIS data, produced relatively high unemployment forecasts for 2001 (37.4 per cent). The 2001 unemployment rate would have been 31.3 per cent if participation rates had not been over-estimated by using NATSIS data. Even if The Job Ahead had accurately predicted employment growth to 2001, the unemployment rate would have been 24.5 per cent (given participation rates in the 1991 Census). That is, about half of the over-estimated unemployment rates in that paper was due to the use of an incompatible data source on labour force participation. The essential message here is that as long as predictions are based on a consistent data source (that is, census data), forecasts will be reasonably robust. Indeed, the unemployment rate estimated for 2001 in Hunter and Taylor (2001a) was accurate to three decimal places.

\section{Future Size of the Working-age Population}

The future size of the population is estimated by the conventional means of applying a cohort component projection to the 2001 post-census estimate of the Indigenous population $(458,520)$. This is done using calculations of survivorship and fertility based on the most recent analysis of 2001 Census data (Kinfu and Taylor, 2002) and held constant for the projection period. In line with previous low series experimental projections of the Indigenous population produced by the ABS, no allowance is made for non-demographic additions or losses to the population. In other words, the Indigenous population is assumed to be affected only by natural increase. It should be noted that this last assumption produces population estimates at the lower end of expectation given the recent experiences of large non-biological intercensal increases in the Indigenous population (Gray, 1997; Kinfu and Taylor, 2002). To this extent, the projections are conservative. The results of the projection are summarised in Table 2.

Overall, by the end of the present decade, the Indigenous population is projected to be more than 550,000. Notwithstanding high adult mortality, this shows that the Indigenous working-age population aged 15 and over will increase markedly both in number, and as a proportion of the total population. As with the 
population generally, the Indigenous population is also ageing, though from a more youthful base. Thus, by 2011, an extra 84,000 Indigenous people are expected to be of working-age - almost as many again as are now employed. Accordingly, the working-age share of the population will rise from 61 per cent in 2001 to 65 per cent by 2011.

Table 2: Projected Indigenous Population by Broad Age-group

\begin{tabular}{|c|c|c|c|}
\hline & 2001 & 2006 & 2011 \\
\hline Age Group & \multicolumn{3}{|c|}{ Numerical distribution } \\
\hline$<15$ & 178,692 & 184,715 & 193,029 \\
\hline $15^{+}$ & 279,828 & 320,497 & 363,577 \\
\hline \multirow[t]{2}{*}{ Total population } & 458,520 & 505,212 & 556,606 \\
\hline & \multicolumn{3}{|c|}{ Per cent distribution } \\
\hline$<15$ & 39.0 & 36.6 & 34.7 \\
\hline $15+$ & 61.0 & 63.4 & 65.3 \\
\hline
\end{tabular}

Source: Hunter, Kinfu and Taylor (2003).

\section{Projecting Labour Force Status, 2001-11}

As for labour force dynamics we refine some of the cruder assumptions made in earlier analyses (Taylor and Altman, 1997; Taylor and Hunter, 1998), for example by allowing Indigenous employment in the private sector in full-time work, and in all jobs, to grow at different rates. We also include an estimate of the effect of large numbers of discouraged Indigenous workers on our forecasts. A discouraged worker is someone who has given up looking for work, for example because there are no jobs available for them in the local area (Hunter and Gray, 2001). Aside from these changes the methodology and rationale, in terms of benchmarking current labour market outcomes and foreshadowing future ones, remains the same as that in other recent forecasts of Indigenous labour force status.

The key to projecting labour force status is to first establish estimates of the future size of the Indigenous labour force. This is done by assuming that the labour force participation rate remains at the level recorded by the 2001 Census which is the most recent indicator of Indigenous labour supply. The empirical basis for adopting this assumption is the fact that the Indigenous participation rate has remained relatively steady for the past decade at around 52 per cent. Using our projections of the Indigenous working-age population to 2011, age-specific participation rates from the 2001 Census may then be applied to derive estimates of labour force numbers, as shown in Table 3. 
Table 3: Projected Estimates of Indigenous Employment, Labour Force and Working-age Population.

\begin{tabular}{lccccc}
\hline & $\begin{array}{c}\text { Mainstream }^{a} \\
\text { employment }^{a}\end{array}$ & $\begin{array}{c}\text { CDEP } \\
\text { employment }^{b}\end{array}$ & $\begin{array}{c}\text { Total } \\
\text { employment }\end{array}$ & Labour force $^{c}$ & $\begin{array}{c}\text { Population } \\
15+\end{array}$ \\
\hline 2001 & 82,508 & 30,474 & 112,982 & 145,790 & 279,828 \\
2006 & 88,013 & 34,224 & 122,237 & 166,979 & 320,497 \\
2011 & 93,884 & 36,974 & 130,858 & 189,424 & 363,577 \\
\hline
\end{tabular}

Notes: a Mainstream based on continuation of 1996-2001 aggregate jobs growth of 1.3 per cent per annum for the Australian labour market.

b Based on an increase of 1,000 CDEP places in 2004 following 2003 budget provisions, plus an assumption that CDEP participants increase by natural growth of 550 per annum after 2001.

c Labour force based on maintaining Labour Force Participation Rate at the 2001 level (52.1 per cent).

As for estimating numbers in employment, separate calculations are made for mainstream employment and employment in the Community Development Employment Projects (CDEP) scheme. For mainstream employment, it is assumed that this will continue to expand at the rate observed between 1996 and 2001 of 1.3 per cent per annum. In projecting CDEP scheme employment, policy and fiscal constraints provide the parameters for growth. On the basis of recent and current planning for the scheme, it is assumed that the number of participants will continue to expand beyond 2001 by 550 participants per annum according to program allowance for natural (administrative) increase in existing schemes, while an extra 1,000 participants are added in 2004 as per provisions in the 2003-04 Commonwealth budget.

Thus, Table 3 indicates that the number of employed CDEP scheme participants is expected to rise from 30,474 in 2001 to almost 37,000 by 2011 . Assuming that mainstream employment continues to grow at the rate observed in the last half of the 1990s, then this rises from 82,508 in 2001 to 93,884 in 2011. Accordingly, total employment is estimated to rise from 112,982 to around 131,000 .

In Table 4, these projected changes in employment numbers are converted to employment/population ratios and unemployment rates. Because the rate of employment growth is anticipated to be slower than population growth, the overall employment rate is expected to fall from 40 to 36 per cent over the projection period. Assuming no change in the labour force participation rate, the reverse side of this equation will see the unemployment rate rise from 22.5 per cent of those in the labour force to almost 31 per cent.

While these projections clearly point to a worsening in the labour force status of Indigenous adults, it must be noted that they are based on the inclusion of CDEP scheme participants in the estimates of persons employed. If these CDEP scheme workers were excluded, and instead counted as unemployed (on 
account of the notional link between CDEP wages and Newstart/Job Search Allowance), then predicted labour market outcomes for Indigenous people become far worse with an unemployment rate of 43 per cent in 2001 rising to 50 per cent by 2011. Even with the growth in CDEP scheme employment, Indigenous employment rates decrease by around five and four percentage points for overall and non-CDEP employment respectively. Thus, planned CDEP growth is currently insufficient to maintain the status quo and will lead to increased employment disparity under current projections.

\section{Table 4: Estimated Indigenous Employment/Population Ratios and} Unemployment Rates. ${ }^{\text {a }}$

\begin{tabular}{|c|c|c|c|}
\hline & \multicolumn{3}{|c|}{ Census } \\
\hline & 2001 & 2006 & 2011 \\
\hline \multicolumn{4}{|c|}{ Employment/population ratios } \\
\hline Total employment $^{\mathrm{b}}$ & 40.4 & 38.1 & 36.0 \\
\hline Non-CDEP employment & 29.5 & 27.5 & 25.8 \\
\hline \multicolumn{4}{|c|}{ Unemployment rates } \\
\hline CDEP counted as employed & 22.5 & 26.8 & 30.9 \\
\hline CDEP counted as unemployed & 43.4 & 47.3 & 50.4 \\
\hline \multicolumn{4}{|c|}{ Unemployment rates when discouraged workers included in labour force ${ }^{c}$} \\
\hline $\begin{array}{l}\text { CDEP counted as employed and ABS definition of } \\
\text { discouraged workers }\end{array}$ & 25.9 & 30.0 & 33.9 \\
\hline $\begin{array}{l}\text { CDEP counted as unemployed and ABS definition of } \\
\text { discouraged workers }\end{array}$ & 45.9 & 49.6 & 52.6 \\
\hline $\begin{array}{l}\text { CDEP counted as unemployed and all people who want } \\
\text { work are included in labour force }\end{array}$ & 55.9 & 58.9 & 61.3 \\
\hline
\end{tabular}

Notes: a Estimates based on post-2001 Census population estimates and projections as shown in Table 2.

b Includes those employed in the CDEP scheme. All of the estimates are based on the data in Table 3. Unemployment rates express the unemployed as a percentage of the labour force.

c The ABS definition of discouraged worker is confined to those who are available to start work and give a reason for not actively looking for work that is related to the supply of jobs or other demand side reasons. Gray, Heath and Hunter (2002) argue that effective labour supply may include all those who want to work because their behaviour is similar to that of the unemployed for the Australian population as a whole.

The second panel in Table 4 includes a calculation of unemployment rates when discouraged workers are included in the labour force. Note that these rates are significantly higher when discouraged workers are included. They are even higher still if all people who want work are included in the labour force. Within 
this hypothetical framework, Indigenous unemployment rates would be as high as 61 per cent by 2011.

It is worth recalling that the equivalent rates for the rest of the Australian population are presently around 6.0 per cent for unemployment. On past experience, and present Budget forecasts, these are likely to remain relatively unchanged (Commonwealth of Australia, 2003). For example, the Commonwealth Budget confidently predicts that further jobs should be created next year, and that the unemployment rate should remain steady at around current low levels. The medium-term prognosis then, all other things being equal, is for a substantial worsening of the overall labour force status of Indigenous people both relatively and absolutely.

\section{Future Employment Requirements}

Using the projected estimates of employment it is possible to calculate the number of jobs required for Indigenous people to maintain the status quo in employment status or achieve an equivalent rate of employment to the non-Indigenous population.

As indicated in Table 4, the 2001 employment/population ratio for Indigenous people is estimated at 40.4 per cent. This was substantially below the ratio of 58.9 per cent recorded by the Census for all other Australians. Assuming that the estimated base Indigenous employment of 112,982 persons is not eroded in future, and that the non-Indigenous employment/population ratio also remains constant, two sets of estimated employment requirements are provided in Table 5:

- a minimalist scenario which indicates the numbers required simply to maintain the Indigenous employment/population ratio at its 2001 level; and

- the numbers required to achieve an employment rate equivalent to that of the rest of the population.

Table 5: Required Indigenous Employment Growth to Maintain the Status Quo or to Achieve Employment Equality, 2001-11.

\begin{tabular}{|c|c|c|c|c|c|}
\hline $\begin{array}{c}\text { Employment/ } \\
\text { Population } \\
\text { ratio }\end{array}$ & $\begin{array}{c}\text { Base } \\
\text { employment } \\
2001^{a}\end{array}$ & $\begin{array}{c}\text { Total jobs } \\
\text { required } \\
\text { by } 2011\end{array}$ & $\begin{array}{l}\text { Extra } \\
\text { jobs } \\
\text { required }\end{array}$ & $\begin{array}{c}\text { Extra } \\
\text { jobs } \\
\text { projected }^{b}\end{array}$ & $\begin{array}{c}\text { Projected } \\
\text { jobs deficit } \\
\text { by } 2011\end{array}$ \\
\hline $40.4^{c}$ & 112,982 & 146,885 & 33,903 & 17,876 & 16,027 \\
\hline $58.9^{d}$ & 112,982 & 214,147 & 101,164 & 17,876 & 83,289 \\
\hline
\end{tabular}

Notes: a The estimated number of Indigenous Australians in employment in 2001.

b From Table 3.

c Estimated employment/population ratio for Indigenous Australians based on 2001 population estimates.

d The employment/population ratio for non-Indigenous Australians from the 2001 Census. 
Because of growth in the population of working age, an additional 33,903 jobs will be required by the year 2011 just to maintain the rate of Indigenous employment at the 2001 level. This means that by the end of the decade, the Indigenous workforce will need to have increased by almost one-third of its estimated present size to avoid any decline in the already low employment level.

However, achieving employment equality between Indigenous and nonIndigenous Australians by the end of the next decade will require many more new jobs. By the year 2011 a total of 101,000 additional jobs will be required, an increase almost equivalent to the current size of the workforce. In annual terms, this translates into more than 10,000 new jobs per annum, which is substantially greater than the 3,362 new jobs estimated to have been created each year in the last half of the 1990s. Given current trends in employment growth, the projected shortfall in jobs for Indigenous people, using non-Indigenous employment levels as a benchmark, is around 83,000. Given the scale of this job deficit, it should be noted that these employment outcomes represent a best-case scenario as they include CDEP scheme participants.

\section{Implications for Reconciliation}

This analysis of 2001 Census data reveals no improvement in the overall position of Indigenous people in the labour market since 1996. Looking ahead, our estimates of future job growth point to a lowering of employment rates and rising unemployment over the remainder of this decade. Overall, the current fiscal cost of this failure to eradicate Indigenous employment disparity is massive — in 2001, it was estimated to be around 0.5 per cent of Australian GDP (Hunter and Taylor, 2002). Clearly, failure to achieve reconciliation already imposes a heavy fiscal burden on government and the results confirm previous findings that the burden will escalate in the future in proportion to the newly calibrated unemployment levels.

While it is not possible to put a dollar value on less tangible social costs of low employment and high unemployment, research has shown that the Indigenous unemployed, especially the long-term unemployed, fare worse than the employed on a range of social indicators - in terms of higher rates of arrest and police harassment, and lower levels of social capital and civic engagement (Hunter and Taylor, 2002).

Thus, a vital issue for policy in the years ahead is the distinct prospect that the overall situation for Indigenous people will continue to deteriorate. This is primarily because of population growth, but also because of the enormous difficulties of economic catch-up in a rapidly changing, skills-based, and competitive labour market. Furthermore, many of the structural factors undermining Indigenous participation in the labour market remain in place locational disadvantage, poor human capital endowments, and social exclusion. In short, we find no reason to retract, or alter, any of the policy implications and contributory factors leading to Indigenous disadvantage in the labour market that 
were outlined in previous such analyses - The Job Ahead (Taylor and Altman, 1997), and The Job Still Ahead (Taylor and Hunter, 1998).

Currently, the feedback between social exclusion and employment status is prominent in public debate. The prevalence of community dysfunction, manifest in domestic violence, substance abuse and accompanying recidivism, is an issue that most concerns many Aboriginal leaders (Ah Kit, 2002; Pearson, 2000a; Pearson, 2000b). While resolution of such issues may well involve new forms of Indigenous governance and leadership, as Pearson proposes, there is also debate about the capacity of Indigenous groups to institute reforms unassisted, and about whether the involvement of government in engineering social change might not carry its own risks (Martin, 2001).

Whatever the outcome stemming from this debate, it is our contention that there will remain a need for the Indigenous unemployed to be better informed about, and better able to engage with, employment opportunities in the mainstream economy (inter alia through greater access to outward looking networks). While Indigenous people may be seen as rich in social capital, this may reflect an excessive reliance on inward looking networks (Hunter, 2000). Equally, the relative educational status of Indigenous people needs to improve so that a wider range of jobs are accessible to them. Structural issues such as the buoyancy of the local economy in regional Australia, where many Indigenous people live, will also need to be addressed.

Employment in the public and community sectors will remain vital to Indigenous labour force participation, but it has been the private sector, albeit starting from a low base, that has been the engine of growth in Indigenous employment in recent years. This relative success coincides with the implementation of the Indigenous Employment Program (IEP). There are signs, then, that the IEP is effective in its aims, mainly through the provision of wage subsidies and the Structured Training Employment Program, though it should be noted that this is mainly in areas with established labour markets (Department of Employment and Workplace Relations, 2003). Indeed, the lack of evident impact in remote areas away from labour markets reinforces the need for flexible policy interventions (see Taylor, 2003b).

We can say with a high degree of confidence that the Indigenous Australian population will be at least 550,000 by the end of the present decade, and with far less confidence that it will approach 750,000 by 2021 . Furthermore, as with the Australian population generally, the future Indigenous population will be older in profile than it is now, with most growth occurring among those of working age. However, this ageing process will continue to lag far behind that underway among the rest of the population with the consequence that social and economic policy issues for Indigenous people will remain disproportionately focussed on the needs of youth and young families, as opposed to mainstream concerns which by then will be firmly focussed on the needs of the aged.

Demographic factors also have ongoing implications for Indigenous education policy settings for the foreseeable future. As with the other policy areas, extra expenditure on Indigenous education is required just to maintain the 
status quo. Even if the practical reconciliation agenda were sufficient to redress Indigenous disadvantage within the education system, the appropriate budget needs to expand at least in proportion with the size of the cohorts entering the relevant age groups. Hunter and Schwab (2003) note that the Indigenous cohort born between 1996 and 2001 appears to be smaller than other recent cohorts, and consequently the expenditure on Indigenous education required to maintain the status quo may possibly fall in about ten years time. Whatever the case, in benchmarking spending on Indigenous economic policy, and in navigating the path to reconciliation, there is clearly a need to take into account the fact of a rapidly expanding population base. Obviously it would be a mistake to deny the difficulties that policy makers face in the near future in attempting to achieve reconciliation. This paper outlines the likely scale of the job at hand and reemphasises the importance of demographic factors.

\section{References}

ABS/CAEPR (1996), 1994 National Aboriginal and Torres Strait Islander Survey: Employment Outcomes for Indigenous Peoples, Cat. No. 4199.0, ABS, Canberra.

Ah Kit, J. MLA (2002), Ministerial Statement from the Minister assisting the Chief Minister on Indigenous Affairs, Northern Territory Parliament, Darwin, available at: http://www.nt.gov.au/ocm/speeches/20020305_ahkit_aboriginal.shtml.

Altman, J. and B. Hunter (2003), 'Evaluating Indigenous Socioeconomic Outcomes in the Reconciliation Decade, 1991-2001’, Economic Papers 22(4):1-16.

Borland, J. (2003), 'Labour Market and Industrial Relations', pp. 94-117 in I. McAllister, S. Dowrick and R. Hassan (eds), The Cambridge Handbook of Social Sciences in Australia, Cambridge University Press, Cambridge.

Commonwealth of Australia (2003), Commonwealth Budget-Overview, Treasury, Canberra (available at: http://www.budget.gov.au/2003-04).

Department of Employment and Workplace Relations (2003), Indigenous Employment Policy Evaluation Stage Two: Effectiveness Report, Evaluation and Programme Performance Branch, EPPB Report 1/2003, Department of Employment and Workplace Relations, Canberra.

Eschbach, K., K. Supple, and M. Snipp (1998), 'Changes in Racial Identification and the Educational Attainment of American Indians, 1970-1990', Demography 35(1):1-9.

Gray, A. (1989), 'Aboriginal Migration to the Cities', Journal of the Australian Population Association 6(2):122-44.

Gray, A. (1997), 'The Explosion of Aboriginality: Components of Indigenous Population Growth 1991-96’, CAEPR Discussion Paper No. 142, CAEPR, Canberra.

Gray, M., A. Heath, and B. Hunter (2002), 'An Exploration of Marginal Attachment to the Australian Labour Market’, Reserve Bank Research Discussion Paper No. 2002/7, RBA, Sydney (available at http://www.rba.gov.au/). 
Hunter, B. (1998), 'Assessing the Validity of Intercensal Comparisons of Indigenous Australians, 1986-96’, Journal of the Australian Population Association 15(1):51-67.

Hunter, B. (2000), 'Social Exclusion, Social Capital and Indigenous Australians: Measuring the Social Costs of Unemployment', CAEPR Discussion Paper No. 204, CAEPR, Canberra.

Hunter, B. (2004), Indigenous Australians in the Contemporary Labour Market, ABS Cat. No. 2052.0, Canberra.

Hunter, B. and M. Gray (2001), 'Indigenous Labour Force Status Re-visited: Factors Associated with the Discouraged Worker Phenomenon', Australian Journal of Labour Economics 4(2):115-37.

Hunter, B., Y. Kinfu and J. Taylor (2003), 'The Future of Indigenous Work: Forecasts of Labour Force Status to 2011', CAEPR Discussion Paper No. 251, CAEPR, ANU, Canberra (available at: http://online.anu.edu.au/caepr/).

Hunter, B. and R. Schwab (2003), 'Practical Reconciliation and Recent Trends in Indigenous Education’, CAEPR Discussion Paper No. 249, CAEPR, ANU, Canberra.

Hunter, B. and J. Taylor (2001a), 'Indigenous Jobs Growth and Unemployment, 19962006: The Impact of CDEP’, Australian Journal of Labour Economics 4(2):65-76.

Hunter, B. and J. Taylor (2001B), 'The Reliability of Indigenous Employment Estimates', Agenda 8(2):113-28.

Hunter, B. and J. Taylor (2002), 'An Overview of the Costs of Indigenous Unemployment', pp. 109-33 in P. Saunders and R. Taylor (eds), The Price of Prosperity, University of New South Wales Press, Sydney.

Kinfu, Y. and J. Taylor (2002), 'Estimating the Components of Indigenous Population Change: 1996-2001’, CAEPR Discussion Paper No. 240, CAEPR, Canberra.

Martin, D. (2001), 'Is Welfare Dependency “Welfare Poison”? An Assessment of Noel Pearson's Proposals for Aboriginal Welfare Reform', CAEPR Discussion Paper No. 213, CAEPR, Canberra.

Pearson, N. (2000a), Our Right to Take Responsibility, Noel Pearson and Associates, Cairns.

Pearson, N. (2000b), 'Strong Families, then Strong Communities', Address to the Indigenous Families and Communities Roundtable, Canberra, October 24, transcript available at: www.brisinst.org.au.

Saunders, P. (2003), 'Income Distribution and Redistribution', pp. 118-37 in I. McAllister, S. Dowrick and R. Hassan (eds), The Cambridge Handbook of Social Sciences in Australia, Cambridge University Press, Cambridge.

Taylor, J. (2003a), 'Indigenous Australians: The First Transformation', pp. 17-40 in S. Khoo and P. McDonald (eds), The Transformation of Australia's Population: 1970-2030, University of New South Wales Press, Sydney. 
Taylor, J. (2003b), 'Indigenous Economic Futures in the Northern Territory: The Demographic and Socioeconomic Background', CAEPR Discussion Paper No. 246, CAEPR, ANU, Canberra.

Taylor, J. and J. Altman (1997), 'The Job Ahead: Escalating Economic Costs of Indigenous Employment Disparity’, Office of Public Affairs, ATSIC, Canberra.

Taylor, J. and M. Bell (1999), 'Changing Places: Indigenous Population Movement in the 1990s’, CAEPR Discussion Paper No. 189, CAEPR, Canberra.

Taylor, J. and B. Hunter (1998), 'The Job Still Ahead: Economic Costs of Continuing Indigenous Employment Disparity’, Office of Public Affairs, ATSIC, Canberra.

A preliminary version of this paper was presented in seminars held at the ANU and the Department of Family and Community Services, both in Canberra, and at the Cranlana Program seminar, 'Pathways for Reconciliation', held in Melbourne on 4 and 5 September 2003. We are grateful for the feedback from those presentations. Thanks are also due to Jon Altman, Matthew Gray, Anne Daly and several anonymous referees. We are especially grateful to Yohannes Kinfu who provided substantial assistance in construction of the demographic forecasts for the Indigenous population. 